\title{
Von Sozialarbeitern und Bauingenieurinnen: Habitushermeneutische Fallanalysen
}

\subsection{Fall Sonja: „Also bei uns in der Familie gehen alle mehr so in die Richtung so technische Sachen"}

\section{Reflexion der Interviewsituation}

Die Terminvereinbarung mit Sonja ist mit einer sehr zuverlässigen Kommunikation ihrerseits verbunden: Als einzige Interviewpartnerin bestätigt sie einen Tag vor dem Gespräch den Termin proaktiv per Email und schreibt, sie hoffe ,etwas Nützliches“ erzählen zu können. Damit betont sie die Relevanz ihrer Rolle als Befragte für das Forschungsvorhaben und begibt sich mit der Forscherin im Vornerein auf Augenhöhe. Dieser Eindruck setzt sich in der Interviewsituation fort: Bevor die Aufnahme gestartet wird, stellt Sonja einige Fragen zum Anliegen und zur Methode des Forschungsprojekts.

Das Gespräch selbst dauert knapp 55 Minuten und ist von einer ruhigen, überlegten Atmosphäre geprägt: Es kommt zu längeren Erzählpasssagen Sonjas und sie berichtet beispielsweise von ihrem Auslandsaufenthalt, ihren Überlegungen zur Studien(fach)wahl und ihren Vorlesungen flüssig und ausführlich. An anderen Stellen wiederum denkt Sonja relativ lange über ihre Antworten nach und kommt ins Stocken. In diesen Passagen geht es teilweise um private oder eher abstrakte Fragen (wie worauf es ihr im Leben ankommt) oder um ihre Sicht auf andere Personen (wie ihren Mathematiklehrer oder ihre türkischen Kommiliton*innen). Hier sucht sie nach den, richtigen Worten' und wirkt vorsichtig. Gegen Ende des Interviews scheint sich Sonja den Fragen zunehmend zu entziehen, insbesondere als es um ihre „drei Wünsche“ geht. Sie beginnt, Rückfragen zu stellen und antwortet erst nach langem Überlegen. Es scheint, als möchte sie die Kontrolle über das Gespräch behalten. Am Ende wirkt sie fast erleichtert, dass die Interviewerin ihre Fragen schließt und Sonja noch die Möglichkeit gibt, selbst weitere Themen 
einzubringen, was diese lachend umgehend ablehnt: „Ähm nö, ich glaub das war echt alles ((Sonja lacht)).“

\title{
Kurzeinführung in den Fall
}

Sonja ist zum Zeitpunkt des Interviews neunzehn Jahre alt und studiert im ersten Semester Bauingenieurwesen. Ihre Mutter hat nach ihrer Fachhochschulreife Informatik studiert und ist jetzt als angestellte Informatikerin tätig. Sonjas Vater hat die allgemeine Hochschulreife absolviert und im Anschluss Elektrotechnik an der Universität studiert - auch er ist in einem Angestelltenverhältnis als Ingenieur tätig. Sonjas Bruder ist sechzehn Jahre alt und besucht das gleiche Gymnasium, auf dem auch Sonja war. Sonjas Großvater war ebenfalls Bauingenieur und ihre beiden Cousins studieren Informatik. Bis auf Sonjas Großvater ist über alle ihre anderen erwähnten studierten oder studierenden Familienmitglieder bekannt, dass sie ihr Studium in der gleichen Stadt wie Sonja absolvier(t)en - ihre Mutter sogar an der gleichen Hochschule.

Sonja selbst hat auf einem Gymnasium ihre allgemeine Hochschulreife absolviert und anschließend ein Jahr als Au-Pair in Australien verbracht. Danach hat sie ihr Studium aufgenommen.

\section{Weg hin zum Studium}

Sonja beginnt die Erzählung zu einem frühen biografischen Zeitpunkt und bereits in ihrem ersten Satz wird deutlich, dass die Tatsache, überhaupt zu studieren, für sie selbstverständlich gewesen zu sein scheint. Nur die Frage nach dem Studienfach hat sie offenbar eingehend beschäftigt und war für sie mit Unsicherheiten verbunden:

\begin{abstract}
„Also am Anfang, als ich zum Beispiel zehn war, hatt ich noch überhaupt keine Ahnung was ich äh mal studieren will oder. arbeiten will und dann hab ich des erste Mal mich damit konfrontiert als wir uns für das Schulpraktikum ähm bewerben mussten und dann bin ich zum Architekten gegangen (...).“
\end{abstract}

Sie wählt an dieser Stelle eine aktive Darstellung ihrer Studienüberlegungen, bei denen sie keine Scheu vor dem Kontakt zum akademischen Beruf des „Architekten“ gehabt zu haben scheint. Zugleich deutet sich durch ihren gewählten Erzählbeginn der Anspruch an, bereits früh zu wissen wohin man will. Die grundsätzliche fachliche Ausrichtung scheint sich bei Sonja schon seit Jahren anzubahnen, versteht man die Architektur und das Bauingenieurwesen als Fächer mit vielen Schnittstellen. 
Für ihre konkrete Studienfachwahl wiederum nimmt sich Sonja Zeit: So ist sie im Anschluss an ihr Abitur ,erstmal in Ausland gegangen ein Jahr weil ich mich auch noch nich entscheiden konnte". Sie war als Au-Pair in Australien und hat diese Zeit auch genutzt, um ,Interessenstests im Internet“ zu machen (,zum Beispiel bei ,Die Zeit“"), die ergaben, dass sie Mathematik studieren ,sollte“. Sonjas Unsicherheit bei der Studienfachwahl - ihrer grundsätzlichen Tendenz zum Studium allgemein hin zum Trotz - prägt ihren gesamten Entscheidungsprozess. Ein Mathematikstudium kam für Sonja aber nicht in Frage, denn die ,reine Mathematik“ ist ihr ,zu trocken“ und sie hatte auch ,en bisschen Angst, dass es dann am Ende viel zu schwer is". Durch weitere Internetrecherchen stößt sie auf den Bauingenieurstudiengang, der ihr bis dahin nicht bekannt war und der sie ,echt angesprochen" hat. Sie informiert sich darüber hinaus auch an der Hochschule (,und dann hab ich auch hier in der Hochschule $n$ paar Gespräche gehabt") und absolviert die nötigen Vorpraktika auf einer Baustelle und in einem Ingenieurbüro. Für das Studium wird sie direkt zugelassen.

Diese Ausführungen deuten auf mehrerlei hin: Sonja geht strategisch und planend vor, um sich für ein Studienfach zu entscheiden. Sie nimmt sich Zeit für eine Entscheidungsphase und sichert ihre Entscheidung mehrfach durch die Unterstützung von aus ihrer Sicht verlässliche Instanzen ab wie ,Die Zeit“ oder Personen aus der Hochschule als Informations- und Beratungsquellen. Ihr Vorgehen zeugt von umfangreichen Orientierungs- und Vorbereitungsschritten bis hin zu zwei Praktika. Ihre Studienentscheidung stellt Sonja so als aktiven, kontinuierlichen Entscheidungsprozess dar, ihre logisch aufgebaute Erzählung und stringente Argumentation und der Einbezug externer Ratgeber verdeutlichen, dass Sonja eine erfolgreiche Bildungsbiografie ohne Abbrüche und Fehlentscheidungen wichtig ist. Dafür setzt sie sich enorm ein und eine gewisse Anstrengung und Unsicherheit schwingt in Anbetracht des unbedingten Wunsches, sich für das ,Richtige“ zu entscheiden, mit. Sich für diesen Entscheidungsprozess die entsprechende Zeit zu nehmen, kann sich Sonja wiederum auch ,leisten“. Ein Studium an sich scheint schon früh selbstverständlich gewesen zu sein, die Fachwahl bringt sie allerdings bei der Mathematik an ihre Grenzen, die sie sich nicht zutraut und von deren abstrakten Inhalten sie sich abgrenzt.

Der Auslandsaufenthalt erfüllte für Sonja nicht nur den Zweck, mehr Zeit für ihre Fachwahlüberlegungen zu haben, sondern sie ,wollte eigentlich schon immer ins Ausland". Da ihre Cousine bereits als Au-Pair in Australien gewesen ist, hat Sonja dadurch ,schon mal son paar (...) Eindrücke gehabt“, wobei ihr ein Work 
and Travel-Aufenthalt ${ }^{1}$, ,zu unsicher" gewesen wäre. Die Tätigkeit als Babysitterin kannte sie wiederum aus ihrer Jugend. Sonja wählt also den sicheren Weg und entscheidet sich für den Auslandsaufenthalt, den sie am besten einschätzen kann und bei dem sie das geringste Risiko vermutet. Ihr Gastfamilie beschreibt sie rückblickend als ,sehr akademische Familie“, in der die Eltern ihre Kinder ,pushen“, damit ihnen ,alle Türen offen" stehen. Sonja berichtet über die Beschreibungen der Gastmutter, dass eine Eliteschule vor Ort „nur aus Asiaten [besteht]“ und der Sohn diese Schule nicht besuchen sollte, denn ,sie will nicht, dass sich ihr eigener Sohn ((lacht kurz)) wien Ausländer auf der Schule" fühlt. Sonja widerspricht dieser Sichtweise an dieser Stelle nicht oder stellt die Einschätzung der Gastmutter in Frage, was darauf hindeutet, dass Sonja diese Überlegungen nachvollziehen kann. Sie und ihre Gastfamilie scheinen einen ähnlichen Blick auf die Welt zu haben. Sonjas Blick auf ,Ausländer` wird an späterer Stelle nochmal eine Rolle spielen.

Auf Nachfrage der Interviewerin geht Sonja auf ihre Überlegungen ein, an einer Universität oder Hochschule für Angewandte Wissenschaften zu studieren. Dass sie in Hierstadt studieren will, scheint für sie klar gewesen zu sein. Sie zählt in dem Zusammenhang alle Personen in ihrem Umfeld auf, die dort studieren oder studiert haben (ihre Eltern, ihre Cousins und ihr Freund). Gegen die Universität habe sie sich vor allem wegen der "Atmosphäre“ entschieden und weil dort das „Bauchgefühl nich so gepasst“ habe. Außerdem gefällt Sonja das ,praktisch Angelegte“ Studium an der Hochschule für Angewandte Wissenschaften. Das Bauchgefühl konkretisiert sie anschließend, indem sie ausführlich eine besonders bürokratisch anmutende Bewerbungssituation an der Universität schildert:

\begin{abstract}
„Ähm also ich war dann da und wollte meine Bewerbung auch abgeben und ähm man musste sich im Internet so anmelden und dann war des alles schon so total verwirrend gemacht und an der Hochschule wars viel übersichtlicher, und dann wollt ich da des abgeben und dann hat mir ein Blatt gefehlt, und dann dacht ich so okay irgendwie, und die Frau war auch total unfreundlich dann ,Ja wo isn das eine Blatt hin ${ }_{i}$. Ich so ja da war kein Blatt, ich hab mich schon gewundert, habs alles so handschriftlich dann geschrieben ((lacht kurz)) dann so ,Ja ne, des geht nicht' ich muss nochmal wann anders wiederkommen. Dann dacht ich so vielleicht war des jetzt irgendwie en Zeichen, dass ich das nich machen sollte aber.. ähm joa irgendwie wars dann einfach nich so das Richtige für mich glaub ich.“
\end{abstract}

\footnotetext{
${ }^{1}$ Bei einem Work and Travel-Aufenthalt arbeitet man im Ausland für Kost und Logis und bereist zugleich das jeweilige Land.
} 
Dass Sonja diese Hürden im formellen Bewerbungsprozess als „Zeichen“ interpretiert, das das von ihr mehrfach angeführte „Bauchgefühl“ gegen die Universität bestätige, lässt sich als Gespür für die ,richtige' Bildungsinstitution für sie deuten. Es scheint, als ginge Sonja hier den akademischen Weg, bei dem sie den sichereren Erfolg für sich vermutet. Zugleich legt sie eine Kontrastierung an zwischen dem „,verwirrend[en]“ Bewerbungsprozess an der Universität und dem „übersichtlicher[en] “ an der Hochschule. Es scheint ebendiese Übersichtlichkeit zu sein, die Sonja auch in diesem vermeintlichen Detail des formellen Bewerbungsprozesses zur Hochschule tendieren lässt.

In ihrer Schulzeit auf dem Gymnasium waren Sonjas Lieblingsfächer Mathematik und Biologie, die sie auch als Leistungskurse gewählt hat. Daran gefällt ihr „,dieses logische Denken, dass alles irgendwie einen Sinn ergibt, dass man jetzt nich gro $\beta$ drumherum redet “. Die klaren Strukturen dieser Fächer, die auf ,logischen“, also folgerichtigen und schlüssigen Schlussfolgerungen basieren, scheinen ihr besonders zu liegen. Von anderen Fächern wie Deutsch oder auch Teilbereichen der Biologie wie der Ökologie (,wo du viel reden musst“) grenzt sie sich dagegen ab, ,weil ich bin jetzt nich so die starke Rednerin, dass ich.. äh zehn Stunden lang reden kann also.. das liegt mir nich so gut“. Ihre Übertreibung an dieser Stelle verweist auf Abgrenzung gegenüber fachlichen Inhalten, die mit dem argumentativen Einsatz von Sprache verbunden sind ${ }^{2}$. Die fachlichen Vorlieben ihrer Eltern schätzt sie ähnlich ein. In der Mathematik wurde sie von ihnen unterstützt - explizit vom Vater - ,,aber in den andern Fächern ähm konnten sie mir auch nich viel helfen, weil die Fächer ja auch jetzt so in Deutsch wo man tausend Bücher liest, da kennen sie sich auch nich so gut aus. " Auch an dieser Stelle übertreibt Sonja und wertet Deutsch als Schulfach ab. Ihre Disposition hin zu mathematisch-naturwissenschaftlichen Fächern mit klaren Strukturen und einer innewohnenden ,Logik' ist offensichtlich.

Während Sonja hier klare fachliche Präferenzen in ihrer Schulzeit äußert, hat sie indes den entsprechenden Unterricht nicht nur positiv in Erinnerung. Ein stärkeres Interesse für Physik etwa habe sie nie entwickelt, da der Unterricht ihrer

\footnotetext{
${ }^{2}$ An späterer Stelle geht Sonja auf ihre Lieblingsfächer im Studium ein - Hydromechanik und technische Mechanik - in denen sie ebenfalls ihre Affinität zum ,logischen Denken“ erfüllt sieht: „Ähm ich glaub des is auch wieder so dieses logische Denken, dass man so Sachen zusammen kombiniert und halt viel ausrechnet und wenn's dann passt, kann man sich freuen“. Sowohl in der Schule wie im Studium liegen Sonja jene Fächer besonders nahe, in denen sie mittels stringenter Denkprozesse wie z. B. dem Rechnen zu eindeutigen Ergebnissen kommt. Dass sie sich an der Schlüssigkeit dieser Ergebnisse wiederum ,freuen kann“, verweist auch auf eine leidenschaftliche Dimension ihrer fachlichen Disposition.
} 
damaligen Lehrerin ,nicht so gut" war - Sonja vermutet als Ursache eine Alkoholkrankheit der Lehrerin - und deshalb viele fachliche „Lücken“ entstanden sein. So hat Sonja Physik zur Oberstufe hin, ,abgewählt damit ich fürs Abi dann nur die Fächer hab die halt, in denen ich halt (...) besser bin". Hier wird ein Zusammenhang zwischen Noten und Leistungskurswahl deutlich und Sonja hat eine entsprechende Kurswahl aus strategischen Gründen und mit Blick auf ihren Notenspiegel vorgenommen. Auch den Mathematikunterricht erinnert sie zu Teilen kritisch: Mathematik habe ihr zwar ,einfach generell immer Spaß gemacht, weils mir gelegen hatte“, aber Sonja hatte

\begin{abstract}
„,...in der Oberstufe dann nen Lehrer, der war noch ziemlich konservativ und.. ich hab immer gute Noten geschrieben und mündlich hat der mich immer runter gedrückt obwohl ich, Mathe immer es einzige Fach war wo ich mündlich mich immer beteiligt hab weil ichs intressant fand.. und einfach weil ich vielleichtn Mädchen bin oder.. ich kanns ihm jetzt nich unterstellen aber es war schon ziemlich auffällig dass er mich immer schlechter benotet hat, und dann hab ich halt immer gute Noten durchweg geschrieben, dann musste er mir irgendwann halt ne bessere Note geben. Aber naja, vielleicht pusht das einfach so unterbewusst dass man.. ihm des dann beweisen will dass mans kann."
\end{abstract}

Sonja vermutet einen Zusammenhang zwischen der von ihr als „konservativ“ wahrgenommenen Mentalität ihres Mathematiklehrers und seiner Benachteiligung von Mädchen im Mathematikunterricht - ein Zusammenhang, den Sonja als Herausforderung annimmt und der sie zu höheren Leistungen antreibt. Ihre fachlichen Präferenzen und ihr entsprechendes Selbstkonzept scheinen so ausgeprägt, dass Sonja ihren Weg hin zu naturwissenschaftlich-technischen Fächern trotz dieser teils negativen Erfahrungen im Unterricht geht, eine Sonderrolle als Frau darin scheint sie jedoch wahrzunehmen und thematisiert diese von sich aus ${ }^{3}$.

\title{
Studien(fach)wahl im Kontext der Herkunftsfamilie
}

Die Kurzeinführung in den Fall lässt eines bereits erahnen: Technische Studienabschlüsse sind in Sonjas Familie keine Seltenheit. Auch Sonjas Bruder, der zurzeit die Oberstufe des Gymnasiums besucht, hat Mathematik und Physik als

\footnotetext{
${ }^{3}$ Auf die „Unterstellung“ der geschlechtsspezifischen Benachteiligung durch den Lehrer will sich Sonja nicht festlegen - ob dies tatsächlich der Fall war, ist an dieser Stelle auch weniger von Bedeutung. Bedeutsam ist, dass Sonjas (Selbst-)Wahrnehmung im Fach Mathematik eine vergeschlechtlichte ist und dieser Blick auf die ,Sonderrolle als Frau“ ihre Erzählung und Bewertung mitstrukturiert.
} 
Leistungskurse gewählt und überlegt, später Physik zu studieren. Sonja zeichnet sogar das Bild einer ,Technikfamilie" schlechthin und ihre Erzählung über den Bauingenieurberuf ihres Großvaters lässt das Bauingenieurwesen wie ihr schicksalhaftes Erbe erscheinen:

\begin{abstract}
„Also bei uns in der Familie gehen alle mehr so in die Richtung so technische Sachen, also mir hat Deutsch überhaupt nich gelegen, meinem Bruder auch nich, meinen Eltern auch nicht ((lacht)) und meine Cousins zum Beispiel studiern auch beide Informatik.. ja meine Eltern ja auch sowas in die Richtung und.. ähm was ich ja nachher erfahren hab, als ich mich für Bauingenieur entschieden hab, dass mein Opa auch Bauingenieur war."
\end{abstract}

Daneben haben Sonjas Eltern ihre Studienfachwahl auch aktiv beeinflusst: Über diese Entscheidung hat sie ,viel mit [ihren] Eltern (...) gesprochen“ und ihre Mutter wollte sie ,überreden“, dass sie - wie sie selbst - Informatik studiert, was für Sonja aber aufgrund ihres fehlenden fachlichen Interesses nicht in Frage kam. Auch ihr Vater war zentraler Ratgeber für sie: „[D]ann hab ich halt viel mit meinem Papa diskutiert ob ich an die TU oder an die FH gehen soll", die beiden haben ,immer so die Punkte rausgeschrieben was wofür sprechen würde“, was wieder auf ein rationales und geplantes Vorgehen verweist. Letztendlich hat er seiner Tochter, ,eher nah, nahe gelegt eher an die FH zu gehen bei meiner Studienwahl“", ein Rat der nach Sonjas Einschätzung ,auch einfach ausm Bauch heraus“ erfolgt ist, weil sie dort ,besser aufgehoben sei“. So ist es nicht nur Sonjas eigenes „Bauchgefühl“, das, wie bereits ausgeführt, zur Wahl der Fachhochschule beiträgt, sondern das „Bauchgefühl“ ihres Vaters - der selbst an einer Universität studiert hat - stützt sie ebenfalls darin und Sonjas nimmt so den für sie von Vater und sich selbst am ,passendsten“ erachteten Platz an der Fachhochschule ein. Gleichzeitig entpuppt sich das von Sonja mehrmals angeführte ,Bauchgefühl' als Resultat eines strategischen und gut überlegten Entscheidungsprozesses. Interessanterweise scheint ihre Mutter zwar eine Rolle in Sonjas Studienfachwahl gespielt zu haben, allerdings nicht so einen zentralen Einfluss darauf ausgeübt zu haben wie ihr Vater, den sie häufiger explizit benennt und an dessen Ratschlägen sich Sonja besonders zu orientiert.

Neben der Begleitung von Sonjas Studienfachwahl geben die Eltern auch ihre eigene Studienerfahrung an Sonja weiter. Hier rückt wiederum ihre Mutter stärker in den Vordergrund, denn ein gewisses Verständnis von der, Sonderrolle als Frau' in einem technisch-naturwissenschaftlichen Studium wurde von ihr kommuniziert, wie Sonja mit Bezug auf das Geschlechterverhältnis in ihrem Studium erzählt: 


\begin{abstract}
„Ähm es sind schon mehr Männer, vielleicht so $25 \%$ Frauen, also ich kenn jetzt halt nur meinen Zug, die andern Züge seh ich ja jetzt nich so, aber es sind schon mehr Männer, das muss man sagen, aber ich hätte jetzt mit mehr Männern gerechnet. So, also ich glaub im Vergleich zu früher hat sich das schon.. echt gebessert. So meine Mutter zum Beispiel erzählt immer, dass sie vielleicht zu zweit oder zu dritt warn in der Vorlesung. So ist das bei uns zum Glück nich ((lacht)).“
\end{abstract}

Sonja konnte sich aufgrund der Erfahrungsweitergabe durch ihre Mutter auf die zahlenmäßige Minderheitenposition in ihrem Studium einstellen und hält den Frauenanteil von $25 \%$ im Bauingenieurwesen sogar für relativ hoch, verglichen mit der Informatik. Dass die berufliche Erfahrung ihrer Mutter auch in anderen Bereichen eine Rolle für Sonja spielt, wird an späterer Stelle nochmal deutlich werden.

Dass für Sonja zwar die Wahl der Hochschulart in Frage stand, nicht jedoch der Hochschulstandort - Hierstadt - wurde bereits deutlich. In dieser Stadt arbeitet ihr Vater und sie ist nur etwa 50 Kilometer von Sonjas Heimatstadt entfernt, die sie alle zwei Wochen besucht. Ihre Heimatstadt bezeichnet sie als ,sehr gutes Umfeld“, in dem ,halt auch sehr viele reiche Leute" wohnen. Sonja hat schon immer dort gewohnt und ist - vor ihrem Umzug nach Hierstadt - noch nie umgezogen. In ihrer Heimatstadt ,kennt sich ja auch jeder" und es sei ein Umfeld, in dem man ,gut aufwachsen“ kann. Ähnliche Bewertungsmuster spiegeln sich auch in der Beschreibung ihres Gymnasiums wieder:

,[I]m Vergleich zu der Hochschule warn da ähm.. Gott wie sagt man das denn.. ich glaub schon Leute, die aus nem sehr guten Familienhaus kommen. Auch aus nem sehr stabilen Familienhaus, dass die Eltern jetzt nicht geschieden warn oder so, das war schon sehr selten. So im Vergleich zu Berlin sind ja viele Eltern.. Patchworkfamilien und das war bei uns eigentlich jetzt sehr selten der Fall.“

Sonja kontrastiert hier das soziale Umfeld der Hochschule mit ihrem ehemaligen schulischen Umfeld und stellt die „stabilen Familien[häuser]“ dort als positiv heraus. Sie legt dabei Wert auf eine ,politisch korrekte' Ausdrucksweise, zögert und ist unsicher, wie sie diese ,sehr guten Familienhäuser" bezeichnen soll. Sie beschreibt die Atmosphäre als ein stabiles soziales Gefüge und kontrastiert sie erneut, nun anhand des Beispiels Berlin als Großstadt, wo es viele „Patchworkfamilien“ gibt, wo es demnach unübersichtlich und instabil ist und - so könnte man ihre Kontrastierung weiterdenken - wo man ,schlecht aufwächst'. Ihre Ausführungen beinhalten zahlreiche Abgrenzungen und Defizitzuschreibungen: Sie ordnet sich selbst einer , heilen Welt" zu, denn „,bei uns“ kämen ,Probleme“ wie Scheidungen, Armut und instabile Familienverhältnisse 
nicht vor. Beide Beschreibungen - von ihrer Heimatstadt und ihrem dortigen Gymnasium - verdeutlichen Sonjas Identifikation mit ihrem geordneten, stabilen und finanziell abgesicherten Herkunftsumfeld.

In Kontrast dazu kommt Sonja an späterer Stelle auf das soziale Umfeld in der Hochschule zu sprechen, als sie über ihre ersten Vorlesungswochen berichtet:

,$\ldots[\mathrm{B}]$ is jetzt find ichs eigentlich ganz gut, weil also ich find den Unterricht ähm bis jetzt echt interessant gemacht also auch die Professoren sind echt lieb und ähm.. also ich fühl mich ganz wohl hier und man kommt auch gut mit in dem Unterricht ähm joa. Ich hätte nur nich gedacht dass der Ausländeranteil so groß ist. (I: Achja) Also.. weil bei Bauingenieurswesen hier ist der echt groß, bei der TU is der jetzt

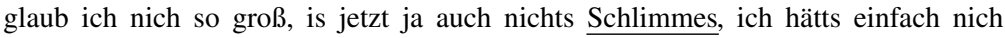
erwartet, dass es so viele Ausländer sind.“

Auf die anschließende Nachfrage der Interviewerin, ob es sich dabei um international Studierende handele, antwortet Sonja: ,Ne, ähm mmh mehr nur Türken, so türkische Gruppen, die reden halt auch alle immer viel Türkisch in den Vorlesungen des is, also, es gibt Schlimmeres aber des hätt ich am Anfang nich erwartet. “ Sie konkretisiert also die Beschreibung der „Ausländer" mit dem Begriff der „Türken“, die in den Vorlesungen häufig türkisch miteinander sprechen.

Zum einen betont Sonja an dieser Stelle die emotionale und soziale Dimension des Studiums („Professoren sind echt lieb"), statt sich etwa die fachliche Ebene des Lernorts Hochschule zu beziehen. Zum anderen thematisiert sie den für sie überraschend hohen „Ausländeranteil“ als Antwort auf die Frage nach ihrer bisherigen Studienzufriedenheit. Diese Ausführungen sind negativ konnotiert: Dass es ja „Schlimmeres“ gebe als viele „Türken“ im Hörsaal, impliziert, dass dieser Umstand an sich ,schlimm“ ist. Kurzum: Wie bereits bei den „Patchworkfamilien“ und „Asiaten“ (in der Au-Pair-Zeit in Australien) kommen auch hier Sonjas offen ausgrenzende Wahrnehmungs- und Bewertungsmuster zum Tragen und sie nimmt eine abwertende Abgrenzung vor, diesmal von der Gruppe der ,Türken“.

An späterer Stelle greift sie dieses Thema nochmals auf, als die Interviewerin fragt, wie Sonja ihre Kommiliton*innen beschreiben würde:

„Ähm also wir haben natürlich einmal so ne große türkische Gruppe und.. wir sind
mehr so ne Gruppe eigentlich, wir sind alle so es gleiche Alter so 19, 21 ähm und
ich hab die mh zwei von denen im Mathevorkurs kennengelernt, Physikvorkurs,
und wir sind eigentlich alle, wie sagt man des jetzt, äh.. alle eigentlich ziemlich
ähnlich, wir kommen auch aus der Umgebung, also die eine wohnt en bisschen
weiter weg, aber wir sind schon alle.. ähm Deutsch, wenn man des jetzt so sagen 
kann. Ähm aber wir haben schon so, wie lernen auch oft zusammen, setzen uns zusammen hin und gehen den Stoff durch (...).“

An dieser Stelle werden die Abgrenzungen, die Sonja vornimmt, besonders deutlich: Sie beschreibt hier ihren eigenen sozialen Kreis von Peers im Studium, in dem ,alle so es gleiche Alter" haben und die ,alle eigentlich ziemlich ähnlich“ und ,alle Deutsch" sind. Wie bereits bei den Patchworkfamilien ringt Sonja auch hier um eine ,politisch korrekte" Ausdrucksweise und wirkt unsicher in ihren Formulierungen (,...wenn man des jetzt so sagen kann“).

Es entsteht das Bild einer durchaus in privilegierten Verhältnissen aufgewachsenen, umsorgten und ,behüteten' Schülerin, die die an sie herangetragenen normativen Erwartungen erfüllt, ihre Schullaufbahn am Gymnasium erfolgreich durchläuft, das Abitur macht, einen sicheren und planbaren Au-Pair-Aufenthalt in Australien absolviert und sich für die familiäre Bildungsumgebung der Hochschule für Angewandte Wissenschaften entschieden hat, an der sie - wider Erwarten - mit sozialen Gruppen konfrontiert ist, die nicht ihrer Herkunftserfahrung entsprechen. In der Folge scheint Sonja irritiert und verunsichert, sei es durch die „Patchworkfamilien“ in Berlin, ,die Asiaten“ bei ihrer Gastfamilie in Australien oder "die türkische Gruppe“ in ihrem Studium.

\section{Studien(fach)wahl und antizipierte Zukunft}

Ihre berufliche Zukunft sieht Sonja im konstruktiven Ingenieurbau: Sie interessiert „mehr so das Planen und nich so das Leiten auf ner Baustelle“, aber auch der Bereich der Hydromechanik spricht sie grundsätzlich an. Ihre Berufsvorstellungen sind damit noch eher unkonkret und sie möchte offenlassen, dass sich das „auch noch während dem Studium ändert". Auch auf die Frage hin, was für sie einen Traumjob ausmacht, spiegelt Sonjas Antwort breite, offene Vorstellungen wider:

\footnotetext{
„Ähm.. dass man ne gute Atmosphäre hat im Job, dass man sich da wohlfühlt, dass man mit seinen Arbeitskollegen gut zurecht kommt, ähm.. dass man.. ähm dass es auchn bisschen vielseitig is, dass man Abwechslung hat, dass man auch manchmal so vor Voraus-, ähm Herausforderungen gestellt wird, dass man dadran wächst und.. ähm dass man vielleicht auch am Anfang vielleichtn bisschen reisen kann, dass man en bisschen was sieht von der Welt, also später dann vielleicht nicht mehr irgendwann, aber vielleicht am Anfang wärs ganz schön, dass man auch nicht nur die ganze Zeit vorm Computer sitzt, das wär mir ganz lieb, dass man halt ähm auch im Team arbeitet und nich alleine so vor sich hin, das wär mir wichtig. Und.. ja eigentlich hauptsächlich dass es Spaß macht. Weil sonst wüsst ich ja nicht, man verbringt ja die meiste Zeit am Arbeiten eigentlich, bei seinem Beruf, und dann ((lacht)) ja.“
} 
Im Vergleich zur Schilderung ihrer Studienfachwahl zu Interviewbeginn antwortet Sonja hier eher unsicher: Sie stockt häufiger, benutzt mehrfach das distanzierende Wort „man“ und abschwächende Beschreibungen (,manchmal“, „,vielleicht“, „,bisschen“, ,irgendwann“...). Konkrete Berufsvorstellungen oder ein bestimmtes berufliches Ziel sind bei ihr nicht vorhanden. Stattdessen ist ihre Antwort geprägt von emotionalen und sozialen Komponenten (,gute Atmosphäre“, „,wohlfühlen“, „,im Team arbeitet“, „Spaß“). Auch eine gewisse Selbstverwirklichung, Abwechslung im Beruf und Reisen gehören zu ihren beruflichen Vorstellungen.

Während ihre beruflichen Vorstellungen noch unkonkret sind, Sonja schon genau, dass sie den Masterabschluss machen will. Dies begründet sie mit dem Ratschlag ihres ehemaligen Chefs, der dem Masterabschluss bessere Arbeitsmarktchancen zuschreibt (,,[D]es hat mir auch mein Chef da bei dem Praktikum nahegelegt, dass ich mir eigentlich von Anfang an vornehmen soll en Master zu machen, weil man sonst einfach nich so weit kommt, mit dem, weil es is schwieriger en Job zu finden weil eigentlich jeder jetzt nur noch en Master. sucht als Absolvent"). Auch hier vertraut Sonja also auf den Rat eines ,Experten' - eines erfahrenen Bauingenieurs - und folgt seinen beruflichen Ratschlägen, zum einen, um überhaupt eine Stelle zu finden und zum anderen, um ,weiter ${ }^{*}$ kommen zu können als mit einem Bachelor-Abschluss. Sowohl berufliche Absicherung wie auch die Aussicht auf beruflichen Erfolg spielen also in ihren Zukunftsvorstellungen eine Rolle.

Über Sonjas Berufsvorstellungen ist des Weiteren aussagekräftig, was sie auf die Frage antwortet, welchen Stellenwert Karriere allgemein für sie hat: „Mmh... äh.. also ich weiß, dass ich später irgendwann gerne mal Kinder haben will, aber ich würde auch ähm gerne erst mal arbeiten (...) “. Die Frage nach Karriere veranlasst Sonja also dazu, mit dem Thema der Familiengründung zu antworten - beide Themenkomplexe scheinen für sie zusammenzugehören. Die Familiengründung nimmt offenbar eine hohe Priorität für sie sein, da sie sie direkt thematisiert, bevor sie überhaupt über ihre Karrierepläne spricht. Auf die spätere Nachfrage der Interviewerin, wie sie sich die Vereinbarung von Familie und Beruf vorstellt, greift Sonja erneut auf die Erfahrungen ihrer Mutter zurück:

„Mmh, ich glaub des wird echt schwierig. Vor allem, ich habs ja auch von meiner Mama mitbekommen dass des schwierig ist, in Teilzeit zu wechseln, dass man des jetzt auch nicht in jedem Job machen kann einfach so, weil man wird ja trotzdem dann immer mehr beansprucht als man will, der Chef braucht halt dann auch einen oder wenn gradn Projekt ist, da muss man halt arbeiten, aber ich glaube es Wichtige ist dann wirklich wenn man Kinder hat, dass die Kinder vorgehen. (...) Und dann würde ich halt echt schauen, dass man irgendwie auf Teilzeit wirklich versucht zu kommen wenns geht. Aber die ersten Jahre dann würd ich halt erstmal nicht 
arbeiten. Aber der Berufseinstieg ist dann halt wieder schwierig, wenn man ne Pause gemacht hat."

Für Sonja scheint es selbstverständlich, dass sie die Erziehungsarbeit ausführen wird und dafür mehrere Jahre keiner Erwerbstätigkeit nachgeht - eine*n Partner*in und dessen*deren potenzielle Beteiligung an der Erziehung erwähnt sie nicht. Sie antizipiert außerdem ein zeitintensives Erwerbsleben, das ihr eine Vereinbarung von Familie und Beruf nach eigenen Vorstellungen erschwert, wobei sie in dieser Frage eine klare Priorität auf das Engagement in der Erziehungsarbeit legt (,[E]s Wichtige ist dann wirklich (...), dass die Kinder vorgehen“). Erst auf eine weitere Nachfrage hin kommt sie auf die mögliche Involvierung eines (männlichen) Partners in die Kindererziehung zu sprechen:

\begin{abstract}
„,̈hm.. is ne gute Frage. Ich glaub ich fänds nich so gut ((Sonja lacht)) (I: Okay). Ich glaub ich würd" mich lieber um die Kinder kümmern. Es kommt, es sind, es ist halt noch dieses klassische Bild, dass sich die Frau um die Kinder kümmert aber, das ises eigentlich gar nichmal so sondern.. ich glaub ich würde meine Kinder gerne aufwachsen sehen. Und nicht, dass ich die ganze Zeit arbeite. Das wär' mir wichtig, denke ich. Aber ich fänds auch gut, wenn er sich dann auch, oder dass man sich halt echt abwechselt, aber es ist halt son Problem, man kann nicht beide Teilzeit arbeiten weil man dann arbeitet man ja zur gleichen Zeit meistens, man kann ja des schlecht so.. kombinieren.“
\end{abstract}

Auf Anhieb lehnt Sonja ab, dass ihr Partner zur Erziehung der Kinder zu Hause bleibt und antwortet spontan „Ich glaub, ich fänds nich so gut". Hier kommen im Affekt inkorporierte Geschlechtsrollenvorstellungen zum Tragen, die sie ,aus dem Bauch heraus' verbalisiert ${ }^{4}$. Eine geteilte Erziehungszeit ist für sie nicht vorstellbar und zugleich sie sich distanziert vom Bild der „klassische[n] “ Arbeitsteilung. Somit betont Sonja, dass dieses Bild im Sinne einer gesellschaftlichen Erwartungshaltung für sie nicht handlungsleitend ist. Stattdessen hebt sie den ,intrinsischen "Wunsch hervor, ihre Kinder „aufwachsen [zu] sehen “ und antizipiert vor dem Hintergrund dieser Begründung auf manifester Ebene die Erziehungsarbeit auf ihrer Seite. Bedenkt man, dass Sonja in der vorigen Interviewpassage auf die Frage nach ihren Karrierewünsche mit ihrem Wunsch nach Familiengründung geantwortet hat, wird umso deutlicher, dass ebendieser Kinderwunsch und die

\footnotetext{
${ }^{4}$ Diese symbolische Dichotomisierung von Geschlecht spiegelt sich auch wider, wenn Sonja auf die Frage antwortet, wie sie ihre Eltern beschreiben würde: „Mein Vater is eher so'n ähm.. joa so'n realistischer Typ, eher so, nich so gefühlsvoll wie meine Mama, meine Mama is ziemlich emotional. Ähm aber sind en bisschen gegensätzlich und ich bin glaub ich so ne Mischung aus beiden. “
} 
Erziehungszeit auf ihrer Seite für sie eine große Priorität einnehmen. Es entsteht das Gesamtbild von Sonja als künftige Mutter mit Erziehungszuständigkeit aus ,freier Entscheidung', hinter dem zugleich latent binäre inkorporierten Geschlechtsrollenvorstellungen wirken.

Abschließend soll noch ein Blick auf Sonjas Antwort geworfen werden, was ihre drei größten Wünsche sind. Hier stockt und zögert Sonja besonders auffällig und weist die Frage gewissermaßen zurück:

„Mh... Da gibts doch immer so Scherzfragen ne, also.. oder so (I: Achso, unendliche viele Wünsche), ja ich will unendlich viele Wünsche für erste Mal ((Sonja lacht - I lacht)) oder ich würd“ mir nochmal drei weitere wünschen. (I: Das ist verboten) Mh... Drei Wünsche, oh Mann... ((seufzt)). Was willste denn aus der Frage herauslesen? ((lacht)) (I: Naja, was deine drei Wünsche sind) ((I lacht)). Sowas ist nicht meine Sache ((lacht)). Ähm, drei Wünsche. ....“

Möglicherweise zeichnet sich hier ab, was sich tatsächlich hinter Sonjas Verunsicherung bei (auch anderen) persönlichen, privaten Fragen verbirgt, die sie entweder gar nicht oder kurz angebunden beantwortet: Sie will sich nicht zum Untersuchungsobjekt machen lassen. Denn an dieser Stelle geht sie in Widerstand und fragt, was die Interviewerin ,denn aus der Frage herauslesen “ will. Offensichtlich geht diese Frage zu weit in den Privatbereich hinein. Sonja möchte sich nicht in die Karten schauen lassen, schottet den allzu privaten Bereich ab und will die Kontrolle über das Interview behalten. Nachdem die Interviewerin noch einmal nachhakt, antwortet Sonja schließlich:

„Mhmh. ......̈̈hm ich denke so ein Wunsch wär`, dass so alle Leute die ich kenne, dass die ähm gesund bleiben und lange am Leben bleiben. Ähm... son zweiter Wunsch ähm, was fürn zweiter Wunsch. Ähm... also beim ersten dass halt einfach Gesundheit für alle die man kennt die einem wichtig sind, da is man ja selbst mit eingeschlossen (I: Mhmh) ((I lacht - Sonja lacht)). So, das ist das Wichtigste denk ich. Und ähm.. ja vielleicht zweiter Wunsch halt mehr so auf die Welt bezogen, das werden jetzt wahrscheinlich viele sagen, so in der letzten Zeit was da jetzt so passiert ist (I: Achso, ja) [Ergänzung LL: Interview wurde kurz nach den Anschlägen in Paris 2015 geführt], ähm, dass sich das vielleicht alles wieder son bisschen.. beruhigt und dass es stabil bleibt und so. Und als dritter Wunsch.. äääh... ähm....... ich denk, schwierig. Das sind eigentlich so die zwei Sachen, das ist so das Wichtigste. Und sonst einfach, dass man sein Leben genießt, dass mans genießen kann.“

Zusammengefasst wünscht sich Sonja also zwei Dinge: Gesundheit und Stabilität. Ihre Antwort ist von impliziten Bedrohungen geprägt, nämlich Krankheit, 
Krieg und Terror, vor denen sie geschützt sein will. Hier bietet sich die Verbindung zu den zahlreichen Abgrenzungen in ihrem Interview und der Konstruktion ihrer ,heilen Welt ' in ihrer Heimatstadt an: Sicherheit und Beständigkeit stehen für Sonja an erster Stelle und scheinen doch in ständiger Gefahr zu sein.

\section{Habitus, Studien(fach)wahl und Milieuspezifika}

Im Fall von Sonja ist ihre Studien(fach)wahl eine Frage der Tradition: Jedes Familienmitglied, von dem sie berichtet, hat ein technisches Studium abgeschlossen, möchte eines beginnen oder befindet sich in einem. Das umfasst sowohl ihre gesamte Kernfamilie wie auch ihre Cousins und den Großvater, der ihr das Bauingenieurwesen über Generationen hinweg vererbt $\mathrm{zu}$ haben scheint. Auch ihre Mutter ist schon eine Frau im technischen Beruf - weiblich Berufslaufbahnen im technischen Bereich sind also ebenfalls Bestandteil von Sonjas Erfahrungen in ihrer Herkunftsfamilie. Sichtlich stolz berichtet sie über ihre ,Technikfamilie‘ und ihre eigene Vorliebe für Fächer, denen eine gewisse Logik und klare Strukturen innewohnen - hier zeichnet sich ihre Passung zur ingenieuralen Fachkultur mit ihrem nüchternen Anwendungsbezug, dem hohen Stellenwert von mathematischen Lösungswegen und ohne kontroverse Diskussionen und Aushandlungsprozesse. Überhaupt $\mathrm{zu}$ studieren wiederum ist von vornerein selbstverständlich für Sonja und auch der Weg zum Abitur scheint ein geradliniger gewesen zu sein ohne weitere Umwege oder Abbrüche ${ }^{5}$.

Ihre Fachwahl hin zum Bauingenieurwesen ist dabei einerseits davon geprägt, dass ihr schulisches Interesse bereits auf mathematisch-naturwissenschaftliche Fächer fokussiert war und sie dieses trotz teils negativer Unterrichtserinnerungen weiterverfolgt hat und dass sie andererseits an ihre Grenzen kommt, was das Studium der Mathematik oder an einer Universität angeht, weshalb sie ihre mathematische Affinität stattdessen durch das fachhochschulische Bauingenieurwesen erfüllen will. Sowohl Sonja wie auch ihr Vater, maßgeblicher Ratgeber in dieser Frage und selbst Universitätsabsolvent, folgen ihrem „Bauchgefühl“ und sehen Sonjas Platz in einem praxisnahen Fach an einer übersichtlichen Hochschule für Angewandte Wissenschaften und damit in einem vergleichsweisen bescheidenen Bildungsweg. In der Frage der Fachwahl stützt sich Sonja zusätzlich auf mehrere externe Ratgeber, die sie als zuverlässige Quellen einstuft - etwa Personen aus der Hochschule. Sonja geht so planvoll und strategisch vor, um die ,richtige " Fachwahl zu treffen - ein Vorgehen, das in seinem Ausmaß von Anstrengung

\footnotetext{
${ }^{5}$ Zumindest tauchen diese in ihren Erzählungen nicht auf, was für diese Deutung maßgeblich ist.
} 
zeugt und damit Elemente der Unsicherheit erahnen lässt, die sich ebenso in ihrer Abgrenzung von Mathematik und Universität widerspiegeln.

Sicherheit als leitendes Motiv in der Wahl von Studienfach, Studienort und Hochschulart spielt für sie grundsätzlich eine zentrale Rolle. So mündet sie in ein Studium, das parallele Beziehungsstrukturen zu ihrer Herkunftsfamilie und -umgebung aufweist: Sonja fühlt sich wohl in einer überschaubaren, verlässlichen, stabilen Lebens- und Studierumgebung, sei es in ihrer Heimatstadt oder im Bauingenieurwesen an der Hochschule für Angewandte Wissenschaften. Irritiert und verunsichert wird sie dagegen von dem, was sie aus ihrer, heilen Welt" nicht kennt - „Patchworkfamilien“, „Ausländer" und „Türken“ werden abwertend benannt und stehen sinnbildlich für eine aus Sonjas Sicht ,instabile“ Lebenswelt, von der sie sich distanziert.

Was ihre Zukunftsvorstellungen angeht, spielt Sonjas Wunsch nach Familiengründung eine tragende Rolle und innerhalb dessen Sonja für sich die überwiegende Erziehungsarbeit antizipiert. Von gesellschaftlichen Erwartungshaltungen zur Frage der Aufgabenteilung grenzt Sonja sich ab und zeichnet stattdessen ein Bild von sich als eigenständig entscheidende, erziehende künftige Mutter. Zugleich mögen hier durchaus inkorporierte binäre Geschlechtsrollenvorstellungen wirken, die sich an mehreren Stellen im Material zeigen: etwa indem sie die alleinige Kindererziehung durch ihren Partner affektiv ablehnt oder indem sie ihren „realistisch[en]“ Vater und ihre „gefühlsvolle“ Mutter kontrastiert.

Spuren der Vergeschlechtlichung finden sich außerdem in ihren studien- und berufsbezogenen Ausführungen, die von der Betonung emotionaler und sozialer Aspekte durchzogen sind und in denen sie aktiv eine ,Sonderrolle als Frau“ konstituiert, etwa bezogen auf ihre Minderheitenposition oder die schwierige Vereinbarkeit von Familie und Beruf. Im Ergebnis lässt sich bei Sonja ein milieuspezifisches doing gender while doing work feststellen, das in ihre herkunftsspezifischen Habitusmuster eingebettet ist: Ihre Selbstsicherheit, überhaupt zu studieren, rührt von ihrer akademisch geprägten sozialen Herkunft her, ebenso wie ihre Fachwahl - strukturiert durch ihre Nähe zur von ihr als logisch und klar wahrgenommen Mathematik - Ergebnis ihrer milieuspezifischen Disposition hin zu Ordnung und überschaubaren Strukturen ist. Die vergeschlechtlichten Selbst- und Fremdzuschreibungen - etwa durch sich selbst, durch einen Lehrer und den Vater - und damit verbundenen Mechanismen der Abdrängung wiederum führen dazu, dass Sonja den vergleichsweisen bescheidenen Weg in das 
fachhochschulische Bauingenieurwesen wählt ${ }^{6}$ und eine dazu ,passende` Form der Familienorganisation entlang binärer Aufteilungen antizipiert.

Die Selbstverständlichkeit, ein Studium aufzunehmen, spricht für eine relativ hohe vertikale Verortung des Falls - allerdings unterhalb der Distinktionslinie, also im Bereich der mittleren Volksmilieus. Darauf deuten die Anstrengungen hin, die Sonja unternimmt, um das ,richtige' Studienfach zu wählen sowie ihre fachwahlbezogenen Unsicherheiten und ihre habitusspezifischen Grenzen hin zu einem Universitätsstudium. Sonjas sicherheitsorientiertes, methodisch-planendes Vorgehen, ihre Orientierung an Tradition und Bekanntem, ihre affektive Ablehnung der Erziehungszeit auf männlicher Seite, ihre Abwertung von „Patchworkfamilien" und Studierenden anderer ethnischer bzw. sozialer Herkunft lassen sich wiederum als spezifische Habitusmuster der ständisch-bürgerlichen Traditionslinie deuten, insbesondere des oberen Bereichs des modernen kleinbürgerlichen Milieus (siehe auch Vester 2015: 167 ff.).

\subsection{Fall Tabea: „,,Die Soziale Arbeit ist der Stachel im Fleisch der herrschenden Systeme ${ }^{\prime \prime \prime}$}

\section{Reflexion der Interviewsituation}

Mit knapp einer Stunde Dauer liegt die Länge des Interviews mit Tabea im Durchschnitt. Die Interviewsituation lässt sich als gesprächsnah und offen beschreiben: Tabea kommt in ihren Antworten ins Erzählen, bezieht sich dabei aber stets auf die Fragen der Interviewerin ohne thematisches Abschweifen oder zeitliches Ausschweifen. Ihr Sprachstil ist überwiegend jugendlich-umgangssprachlich (,geil", ,kein Bock") und sie formuliert ihre Antworten spontan ohne langes Nachdenken. Emotionalere Passagen sind besonders von diesen umgangssprachlichen Formulierungen sowie von auffälligeren Betonungen geprägt, was etwa bei den Beschreibungen von Tabeas Vater und ihren ehemaligen Mitschüler*innen am Gymnasium hervortritt. Inhaltlich sind ihre Erzählungen von Beginn des Interviews an von Offenheit geprägt, sie erzählt auch Privates ohne zu Zögern. Sowohl was Stil wie auch Inhalt ihrer Erzählungen angeht, unterscheidet sich dies also von der Gesprächssituation mit Sonja, die häufiger über ihre Antworten nachdenkt, nach den ,richtigen“ Worten sucht und allzu private Themen tendenziell abschottet.

\footnotetext{
${ }^{6}$ Und auch wirken milieuspezifische Muster hinein, da etwa die ,Übersichtlichkeit' an der Hochschule für Angewandte Wissenschaften Sonja besonders anspricht.
} 
Ein Thema, das sich in Tabeas Erzählungen mehrfach wiederholt und das sie auch auf die letzte Frage hin anspricht (,Ist bei dir noch irgendwas im Kopf über Soziale Arbeit oder deine Entscheidung fürs Studium, was du wichtig findest, was jetzt noch nich angesprochen wurde?") ist die gesellschaftliche Wertschätzung und Sinnhaftigkeit von (Sozialer) Arbeit: ,...[D]ass ich eigentlich finde dass Sozialarbeiter. total gut bezahlt werden sollten.. weils halt so ne wichtige Arbeit is weil ich mein.. also.. des is ja eigentlich fast diewichtigste Arbeit in der Gesell-, find ich." Diese ,Botschaft" scheint für Tabea zentral zu sein und sie verweist neben ihrem idealistischen Blick auf die Profession auch auf ihre Identifikation mit dem Beruf der Sozialarbeiterin, die bei ihr für das erste Studiensemester vergleichsweise ausgeprägt ist.

\section{Kurzeinführung in den Fall}

Tabea ist zum Zeitpunkt des Interviews 25 Jahre alt und studiert seit zwei Monaten Soziale Arbeit. Ihr Abitur hat sie auf einer katholischen Privatschule in Hierstadt absolviert, anschließend ein Freiwilliges Soziales Jahr in einer Schule für praktisch Bildbare ${ }^{7}$ durchlaufen und danach ein Studium der Kulturanthropologie begonnen. Das hat sie allerdings abgebrochen und eine Schreiner*innenlehre absolviert. Ein Berufseinstieg folgte auf diese Ausbildung nicht, sondern Tabea hat sich direkt danach für das Studium der Sozialen Arbeit beworben und wurde zugelassen.

Tabeas Mutter ist mittlerweile verstorben. Sie war Sozialarbeiterin und hat an der Hochschule studiert, an der auch ihre Tochter nun eingeschrieben ist. Tabeas Vater hat an einer Universität mehrere kulturwissenschaftliche Studienfächer belegt, unter anderem Theologie, und anschließend promoviert. Heute ist er als Berufsschullehrer tätig. Ihre Eltern haben sich in Tabeas früher Kindheit getrennt, wonach ihr Vater eine neue Partnerschaft eingegangen ist und eine zweite Tochter bekommen hat. Diese studiert heute Schauspiel.

Die gesamte Familie - Tabeas Vater, ihre Mutter und ihre Großeltern wohnt(e) im gleichen innerstädtischen Viertel in Hierstadt jeweils in Mietwohnungen. Tabea selbst hat ihre Kindheit größtenteils bei ihren Großeltern gelebt - Gründe hierfür nennt sie nicht - und ist mit zwölf Jahren zu ihrer Mutter gezogen. Mit ihr hat Tabea anschließend in einem „Wohnprojekt für Alleinerziehende" gewohnt. Während ihrer gesamten Kindheit hatte Tabea zu ihrem Vater regelmäßigen Kontakt, vereinfacht durch die räumliche Nähe, und hat so auch viel Zeit mit ihrer Halbschwester verbracht, die sie z. B. häufig vom Hort abgeholt hat.

\footnotetext{
${ }^{7}$ Eine Form der ,Sonderschule‘ für Schüler*innen mit körperlicher und/oder geistiger Beeinträchtigung.
} 
Heute wohnt Tabea in einer Wohngemeinschaft in Hierstadt. Sie befindet sich zurzeit in einer Partnerschaft mit einem Mann, über den keine weitere Informationen bekannt sind.

\title{
Weg hin zum Studium
}

Tabeas Eingangserzählung deutet auf einige Suchbewegungen und Umorientierungen hin, die sie bis zu ihrem Studienbeginn unternommen hat. Diese Aspekte der Vagheit und Flexibilität bilden einen Gegensatz zur Eingangserzählung, wie sie von Sonja vorgenommen wurde.

\begin{abstract}
„Ähm weil ich davor ähm schon einige Sachen, also ich hab erst Abi gemacht und dann halt so FSJ und Studium angefangen, dann wieder abgebrochen, dann ne Ausbildung gemacht.. und ähm... ja dann hab ich irgendwie.. gemerkt, dass mein Ausbildungsberuf in dem ich eigentlich arbeiten wollte, Schreiner, nicht so.. also ähm nicht so geeignet für mich ist.“
\end{abstract}

Nach ihrem Abitur hat Tabea ein Freiwilliges Soziales Jahr in einer Schule für praktisch Bildbare absolviert. Diese Zeit sieht sie als maßgeblich für ihre spätere Entscheidung an, Soziale Arbeit zu studieren. Denn während des FSJ ,wurd mir halt auch immer gesagt ich soll unbedingt was Soziales machen" und obwohl sie gemerkt hat, dass sie diese Tätigkeit „schon sehr anstrengt“, war sie für Tabea auch "total die Bereicherung“, weil sie dort „immer das Gefühl [hatte] ja das ist irgendwie sinnvoll dass ich mich dafür. engagier oder so". Schon in diesen ersten Passagen finden sich Hinweise darauf, dass für Tabea sowohl die Rückmeldung und Einschätzung aus ihrem sozialen Umfeld wie auch die - an dieser Stelle nicht näher definierte - ,Sinnhaftigkeit ' ihres Berufs eine wichtige Rolle in ihren beruflichen Überlegungen spielen. Dass sie ihren Einsatz in einer Schule für praktisch Bildbare als ,sinnvolles Engagement' sieht, könnte auch auf einen gewissen Idealismus hindeuten. An der Sozialen Arbeit reizt Tabea außerdem, dass sie damit Abwechslungsreichtum und Unkonventionalität verbindet: „[F]ind ich bei Sozialer Arbeit halt auch cool, dass man dann.. nich son Büro0815-Job hat sondern halt irgendwie auch Abwechslung “. Diese betonte ,Abkehr vom Normalen" mag auch durchaus distinktive Anteile haben, schließlich erhebt sich Tabea mit diesem Urteil über die Lebensgestaltung eines ,Ottonormalverbrauchers'. Diesen ersten Spuren soll in der folgenden Analyse nachgegangen werden.

Wie es zu Tabeas Entscheidung für das Freiwillige Soziale Jahr kam, wird im Interview nicht deutlich. Was aber deutlich wird, ist ihre Motivation, im 
Anschluss an dieses Jahr ein Studium der Kulturanthropologie zu beginnen - darauf geht Tabea direkt nach der oben erwähnten Ausführung zur ,Sinnhaftigkeit` ihrer Tätigkeit in der Schule für praktisch Bildbare ein:

„Und... joa und dann hab ich äh im Studium, in meinem ersten Studium hab ich irgendwie das war Kulturanthropologie und äh das, das hab ich halt auch gemacht weil ich irgendwie so dachte da kann man irgendwie so das Intresse für Menschen und wie die.. wie sich die Kulturen entwickeln und so aber das war mir dann irgendwie zu trocken und auch zu theoretisch.“

Tabeas fachliche Erwartungen an das Studium der Kulturanthropologie, mehr über „Menschen“ und „Kulturen“ zu erfahren, wurden im Studium enttäuscht, von dessen abstrakter Ausrichtung (,trocken“, „,theoretisch“) sie sich abgrenzt. In einer späteren Passage deutet sie ihr ,Scheitern“ im Studium um, indem sie den Grund für den Abbruch in der Gestaltung des Studiums verortet und diese abwertet:

„[B]ei Kulturanthropologie da konnt" ich diese Texte einfach auch nicht verstehn also das war so.. komisch, kompliziert, fachmäßig formuliert dass ich dann auch keine Lust hatte das zu verstehn weil ich mir dachte.. das ist doch grad mit Absicht, dass es grad nur die Fachidioten verstehn."

Die Textarbeit in der Kulturanthropologie lag Tabea offenbar nicht: In einer dichotomen Sichtweise blickt sie auf die „Fachidioten“, die aus ihrer Perspektive als einzige die kulturanthropologischen Texte verstehen können und weist ihnen mit diesem Begriff eine gewisse Realitätsferne zu. Dabei scheinen es nicht die Inhalte an sich zu sein, die für sie unverständlich waren, sondern sie kritisiert deren bewusst vorgenommene (,,mit Absicht“) Gestaltung bzw. Form (, komisch, kompliziert, fachmäßig formuliert“). Wie sich diese Ablehnung einordnen und nachvollziehen lässt, wird in Tabeas weiteren Ausführungen noch deutlich werden.

Ihre Überlegungen zum Studienabbruch stellt sie gemeinsam mit einer damaligen Kommilitonin an (,,[W]ir haben irgendwann in der Mensa gesessen und haben so gemerkt ey das wird hier nix mehr das ist irgendwie nich" unser Ding “). Nachdem sie sich für den Abbruch des kulturanthropologischen Studiums entschieden hat, geht Tabea "wieder halt voll in die praktische Schiene“ mit ihrer Ausbildung zur Schreinerin, die sie zum vorigen Studium kontrastiert: „[A]lso weil ich schon immer irgendwie gern auch Sachen bau und so und da dacht ich mir ja das muss ich jetzt machen irgendwie, das ist voll.. das brauch ich irgendwie son hand-was Handfestes wo man wirklich auch was lernt was irgendwie bodenständig ist was man immer wieder gebrauchen kann. " Das 
„Handfeste“ und „Bodenständige“ an der Schreiner*innenausbildung und dass sie die dort erlangten Fähigkeiten ,immer wieder gebrauchen kann" bildet einen Gegensatz zu dem ihrer Darstellung nach abstrakten, praxisfernen, , abgehobenen “ kulturwissenschaftlichen Studium mit seinen realitätsfernen „Fachidioten“.

Die Ausbildung lag Tabea allerdings nicht besonders, weil sie dort vor allem an Kernsanierungen beteiligt war und nicht am „Möbelbau“, der sie ursprünglich angesprochen hatte. So war die Ausbildung ihrer Sicht nach zum einen „,körperlich viel zu anstrengend" und zum anderen hat sie ihr auch aus anderen Gründen nicht entsprochen:

\begin{abstract}
„,[D]as hatt“ ich immer bei mei-, bei, in der Ausbildung, dass ich abends wirklich gar nicht abschalten konnte weil ich dachte scheiße jetzt hab ich den Zuschnitt vergessen, jetzt hab die, des falsch gemacht, jetzt hab ich d-, und irgendwie so.. ich finds halt wichtig, dass man nich“ so.. so nach der Produktivität beurteilt wird weil.. also in den meisten Jobs is es ja wirklich so, dass man.. ne bestimmte Leistung am Ende des Tages haben muss und wenn du die nicht hast bist du halt irgendwie schlecht oder so.“
\end{abstract}

Tabea kritisiert die geforderte „Produktivität“ in der Ausbildungszeit und die damit verbundene Leistungskontrolle. In einem Arbeitsverhältnis beschäftigt zu sein, in dem Menschen nach ihrer Leistung beurteilt werden ${ }^{8}$, widerstrebt Tabea ein Charakteristikum, was sie ,in den meisten Jobs" vermutet. Die Soziale Arbeit hingegen nimmt sie davon explizit aus und schließt an die obigen Ausführungen an:

„,[U]nd in der Sozialen Arbeit hab ich eher es Gefühl es geht halt so ums große Ganze wenn man irgendwie, man kann ja nich' irgendwie die Kinder zwingen irgendwas zu lernen oder was weiß ich, sondern.. des is ja eher dann son.. ja so da kommts glaub ich eher auf andere Qualitäten an, sodass man halt irgendwie.. keine Ahnung irgendwie halt so Grundcharaktereigenschaften hat, die irgendwie.. ähm joa wo die Klienten im Prinzip von profitieren können.“

Mit dem „große[n] Ganze[n]“, das über die erwähnte Produktivität und Leistungskontrolle in den meisten Berufen hinausgeht und das Tabea an der Sozialen Arbeit schätzt, bezieht sie sich auf das (Zwischen-)Menschliche: die Beziehungsarbeit, die Vorstellung vom persönlichen Wachstum der Klient*innen, das unterstützt wird durch die Persönlichkeit der Sozialarbeiterin und eine Zusammenarbeit, die auf Freiwilligkeit beruht. Sozialarbeiterische (Fach-)Kompetenz

\footnotetext{
${ }^{8}$ Bzw. in dem sie sogar auf ebendiese Leistung reduziert werden, worauf Tabeas Formulierung ,... und wenn du die nicht hast bist du halt irgendwie schlecht“ hindeutet.
} 
dagegen, die im Studium erlernt würde, führt Tabea hier nicht an. So wird ein Gegensatz konstruiert mit einer ausschließlich ,produzierenden " und an dieser Produktivität bemessenen Tätigkeit, von der sich Tabea abgrenzt, und der Tätigkeit als Sozialarbeiterin, die für sie weniger Kompetenz- als vielmehr ,Charaktersache ${ }^{6}$ ist und die sich an zwischenmenschlichen Beziehungen und freiwilliger Zusammenarbeit zwischen Sozialarbeiter*in und Klient*in orientiert - ein (durchaus idealisiertes) sozialarbeiterisches Berufsbild, das Tabeas Dispositionen zu entsprechen scheint. Doch auch andere Aspekte spielen bei ihrer Abkehr vom Schreiner*innenberuf eine Rolle:

„[D]ann hab ich irgendwie.. gemerkt dass mein Ausbildungsberuf in dem ich eigent-
lich arbeiten wollte Schreiner nicht so.. also ähm nicht so geeignet für mich ist und..
joa.. keine Ahnung dann hab ich, eigentlich wars eher so, dass mein Freund dann
irgendwann meinte heute ist der letzte Tag wo man sich noch einschreiben kann für
Soziale Arbeit weil ich da vorher irgendwie schon öfter drübern bisschen drüber
nachgedacht hab weil ja ganz viele Freunde von mir das auch studieren und weil
ich irgendwie so dachte das ist eher so der Job den ich mir für mein Leben vorstel-
len kann als Schreiner zu sein, ja.. naja dann hab ich mich halt mal eingeschrieben
und dacht so naja wenns nicht klappt dann halt nicht und dann hats aber geklappt.“

Es verdichtet sich der Eindruck vom zentralen Stellenwert der Rückmeldungen aus Tabeas sozialem Umfeld für ihre Entscheidungen - so orientiert sie sich an ihren Freunden in der Sozialen Arbeit und folgt dem Hinweis ihres Freundes zur Immatrikulationsfrist für das Studium. Ihre Bewerbung für das Studium scheint sie dabei unbelastet und ohne spürbaren Druck, sondern eher mit Leichtigkeit anzugehen („,.. hab ich mich halt mal eingeschrieben“, „,wenns nicht klappt, dann halt nicht“) - eine Lesart, die sich im späteren Material bestätigt. Zugleich wird hier die Relevanz der finanziellen Versorgung deutlich:

\begin{abstract}
„Also ich bin im Sommer mit der Ausbildung fertig geworden und äh.. joa dann dacht ich mir halt okay was mach ich jetzt dann wars auch son bisschen wegen Krankenkasse und so ist dann ja billiger wenn man Student ist und dann dacht ich mir ey ich kanns ja mal versuchen irgendwie.. schadet ja nicht irgendwie und dann.. joa.. also war, es war eher spontane Entscheidung Soziale Arbeit zu studieren aber da hab ich jetzt eh also hab ich echt schon seitm Abi mehrfach drüber nachgedacht.. und jetzt bin ich auch froh, dass ich das mache."
\end{abstract}

Tabeas Ausführungen über die „spontane Entscheidung“ für die Soziale Arbeit sind von dem Gedanken an ihre finanzielle Absicherung geprägt und auch hier von einer gewissen Leichtigkeit, durch die das Studium nicht als früh und fix gestecktes Ziel am Ende eines disziplinierten und geplanten Weges erscheint, sondern als 
Resultat eines abwechslungsreichen und flexiblen beruflichen Orientierungsprozesses. Zugleich ist diese Entscheidung weniger „spontan“ als Tabea es an dieser Stelle ausdrückt, schließlich spielt der Gedanke an die Soziale Arbeit für sie bereits seit dem Schulabschluss eine Rolle.

\section{Studien(fach)wahl im Kontext der Herkunftsfamilie}

Wenn also Tabea schon in ihrem Freiwilligen Sozialen Jahr mit dem Gedanken gespielt hat, Soziale Arbeit zu studieren und eine Nähe zu diesem beruflichen Feld antizipiert hat, fragt sich, warum sie sich nicht schon damals für dieses Studium entschieden hat. Hier wird der Blick auf Tabeas mittlerweile verstorbene Mutter gelenkt, die an der gleichen Hochschule wie Tabea studiert hat und Sozialarbeiterin war und die ihrer Tochter von ebendieser Studienfachwahl abgeraten hat:

„(...) [W]eil meine Mutter nämlich immer meinte ich solls auf gar keinen Fall machen. (I: Sie hats selbst studiert?) Ja ((Tabea lacht - I lacht)) weil sie, also sie meinte halt sie war halt irgendwie dann lange arbeitslos und hat halt auch keine Stelle mehr gefunden und hat halt gemeint sie kotzt es so an, dass äh.. halt.. dass man irgendwie als, und die hatte ganz viele noch Zusatzausbildungen und bla, dass man halt irgendwie keine Stelle in dem Bereich findet und (...) da hatse immer gesagt ich soll bitte was machen wo man nich.. so von diesem ähm Einspar-ähm..-dings so betroffen ist halt und.. ja.“

Die negativen Erfahrungsberichte der Mutter über die prekären Beschäftigungsverhältnisse in der Sozialen Arbeit und ihr expliziter Rat, nicht diesen Beruf zu wählen, halten Tabea letztendlich nicht vom Studium der Sozialen Arbeit ab. Dass die berufliche Laufbahn ihrer Mutter und damit auch Teile von Tabeas Kindheit selbst von finanziellen Engpässen geprägt waren, schlägt sich auch in Tabeas Kindheitserzählungen nieder - etwa, als es um das katholische Privatgymnasium geht, das sie besucht hat:

„,[A]lso ich hab mich da gar nicht wohlgefühlt in dem.. Umfeld weil.. also so.. das war dann alles so diese typischen reichen.. Schnöselkinder also, es tut mir Leid das so zu sagen also da waren auch coole Leute natürlich aber.. ähm, ja und keine Ahnung wir kommen eigentlich eher aus so nem sag ich mal finanziell.. niedrigen Umfeld würd ich sagen also so meine Mutter hat auch Jahre lang Hartz IV bekommen und ich hatte wirklich als Kind nich" viel Geld und deshalb konnt" ich mich da in der Schule gar nich" mit identifizieren also.. da war ich auch eher immer so der Anti.., also da hab ich eher son bisschen äh aus Trotz so dagegen gehalten irgendwie weil ich das irgendwie nich" so gut fand... Ja.“ 
Tabea identifiziert sich mit dem ,niedrigen Umfeld“, in dem sie aufgewachsen sei und das von Arbeitslosigkeit und geringen finanziellen Mitteln geprägt war also auch Notwendigkeitserfahrungen umfasste - und grenzt sich im gleichen Zug von den ,reichen Schnöselkindern“ an ihrem Gymnasium ab. Es entsteht der Eindruck von Tabea als rebellischer ,Anti“"Schülerin an einer sonst eher elitär geprägten Privatschule. Zugleich bleibt die Frage offen, was genau sie an der Schule bzw. ihrer Schüler*innenschaft ,,irgendwie nich so gut fand “ - eine Frage, die weiterverfolgt werden soll. Entsprechend dieser Beschreibungen zeigen ihre weiteren Ausführungen, dass Tabea an der Schule keinen festen Freundeskreis hatte, sondern ihr enges soziales Umfeld vor allem in ihrer Wohngegend zu verorten ist, wo sie mit ihrer Mutter in einem Wohnprojekt für Alleinerziehende gelebt hat (,[D]as war son soziales Wohnprojekt für. alleinerziehende Mütter. und da warn halt, das war total geil, da warn sauviele Kinder, alle in meinem Alter"). Ihre Freund*innen dort beschreibt sie schließlich sogar als „Familie“. Diese Gemeinschaft wird von Tabea besonders herausgehoben und ist für sie von hoher Bedeutung.

Dass Tabea überhaupt das Gymnasium besucht hat, ist auf den Einfluss und die Entscheidung ihres Vaters zurückzuführen: „, [A]lso da wollte halt mein Vater, dass ich da unbedingt hingeh weils halt ne katholische.. Privatschule is ". Offensichtlich war die kirchliche Ausrichtung der Schule für den Vater entscheidend, was auch deshalb nahe liegt, weil er selbst unter anderem Theologie studiert hat. Interessant ist, dass diese Entscheidung über den Schulbesuch vom Vater getroffen wurde, obwohl Tabea zu der Zeit bei ihren Großeltern und später bei ihrer Mutter gewohnt hat und der Kontakt zu ihrem Vater nur durch Besuche am Tag gegeben war - seiner geringeren Involvierung in die alltägliche Erziehung zum Trotz lag diese Entscheidung über den schulischen Bildungsweg von Tabea bei ihm. Wie genau die weitere Erziehung von Tabea zwischen den unterschiedlichen Familienmitgliedern organisiert war, geht aus dem Material nicht hervor.

Was allerdings besonders deutlich wird, ist Tabeas Abgrenzung von ihrem Vater. Auf die Frage hin, welche Rolle er - außer bei der Entscheidung über ihren Schulbesuch - in ihrer Berufsorientierung gespielt habe, antwortet sie:

„Ja also eher so ausm Anti, also weil der ist halt so sehr der Akademiker, der hat irgendwie Philosophie, Jura und Theologie studiert und Psychologie, genau. Und.. dem wars halt immer sauwichtig dass ich halt ne akademische Karriere mach so also auf jeden Fall auf Abi und auf jeden Fall irgendwie halt mh am besten Doktortitel ja oder und dann hab ich halt.. ja ich weiß nich“ so ich hab auch manchmal das Gefühl das Schreinerding hab ich auch son bisschen gemacht äh um so zu zeigen nöö kein Bock auf dein, auf deine äh Unikarrierepläne für mich aber.. ja. Also der, 
dem wars eigentlich, der wollte immer, dass ich sowas wie Jura oder Medizin oder so studiere, ja.“

Erneut benutzt Tabea den Begriff „Anti“, um ihre konträre Haltung - diesmal ihrem Vater gegenüber - zu verdeutlichen. Ihre Abgrenzung von den „Unikarriereplänen“ ihres Vaters, der für sie „sehr der Akademiker" ist, und von den von ihm intendierten prestigeträchtigen Universitätsfächern Jura und Medizin ist augenscheinlich - die Schreiner*innenausbildung wirkt in diesem Licht wie ein Akt der Rebellion und auch die Soziale Arbeit ist ein Weg jenseits der akademischen Karriere- und Statusvorstellungen, die Tabea ihrem Vater zuschreibt. Tabeas betonte Lässigkeit im Umgang mit den väterlichen Plänen (,nöö kein Bock") kann auch als Distinktion gelesen werden, da sie sich damit über seine Lebensvorstellungen erhebt und eine universitäre Laufbahn - im Gegensatz zu ihm - gar nicht , nötig hat ${ }^{9}$. Eine alternative Lesart könnte lauten, dass Tabea mit den Bildungsvorstellungen ihres Vaters an ihre Grenzen kommt und sich deshalb davon so betont abgrenzt - auch diese Auslegung kann nicht ausgeschlossen werden.

Eine nähere Betrachtung dieser Abgrenzungsfolie verweist auf Parallelen zwischen Tabeas Sicht auf ihr Kulturanthropologiestudium, dessen Texte sie als „komisch, kompliziert, fachmäßig formuliert“ und nur für „Fachidioten“ geschrieben darstellt, und auf ihren Vater:

„[A]lso meine Schwester ist äh auch eher wie mein Vater die ist da auch sehr geistig, das ist für die so ganz, die diskutieren dann auch immer und so aber.. also mich, mich nervt das eher dann mit so vergeistigten Akademikern zu diskutieren weil für mich kommt da irgendwie nix bei raus immer son bisschen oder ich brauch irgendwie,.. also ja. Bin glaub ich dann eher wie meine Mutter son bisschen.“

Dass Tabea ihre biologische Halbschwester, die beim Vater und dessen neuen Partnerin wohnt, als ihre „Schwester" bezeichnet, verweist zum einen auf die

\footnotetext{
${ }^{9}$ Über ihren Vater berichtet Tabea, dass dieser in seinen aktuellen Beruf als Berufsschullehrer erst vor wenigen Jahren ,reingerutscht“ ist: „,[U]nd davor hat er eigentlich nicht wirklich gearbeitet da hat er eigentlich nur studiert.. sein Leben lang“. Vor diesem Hintergrund liegt nahe, dass der Vater mit seinen „Unikarriereplänen“ für seine Tochter versucht, sie zum Ergreifen einer akademischen Karriere zu bewegen, die bei ihm selbst nach der Promotion gescheitert zu sein scheint.
} 
gelebte Familienpraxis, innerhalb derer für Tabea die Bedeutung der biologischen Verwandtschaft hinter der sozialen Beziehung zurücktritt ${ }^{10}$. Zum anderen konstruiert Tabea zwei familiäre Fronten. Es liegt die Lesart nahe, dass diese zwei Fronten zugleich auf zwei unterschiedliche familiär angelegte Habitussyndrome verweisen: mit ihrem Vater und dessen Tochter auf der einen Seite, die ,immer" wie ,vergeistigte Akademiker" zu ,diskutieren“ scheinen, und Tabea und ihrer Mutter auf der anderen Seite, wobei Tabea „kein Bock" auf eine Universitätslaufbahn hat und stattdessen das „Handfeste“ und „Bodenständige“ bevorzugt. Vor dem Hintergrund betont Tabea zwar die Nähe zu ihrer Mutter, sie orientiert sich an ihr und wählt sogar den gleichen Beruf wie sie - allerdings beinhaltet auch diese Anlehnung eine ,Rebellion', denn Tabea setzt sich über den expliziten Rat ihrer Mutter, nicht das Berufsfeld der Sozialen Arbeit zu wählen, hinweg. Ihre ,Anti-Haltung' schlägt sich so mehrfach nieder.

Dabei bezieht sich Tabeas Abgrenzung nicht nur auf die von ihr erwähnten Fächer Jura und Medizin, sondern umfasst noch mehr - darauf verweist ihre Antwort auf die Frage, welche Studiengänge für sie auf keinen Fall in Frage gekommen wären:

„Boah, des is‘ jetzt schwierig. Jura, glaub ich. Oder Theologie, ja sowas. (I: Mhmh) Oder.. ja halt irgendwie so Mathe,.. obwohl des fänd" ich sogar noch cooler als Jura glaub ich, aber halt irgendwie so diese.. oder ja so Bauingenieur-, halt so Sachen wo man so extrem viel lernen muss (...). [D]a hätt ich auch keine Lust drauf, dann irgendwie nur zu lernen und mir da irgendwelche Formeln einzutrichtern und.. des wär mir glaub ich zu, zu theoretisch oder.. ja,.. ja.“

Mit Jura und Theologie wählt Tabea hier erneut zwei Fächer, die eng verbunden sind mit der Laufbahn ihres Vaters, und ergänzt sie um das Bauingenieurwesen. Ihre Wahrnehmung des Bauingenieurwesens als ,zu theoretisch“ erinnert zwar an Tabeas Abgrenzung von ,übertheoretisiertem" (,vergeistigtem") Wissen, wo „nix bei raus kommt“, verweist in diesem Kontext aber noch auf eine zusätzliche Komponente: Dass Tabea kein Fach studieren will, in dem sie ,extrem viel“ lernen muss, ist zugleich eine Abgrenzung von einem bestimmten Lernverständnis, das Tabea dem Bauingenieurwesen zuschreibt und das sich vor allem auf das Auswendiglernen vorgegebener Inhalte (,Formeln einzutrichtern“) beschränkt. Ihre geringe Passung zur ingenieuralen Fachkultur und den dortigen Vermittlungs- und Lehrformen werden an dieser Stelle deutlich.

\footnotetext{
${ }^{10}$ Bezeichnenderweise lebt Tabea damit in einer Form von ,Patchworkfamilie' mit getrennten Elternteilen, von denen sich Sonja in ihrer Traditionsorientierung so vehement abgrenzt.
} 


\title{
Studien(fach)wahl und antizipierte Zukunft
}

Tabeas Vorstellungen von ihrem Traumberuf in zehn Jahren sind relativ unkonkret:

\begin{abstract}
„Ähm.. irgendwie auf jeden Fall nette Kollegen, nettes Arbeitsumfeld.. und äh... ja irgendwie auf jeden Fall auch mit was Kreativem also.. jetzt nich" nur sowas wie Hausaufgabenbetreuung also.. schon, ja. Ja und vielleicht auch also keine Ahnung.. halt irgendwie... keine Ahnung.. halt ähm vielleicht auch irgendwie nich" mit so ganz festgefahrenen Strukturen sondern vielleicht auch so dass man selber son bisschen seinen Arbeitsalltag auch gestalten kann und.. joa.“
\end{abstract}

Erneut stellt Tabea das Zwischenmenschliche in den Fokus (,nette Kollegen“, „,nettes Arbeitsumfeld“), ihr Wunsch nach etwas „Kreativem“ verweist sowohl auf Gestaltungsfreiheit wie auch auf Unkonventionalität, was konträr zu ihren Ausführungen über das „Formel eintrichtern“ im Bauingenieurwesen steht. Statt „festgefahrenen Strukturen“ zu folgen will Tabea ihren „Arbeitsalltag gestalten“.

Zusätzlich erläutert Tabea, man brauche als Sozialarbeiterin zum einen „Empathie“ und „Selbstreflexion“, aber man dürfe auch nicht so ,festfgefahrn [sein] in seinen Vorstellungen“, sondern solle „ergebnisoffen“ und ,experimentierfreudig“ an die pädagogische Tätigkeit herantreten. An anderer Stelle betont sie ihren Wunsch, nicht , sinnlos meine meine Lebenszeit damit $z u$ verschwenden irgendwie. mich voll in die Karriere reinzuhängen weil wer weiß was morgen ist“ und stattdessen „denk ich mir, hab ich lieber. ne relativ.. sag ich mal entspannteZeit" ohne das Ziel, möglichst viel Gehalt zu beziehen, denn: „Mehr Zeit mit Familie und Freunden, das ist mir dann viel wichtiger als irgendwie.. Statussymbole sag ich jetzt mal". Hier verdichten sich die Hinweise sowohl auf Tabeas Abgrenzung von Karriere- und Aufstiegsstreben wie auch auf ihre Dispositionen hin zur Orientierung an der Gemeinschaft, aber auch an Genuss, Spontanität, Hedonismus und an Unkonventionalität jenseits von einengenden Strukturen oder festgelegten Ergebniszielen - denn: ,wer weiß was morgen ist".

Dieser Ausblick auf ihr Berufsleben lässt sich noch konkreter fassen, bringt man ihn in Verbindung mit Tabeas Verständnis von der Sozialen Arbeit, das in den Ausführungen über ihre Professor*innen an der Hochschule zum Tragen kommt: Diese bezeichnet sie als „ziemlich politisch“ - , und des find ich auch gutweil irgendwie find ich muss man das sein wenn man Soziale Arbeit studiert". Diese ihrer Sicht nach sinnvolle und notwendige Verknüpfung von ,politisch sein “ und sozialarbeiterischem Handeln begründet Tabea folgendermaßen: 
„Ja weil man halt ähm.. ich weiß nicht weil man halt so.. sich mit so Themen befasst oder halt einfach so mit dem Menschen an sich befasst oder.. mit einfach den Problemen die wir auch in unserer Gesellschaft ham und.. also wenn man ich weiß nicht, ich find des führt einen immer son bisschen dazu, dass halt dieses ewige irgendwie Kapitalstreben und Karriere und.. also da frag ich mich immer son bisschen wozu denn, also.. ich mein die Wirtschaft, wir produziern eh schon so viel und irgendwie keine Ahnung, stellt man sich dann eher son bisschen die Frage, wie könnt mans denn so machen, dass es allen gut geht und nich“ nur.. so denen, die halt stark genug sind in dem System irgendwie mitzumachen irgendwie, ja."

Es zeichnet sich eine diffuse Abgrenzung von Tabea gegenüber maßloser Produktion, gegenüber dem maßlosen Streben nach wirtschaftlichem und karrierebezogenen Wachstum und gegenüber den damit verbundenen sozialen Ausgrenzungsprozessen ab und es deutet sich ein partizipatives, egalitäres Idealbild der Gesellschaft an. Dieser Eindruck erhärtet sich im weiteren Verlauf von Tabeas Ausführungen, in der sie vor diesem Hintergrund die Soziale Arbeit als gesellschaftsformende Instanz beschreibt: „[D]es hat letztens im Seminar auch äh der [Herr A] wars glaub ich, n Zitat gesagt was ich voll gut fand irgendwie: ,Die Soziale Arbeit ist der Stachel im Fleisch der herrschenden Systeme'. Und des fand ich dann schon.. cool irgendwie weil dann dacht ich mir ja dann verbringt man halt auch seine Zeit mit was, was irgendwie die Gesellschaft vielleicht mehr in ne Richtung formt, die man selber auch gut findet." Indem sich Tabea dieses Zitat eines Professors zu eigen macht, demonstriert sie ihr schon nach wenigen Wochen des ersten Semesters erlangtes studienbezogenes Wissen. Zudem unterfüttert sie damit ihre Sicht auf die Soziale Arbeit mit einer akademischen Quelle, wodurch ihre Definition der Profession als distinktiver Akt gelesen werden kann.

Interessant ist noch ein Blick darauf, wie sich Tabea ihr Privatleben in zehn Jahren vorstellt: Sie antwortet hier ohne Zögern und recht knapp, dass sie ,halt Kinder, $n$ Hund, Katze" will und ,schon eher so standardmäßig Familie, vielleicht irgendwie coole große Wohnung oder größer als jetzt zumindest". Was die Kindererziehung angeht, ,würd [sie] dann einfach auch nich so viel arbeiten" und ihr „Kind nicht schon so früh weggeben“ - mit einem halben Jahr wäre ihr etwa $\mathrm{zu}$ früh. Außerdem antizipiert sie mehrere unterstützende Betreuungsstrukturen: „,[A]ber sonst klar irgendwie halt in die Krippe, inen Kindergarten, Hort was weiß ich. irgendwie Betreuungs-, oder vielleicht haben dann ja auch meine Eltern, irgendwie sind dann Großeltern die auf die Kinder aufpassen können oder keine Ahnung, oder man findet halt irgendwie, also auch alle meine Freunde wohnen im [gleichen Viertel]“. 
Eine Familiengründung ist für Tabea also selbstverständlich und gleichzeitig ist sie pragmatisch, bescheiden und sicherheitsorientiert, was ihre künftigen Wohnverhältnisse angeht - mehr als eine große Mietwohnung in ihrem Heimatviertel strebt sie nicht an. Aufschlussreich ist außerdem, dass sie die Zuständigkeit für die Kindererziehung antizipiert - ihren Partner erwähnt sie hier nicht - und nicht nur formelle Formen der Kinderbetreuung im Hort oder der Krippe in Anspruch nehmen will, sondern auch auf die Unterstützung ihrer Eltern und Freunde im gleichen Stadtviertel setzt. Erneut zeichnet sich die hohe Bedeutung ihres sozialen Netzes ab und zugleich entpuppen sich ihre Vorstellungen von Familiengründung als recht konventionell.

Auf die Nachfrage hin, ob sie sich auch vorstellen könnte, dass ihr Partner sich Elternzeit nimmt, antwortet Tabea:

„Und ich soll dann arbeiten gehen? (I: Genau) Boah, das fänd“ ich glaub ich nich“ so doll ((Tabea lacht - I lacht)), also, also ne, Quatsch, keine Ahnung.. vielleicht fänd“ ichs auch gut, keine Ahn-, ich hab ja noch kein Kind, vielleicht denk ich mir auch boah endlich mal Ruhe oder so. Aber... ja keine Ahnung, kann ich irgendwie noch gar nich" sagen."

Spontan lehnt sie diese Vorstellung vehement, sogar belächelnd, ab. Wieder kommt hier Tabeas Abgrenzung von einem Fokus auf das Erwerbsleben zum Tragen, wenn sie fast bestürzt nachfragt „Und ichsoll dann arbeiten gehen?“. Anschließend relativiert sie ihre spontane Reaktion, der Eindruck ihrer starken Abwehr der Elternzeit auf Seite ihres Partners bleibt aber bestehen und scheint eng verknüpft zu sein mit Tabeas Abgrenzung von Karrierestreben. Im Vergleich zu Sonja zeigt sich so bei beiden ,weiblichen' Fällen, dass sie die schwerpunktmäßige Zuständigkeit für die Kindererziehung antizipieren und diese für einen männlichen Partner ablehnen. Diese Vorstellungen sind zugleich unterschiedlich konnotiert: So schwingt bei Tabeas Antizipation der Erziehungszeit insbesondere ihre Abgrenzung von einem Fokus auf das Erwerbsleben mit, während Sonjas Orientierung an der Kindererziehung stärker auf einer positiven Identifikation damit beruht (,[I]ch glaub ich würde meine Kinder gerne aufwachsen sehen“). Im Ergebnis sind sich beide Fälle in dieser Frage relativ nah und in den Vorstellungen der zwei Studentinnen bahnt sich eine Familiengründung und Arbeitsteilung nach traditionell-binären Mustern an. 


\section{Habitus, Studien(fach)wahl und Milieuspezifika}

Die berufliche Orientierung von Tabea ist geprägt von den unterschiedlichen Einflüssen durch ihre beiden Elternteile, die zugleich auf unterschiedliche Habitusdispositionen verweisen. Mit ihrer Mutter identifiziert sich Tabea und betont das Positive ihres „niedrigen Umfelds“, in dem sie mit ihr aufgewachsen ist denn dort hatte sie immer Freund*innen um sich, die für sie „Familie“ waren. Diese Werte von Gemeinschaft, vom Zwischenmenschlichem und von Beziehungen tragen sich durch das gesamte Material. Vor dem Hintergrund der Rahmenbedingungen von Tabeas Aufwachsen, das auch von Notwendigkeiten geprägt war, scheinen diese eng verknüpft mit ihren Handlungsmustern der Flexibilität und Spontanität - denn: „,wer weiß was morgen ist“.

Zugleich findet eine starke Abgrenzung gegenüber ihrem Vater und dessen Bildungs- und Lebensvorstellungen statt: Seinen „Unikarrierepläne“ schließt sie sich nicht an, sondern die damit verbundenen Studienfächer Medizin, Jura oder Theologie sind das Letzte, was Tabea sich für sich vorstellen könnte. Eine Abgrenzung von Statusdenken und Aufstiegsstreben geht damit einher. Personifiziert durch die „Schnöselkinder", die „Fachidioten“" und die ,vergeistigte[n] Akademiker" (auch explizit ihren Vater der ebenfalls ,sehr der Akademiker" sei), nimmt Tabea eine ausgeprägt ablehnende Haltung gegenüber dieser für sie scheinbar ,realitätsfernen' Welt ein. Abwertend steht sie auch Studienfächern gegenüber, in denen es nur um „Formeln“ und das Auswendiglernen vorgegebener Inhalte geht.

Vor diesem Hintergrund ist Tabeas Orientierungsprozess von Pendelbewegungen geprägt vom Freiwilligen Sozialen Jahr über die Kulturanthropologie und die Schreinerinnenlehre bis zur Sozialen Arbeit. Dass die bildungsnahen Habitusdispositionen von väterlicher Seite sich dabei auch in Tabeas Orientierungen niederschlagen, spiegelt sich sowohl in ihrem erfolgreichen Abitur an einem Privatgymnasium wie auch der durchaus abstrakten universitären Studienfachwahl zur Kulturanthropologie hin. Diese Wahl kehrt Tabea jedoch schließlich in ihr Gegenteil um hin zum „,handfesten“ und „bodenständigen“ Schreinerinnenberuf - der ihr letztlich jedoch zu stark auf Produktivität und Leistungskontrolle ausgerichtet ist. Im Ergebnis wählt Tabea mit der Sozialen Arbeit an der Hochschule Hierstadt den Weg aus, den auch ihre Mutter genommen hat.

Geprägt sind diese Suchbewegungen zudem von einer distinktiven Betonung des Unkonventionellen, die auch hedonistische Züge hat: Tabea grenzt sich ab gegenüber einer ,normalen“ Berufslaufbahn ab (einem „Büro-0815-Job“), hat „kein Bock" auf eine akademische Karriere und möchte nicht ,sinnlos meine 
Lebenszeit verschwenden" für einen solchen Beruf ${ }^{11}$. Stattdessen sieht Tabea sich in der Sozialen Arbeit als einer durchaus idealisierten gesellschaftsformenden Instanz, in der es um das ,große Ganze“ geht jenseits überakademischer Diskussionen oder wirtschaftlichen Wachstums. Dabei deuten sich in Tabeas Perspektive auf die Gesellschaft zusätzlich egalitäre Züge an, die sie sich als gleichberechtigte Gesellschaft jenseits von Materialismus und Statusdenken vorstellt.

Dass Tabea lieber "[m]ehr Zeit mit Familie und Freunden" verbringen statt diese in die Berufslaufbahn oder "Statussymbole“ investieren will, spiegelt sich auch in ihren Vorstellungen von der Familiengründung wider: Diese sind recht konventionell (Partner, Katze, Kinder) und damit verbunden, selbst die Erziehungsarbeit auszuüben. Ihre Abgrenzung von einem Erwerbsfokus führt zur affektiven Abwehr der Erziehungsarbeit auf Seiten ihres Partners. Auch hier ist also eine Festigung der binär-geschlechtlichen Arbeitsteilung naheliegend. Darüber hinaus spielt die Dimension von Geschlecht in Tabeas Studien(fach)wahl vor allem dahingehend eine Rolle, dass sie den Großteil ihrer Kindheit und Jugend mit ihrer alleinerziehenden Mutter zusammengelebt hat und sich mit dieser stark identifiziert - sowohl was die berufliche Orientierung wie auch ihre Persönlichkeit angeht. Die väterlichen Bildungsstrategien und Lebensvorstellungen mögen für Tabea nicht nur nicht umsetzbar sein für sie, sondern scheinen für sie auch eine emotional aufgeladene Abgrenzungsfolie nach der Trennung ihrer Eltern sein.

Tabeas distinktive Betonung des Unkonventionellen, ihre Abgrenzung (und Abwertung) von Statusdenken und Aufstiegsstreben sowie ihre Orientierung hin zu Gemeinschaft und zu Genuss und Hedonismus verweisen auf eine Verortung des Falls im vertikal-mittleren Bereich der Traditionslinie von Facharbeit und praktischer Intelligenz, nämlich im modernen Arbeitnehmermilieu mit Nähe zum Hedonistischen Milieu (siehe auch Vester 2015: 164 ff.; 172 ff.).

\footnotetext{
${ }^{11}$ Obwohl Tabeas Aufwachsen von Notwendigkeiten geprägt sein mag, sprechen diese distinktiven Anteile und die damit verbundene Selbstsicherheit für eine relativ gesicherte/hohe soziale Position.
} 


\subsection{Fall Achim: „,[Da] wollt ich Tanzlehrer werden und alle ham gesagt ,Ja klar' wenn es das is was du möchtest, mach ${ }^{\prime \prime}$}

\section{Kurzeinführung in den Fall}

Mit einer Dauer von eineinhalb Stunden ist das Interview mit Achim das längste des Samples. Wie beschrieben, wurden die Interviewinteressent*innen aus der Sozialen Arbeit zu einer Online-Umfrage eingeladen, um eine handhabbare Auswahl an Gesprächspartner*innen zu treffen. An dieser Umfrage haben fast ausschließlich weibliche Interessentinnen teilgenommen. Aus diesem Grund hat die Interviewerin männliche Interessenten, die sich im Seminar gemeldet, aber nicht an der Umfrage teilgenommen haben, explizit angeschrieben und zu einem Interview eingeladen - so auch Achim. Er hat wenige Tage später auf diese Nachricht geantwortet und sein Interesse, die Interviewerin ,bei [ihrer] Forschung zu unterstützen", bestätigt.

Das Interview selbst ist von zwei Auffälligkeiten geprägt: Achim spricht vergleichsweise schnell und besonders ausführlich. Seine Erzählungen scheinen größtenteils nur so aus ihm ,herauszusprudeln'. An einigen Stellen überschlagen sich seine Worte, was zu einer undeutlichen Aussprache und unklaren Transkriptionsstellen führt. Bei Fragen, die über das Berichten seines Weges hinausgingen und ihn stärker zu Reflexion anregen (wie die nach seinen Zukunftsvorstellungen und Wünschen), nimmt er sich zugleich einige Zeit zum Überlegen, bevor er antwortet. Diese Antworten fallen jedoch ebenfalls ausführlich aus, etwa im Gegensatz zu den eher verhaltenen Antworten von Sonja in diesem Teil des Interviews.

Nach Ende der Aufnahme zeigt sich Achim begeistert und enthusiastisch und betont von sich aus, wie angenehm das Gespräch für ihn war und dass es für ihn sehr interessant war, über seinen Weg in die Soziale Arbeit so intensiv nachzudenken.

\section{Kurzeinführung in den Fall}

Achim ist zum Zeitpunkt des Interviews 27 Jahre alt und studiert im ersten Semester Soziale Arbeit. Er ist der Erste in seiner Familie, der studiert. Sein Vater ist verstorben, als er zwei Jahre alt war. Im Anschluss daran war seine Mutter lange Zeit alleinerziehend und hat mittlerweile einen neuen Lebensgefährten. Über den Vater ist nur bekannt, dass er einen Realschulabschluss hatte. Achim hat einen älteren Bruder, der - wie Achim auch - das Abitur auf einer Gesamtschule absolviert hat. Sein Bruder wollte eigentlich Tierarzt werden und hat sich hierfür auch 
mehrmals an einer Universität beworben, wurde aber nicht zugelassen. Stattdessen hat er eine Ausbildung zum Altenpfleger durchlaufen und es ,dann halt auch dabei belassen“" weil es ihm „da gefällt“.

Die Mutter der beiden hat einen Volksschulabschluss und ursprünglich eine Ausbildung zur Friseurin begonnen, diese allerdings abgebrochen, weil ihr Vater pflegebedürftig wurde und sie diese Aufgabe übernommen hat. Im Anschluss an diese pflegerische Tätigkeit ist sie nicht wieder in das Berufsleben zurückgekehrt, sondern ist seitdem „Hausfrau und Mutter“. Die dreiköpfige Familie lebte von der Witwenrente der Mutter, wodurch sie "nich so die Geldprobleme [hatten], aber halt natürlich jetzt auch nich so viel".

Nach dem Tod des Vaters ist seine Mutter mit Achim und seinem Bruder zwischen verschiedenen vorübergehenden Orten gependelt, wo sie bei Verwandten wohnen konnten, bis sie schließlich in den dörflichen Stadtteil zurückgehrt sind, wo sie auch vorher mit dem Vater gewohnt haben. Dort hat Achim bis zu seinem 21. Lebensjahr gelebt.

Achim selbst hat nach seinem Abitur ein Freiwilliges Soziales Jahr in einer Behindertenwerkstatt absolviert und anschließend zwei Studiengänge an einer Universität begonnen und abgebrochen: Geophysik/Meteorologie und Jura. Danach hat er eine Ausbildung zum Erzieher in einer Kindertagesstätte ${ }^{12}$ absolviert und im Anschluss ein Studium der Sozialen Arbeit an einer Hochschule für Angewandte Wissenschaften begonnen. Achim lebt in einer Wohngemeinschaft mit zwei Studentinnen und ist zurzeit nicht in einer Partnerschaft.

\section{Weg hin zum Studium}

Achim beginnt die Erzählung über seinen Weg in das Studium damit, dass er schon seit seinem Freiwilligen Sozialen Jahr in einer Behindertenwerkstatt vor sechs Jahren „weiß“, dass er Soziale Arbeit studieren will (,[A]lso eigentlich weiß ich das seitdem ich en FSJ gemacht hab“). Dort sei ihm „,bewusst geworden“, dass er gerne mit Menschen zusammenarbeitet, um sie zu „,unterstützen im Alltag“ und den „Alltag mit denen zu gestalten“. Damit beschreibt Achim seine berufliche Tätigkeit sehr ähnlich wie Tabea ihre berufliche Wunschtätigkeit: als freie, niederschwellige, gemeinsame Alltagsgestaltung. Für ein FSJ wiederum hat sich Achim entschieden, weil er schon während seiner Schulzeit als Ferienbetreuer in einem Jugendzentrum gearbeitet hat und das für ihn „dasselbe im Grunde“ ist wie die Alltagsbegleitung in der Werkstatt - in beiden Fällen

\footnotetext{
${ }^{12}$ Die Ausbildung bestand aus einer zweijährigen theoretischen Ausbildungszeit an einer Fachschule und einer einjährigen Praxiszeit in einer Kindertagesstätte.
} 
hat ihm die Tätigkeit „superviel Spaß gemacht“ und war für ihn ,sehr entspannt". So hat er sich über Studienmöglichkeiten in diesem Bereich informiert und, nachdem er die Soziale Arbeit gefunden hatte, während des FSJs noch ein „studiumvorbereitendes Praktikum" im Jugendzentrum absolviert. Seit dieser Zeit habe er „verbissen“ daran festgehalten, Soziale Arbeit zu studieren.

Achims Ausführungen über seine ersten Erfahrungen im pädagogischen Bereich, über die ,Bewusstwerdung' seiner Freude an dieser Arbeit und seinen ,entspannten' Zustand verweist auf eine hohe Passung zwischen ihm und diesen Tätigkeiten, perspektivisch auch den entsprechenden sozialarbeiterischen Handlungsfeldern. Dass er an diesem Berufswunsch „verbissen “ festgehalten hat, deutet auf seinen unbedingten Berufswunsch hin, auf ein diszipliniertes Verfolgen desselben und eine gewisse Anstrengung. ,Festhalten' musste Achim daran über längere Zeit, das lässt auch sein Alter von 27 schon erahnen.

So hat sich Achim seit seinem FSJ jedes Semester für die Soziale Arbeit an verschiedenen Hochschulen beworben, wurde aber aufgrund des Numerus Clausus nicht zugelassen. Um weiterhin seine Halbwaisenrente zu beziehen, musste er allerdings ein Ausbildungsverhältnis nachweisen und beginnt daher andere Studiengänge, die ihn interessieren. Dies diente für ihn nicht nur der Überbrückung, sondern er sah in diesen Studiengängen auch das Potential, dass er sich letztendlich für sie und gegen die Soziale Arbeit entscheidet (,[H]alt eigentlich immer mit der Option okay vielleicht hat es seinen Grund und vielleicht isses dann das andere doch was ich halt machen möchte"). Achim hält sich also die Möglichkeiten der Umorientierung und -entscheidung offen. Zuerst schreibt er sich für den zulassungsfreien Studiengang Geophysik/Meteorologie an einer Universität ein, bezeichnet seine Erwartungen daran allerdings im Nachhinein als ,naiv“, denn er hat ,nich unbedingt so die Affiniti-, Affinität (...) zu Physik“, dachte aber er könne sich diesen Anteil in der Geophysik ,anlesen“ - was nicht der Fall war. Eine ähnliche Fehleinschätzung findet sich in seiner Bildungslaufbahn auch bei der Wahl seiner Leistungskurse: Achim hat ,en Jahr wiederholt weil ich dann.. äh.. ja vorher Mathe LK hatte und das war keine gute Entscheidung ((schmunzelt))“ - auch hier hatte er sich fachlich überschätzt und die Oberstufe neu begonnen, um einen anderen Leistungskurs als Mathematik belegen zu können. Sein Schmunzeln an dieser Stelle verweist wiederum auf seinen gelassenen Umgang mit dieser Erfahrung - eine Gelassenheit, die mehrere Stellen des Interviews prägt.

So wechselte Achim auch den Studiengang und bewarb sich - neben seiner regelmäßigen Bewerbung für die Soziale Arbeit - für Jura, wofür er ebenfalls zugelassen wurde. Doch auch dieses Studium trifft nicht seine Vorstellungen, denn Achim hat sich ,(...) bestimmt irgendwo en bisschen täuschen lassen wie das so 
im Fernsehn so in Amerika is 'oder halt so irgendwie, und is ' das dann.. stellt sich das dann dochn bisschen intressanter vor."

Achim musste also ein Studium bzw. eine Ausbildung beginnen, um sich finanziell abzusichern, bis er durch Wartesemester zur Sozialen Arbeit zugelassen würde - das übt auf der einen Seite einen gewissen Zwang auf ihn aus, den er im Sinne einer Wahlfreiheit für sich umdeutet. Dabei geht er interessensgeleitet, unbeschwert und spontan vor und entscheidet sich für Studiengänge, in denen er sich eine Tätigkeit durchaus vorstellen könnte, von denen er aber keine oder nur sehr vage inhaltliche Vorstellungen hat. Dabei lässt er sich unter anderem von seinen Eindrücken der Berufsfelder aus Fernsehsendungen leiten, was etwa ein Gegensatz ist zu der methodisch-planenden Studienwahlvorbereitung von Sonja (Beratung durch Eltern, Interessenstest, Gespräche mit Vorgesetztem und an der Hochschule). Nachdem er sich auch gegen Jura entscheidet und bislang nicht zur Sozialen Arbeit zugelassen wurde, stellt Achim fest:

„,[U]nd hab dann halt auch, dann auch den Entschluss gefasst okay.. irgendeinen Studiengang $\mathrm{zu}$ machen, das bringt nichts, du machst ne Ausbildung, verbesserst deine Wartezeit.. und hab dann auch ähm die Erzieherausbildung gemacht.“

Bei seiner Erzieherausbildung war „klar dass des nur zweckmäßig halt fürs Studium war, um Wartezeit zu verbessern “. Das ,verbissene“ Festhalten am Studium der Sozialen Arbeit ist damit verbunden, dass Achim von seinen interessensgeleiteten und unbeschwerten Überbrückungsfachwahlen zu einer neuen Strategie übergeht und nun planvoll und strategisch eine Ausbildung beginnt, um zum Studium zugelassen werden - mit Erfolg: Nach dem Ende seiner Ausbildung bewirbt er sich erneut für die Soziale Arbeit und wird an der Hochschule in Hierstadt zugelassen.

\section{Studien(fach)wahl im Kontext der Herkunftsfamilie}

Wie die Rekonstruktion von Achims Stationen vor dem Studium deutlich macht, beginnt sein Einsatz in pädagogischen Tätigkeiten schon in seiner Jugend und zieht sich von der Schulzeit über das Freiwillige Soziale Jahr bis hin zur Erzieherausbildung und zum Studium der Sozialen Arbeit. Die Nähe zu diesem Bereich hat er also schon früh aufgebaut - nämlich im Kontext seiner Herkunftsfamilie.

Achim ist mit seinem älteren Bruder bei seiner Mutter aufgewachsen, sein Vater ist früh verstorben. Achims Mutter war nie berufstätig, sondern hat in der frühen Kindheit ihrer Söhne ihren Vater gepflegt und war anschließend für die Erziehung zu Hause. Außerdem hat sie während der Schulzeit ihrer Söhne umfangreich ehrenamtlich in der Schule engagiert - von der ersten Klasse des 
großen Bruders an bis zum Schulabschluss von Achim, also über „dreizehn Jahre“ und das „konsequent“. Sie hat die Cafeteria der Schule mit betreut, als Vertretung Arbeitsgemeinschaften geleitet und Ausflüge begleitet. Für Achim ist sie eine - wenn nicht sogar die - zentrale Bezugsperson (,„[M]eine Mama war

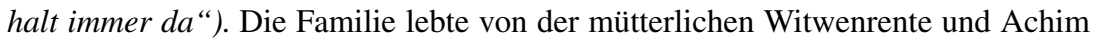
beschreibt die finanzielle Situation so, dass „(...) wir jetzt nich so die Geldprobleme [hatten], aber halt natürlich jetzt auch nich so viel (...). Und was halt möglich war, hatse [die Mutter, L.L.] dann halt auch versucht zu ermöglichen. “ In diesem Rahmen waren etwa Klassenfahrten und Schüler*innenaustausche nicht selbstverständlich, wurden aber von der Mutter ihren Möglichkeiten entsprechend finanziert. Von weiteren engen Bezugspersonen berichtet Achim nicht, aber von einem breiten sozialen Umfeld, bestehend aus Nachbar*innen und Freund*innen der Familie in seinem überschaubaren, dörflich anmutenden Herkunftsort, in dem die nachbarschaftliche Gemeinschaft eine zentrale Rolle spielt und Sicherheit gibt (,,[E]s is dann auch so typisch Dorf gewesen, dass andere immer wussten okay, ich bin der und der und gehöre zu meiner Mutter und irgendwie so achten dann Leute automatisch immer son bisschen darauf“).

Wann der neue Lebensgefährte der Mutter in die Familie gekommen ist, ist unklar. Er wird von Achim im gesamten Interview nur einmal erwähnt, als um die Organisation von Zusammenleben und Haushalt geht ${ }^{13}$ :

\begin{abstract}
„Äh sei es jetzt meine Mutter und mein Bruder oder äh halt äh der Lebensgefährte den meine Mutter hat, halt da auch noch nach anderen zu gucken, dass man sich dann halt absprechen wer jetzt halt wann ins Bad geht oder guckt dass halt die Aufgaben gerecht verteilt sind. Das ist halt von meiner Seite her nie son Problem gewesen, weil meine Mutter dann halt auch gesagt hat so wir sind schließlich drei Jungs, wir können helfen im Haushalt.. und halt auch so erzogen worden sind dass wir halt auch Dinge machen die wir halt auch sehn. Und nicht nur Dinge machen die halt unsere Aufgabe sind sondern halt so en normalen Alltag einfach und ich kanns jetzt halt grad machen also mach ichs grad.“
\end{abstract}

Dass Achim abgesehen von dieser Passage den Lebensgefährten nicht erwähnt, verweist auf dessen vergleichsweise geringe Bedeutung für ihn und möglicherweise auch darauf, dass er erst spät zu der Familie gezogen ist. Gleichzeitig wird hier deutlich, dass Fragen der Haushaltsführung und des Zusammenlebens in Achims Jugend in gemeinsamen Aushandlungsprozessen geklärt wurden (,,absprechen“) und dass man dabei Rücksicht aufeinander genommen hat (,nach anderen zu gucken"). Achims Mutter schient hierbei durchaus die tonangebende

\footnotetext{
${ }^{13}$ Mit dieser Passage leitet Achim seine Antwort auf die Frage ein, wie er sein bisheriges WG-Leben in Hierstadt beschreiben würde.
} 
Person gewesen zu sein, hat ihre Söhne und ihren Lebensgefährten aber gleichermaßen in die entsprechenden Tätigkeiten eingebunden. Leitend war hierbei ein gemeinschaftliches Prinzip der Aufgabenteilung (,gerecht verteilt“") mit dem Ergebnis, dass Achim heute Haushaltsaufgaben mehr als Selbstverständlichkeit sieht denn als auferlegte Pflicht.

In der Schulzeit konnte die Mutter ihre Söhne nur bedingt unterstützen, wie Achim erzählt: „,[A]lso meine Mama hat ziemlich schnell gesagt so ähm.. ähm bis zu nem gewissen Grad kann ich euch helfen, das wird wahrscheinlich so des zweite Schuljahr sein, und dann wirds schon schwer. Also äh, ja also schon von Anfang an eigentlich gesagt, Bitte verlasst euch da nicht auf mich wenn ihr da mal was nicht wisst oder so' " Achim vermutet, dass diese Distanzierung vom Lernstoff der Kinder auf den eigenen negativen Erfahrungen der Mutter in ihrer Schullaufbahn beruht, die sie mit ihrem Volksschulabschluss beendet hat. Den beiden Brüdern wurde von ihr freigestellt, nach eigenem Ermessen zu lernen oder Nachhilfestunden in Anspruch zu nehmen, eine weitergehende Kontrolle der Leistungen mütterlicherseits gab es nicht. Gleichzeitig wurde auch kein Druck auf ihre Söhne hinsichtlich ihres Schulabschlusses ausgeübt - vom Hauptschulabschluss bis zum Abitur hätte sie alles positiv aufgenommen, so Achims Einschätzung (, ,[J]etzt nich unbedingt so diese.. Kontrolle. Weil meine Mama halt auch ziemlich schnell oder halt auch gesagt hat wir lernen halt für uns (...). [U]nd seis jetzt en Hauptschulabschluss oder so, dann is das halt en Hauptschulabschluss“). Der familiäre Umgang mit Schulbildung ist damit nicht auf das Erlangen des höchsten Schulabschlusses ausgerichtet, stattdessen standen frühe Eigenständigkeit, eigene Handlungsfreiheit und emotionaler Rückhalt im Fokus.

Diese Offenheit - sowohl in der Familie wie auch im weiteren sozialen Umfeld - prägt auch Achims Berufswahl:

„Ich konnt“ eigentlich wirklich immer gucken, dass ich halt machen konnte was ich wollte, oder halt auch wirklich jede Idee umsetzen und das halt auch bis heute. Wenn ich gesagt hab so ich möcht' Architekt werden ham alle immer gesagt ,Ja okay, mach das wenn du das möchtest" oder äh ich werd Anwalt oder, oder ne Phase hatt ich auch, wollt ich Tanzlehrer werden und alle ham gesagt ,Ja klar, wenn es das is was du möchtest, mach ' und standen eigentlich immer alle hinter mir und ham in allem was ich machen wollte halt auch immer gesagt, So wir stehn hinter dir und wenns das is was du möchtest und wenn es dich glücklich macht, dann mach das. " Und wos dann halt hieß Soziale Arbeit, und das dann halt auch mehrere Jahre, dann halt auch genauso."

In seinen vielfältigen Berufswünschen, die in Status und Prestige eine große Varianz aufweisen, stößt Achim auf eine offene und bereitwillige Unterstützung durch 
sein soziales Umfeld. An ihre Grenzen stößt diese ergebnisoffene Unterstützung nur, als es um die Wahl des Studienortes und die Finanzierung des Studiums geht. Auf den 200 Kilometer weiten Wegzug reagiert Achims Umfeld kritisch (,[W]os dann klar war, dass es [Hierstadt] is, waren klar alle nich so begeistert") und seine Mutter sieht das Studium als finanzielles Risiko:

„[E]n bisschen Bedenken hatte sie halt schon, aber jetzt halt auch einfach so dieser finanzielle Faktor also, dass ich halt zum Beispiel meine Halbwaisenrente kriegt man halt nur bis zum Ende des 27. Lebensjahres.. und halt so diese.. ja, dass ich halt diese Sicherheit aufgegeben hab zu sagen so jetzt geh ich halt in den Beruf und verdien' regelmäßig Geld, nein, Sohnemann sagt so ich geh jetzt mal Vollzeit studieren und gucke wie das Geld reinkommt und wenns dann halt irgendwie Bafög oder Studienkredit sein muss was ich dann halt zurückzahl, dann ist das halt so, schon en bisschen Bauchschmerzen.“

Hier wird die Fremdheit einer akademischen Ausbildung bei Achims Mutter deutlich, da sie diese nur schwer bewerten kann. Es ist für sie nicht selbstverständlich, für das Studium einen Kredit aufzunehmen und sie wiegt die Schulden und die daraus entstehende Verpflichtung stärker als den antizipierten Nutzen einer akademischen Ausbildung. Ihre „Bauchschmerzen“ beim Gedanken an einen Studienkredit des Sohnes illustrieren ihre Disposition hin zu einem schuldenfreien, sicherheitsorientierten Umgang mit Geld und einem Streben nach (finanzieller) Unabhängigkeit.

In Achims Herkunftsfamilie zeigen sich also zum einen finanzielle Grenzen wie auch eine grundsätzliche Distanz zu einer akademischen Ausbildung. Gleichzeitig ist seine schulische und berufliche Orientierung von einem offenen, wenig lenkenden Umgang durch seine Mutter und das weitere Umfeld jenseits von Status- und Prestigedenken geprägt. Was wiederum die Tätigkeiten seiner Mutter angeht, deuten sich Parallelen zu den Berufswahlen ihrer Söhne an: So ist Achims älterer Bruder in einem pflegerischen Beruf tätig, während die Mutter ihren Vater über Jahr gepflegt hat. Achims selbst war von seiner Tätigkeit als Ferienbetreuer in einem Jugendzentrum so begeistert, dass er den Weg in einen entsprechenden sozialen Beruf weiterverfolgt - die Ähnlichkeit zu den ehrenamtlichen Tätigkeiten der Mutter sind unverkennbar. ,Soziale " - also etwa sorgende, pflegerische, erziehende Tätigkeiten - scheinen in der Familie positiv besetzt und eine Nähe dazu dispositional angelegt zu sein.

\section{Studien(fach)wahl und antizipierte Zukunft}

Was Achims Zukunftsvorstellungen angeht, ist er sich sicher, wieder in seinen Heimatort zurückkehren zu wollen: ,[A]lso ich fühl' mich halt schon sehr mit 
Großdorf verbunden, also ähm für mich is' halt.. halt auch so der Wunsch, also nich" nur halt nach NRW halt irgendwann wieder zu ziehen, sondern halt auch so gucken halt auch hm in [meinem Herkunftsort] irgendwie son Plätzchen zu finden. “ Achim möchte ein „Plätzchen finden“ in dem Ort, in dem er aufgewachsen ist. Hier kumulieren seine Bescheidenheit und die Verwurzelung in seinem dörflichen Herkunftsumfeld darin, dass er dorthin zurückkehren möchte, wo er hergekommen ist. Mit Rückblick auf die kritische Reaktion von Achims Mutter auf seine Studienentscheidung lässt sich also sagen, dass Achim einen mutigen Schritt aus seinem Herkunftsumfeld herauswagt - und damit auch aus den Bildungs- und Berufsvorstellungen seiner Mutter - aber antizipiert, sich letztendlich wieder in die für ihn bekannten Bahnen einzuordnen.

Auch seinen Traumberuf hat Achim schon im ersten Studiensemester klar vor Augen:

„Ganz einfach, äh ich bin in einem Jugendzentrum (I: Okay). Und, und leite das entweder mit Kollegen oder je nachdem was halt der Träger ist, leit" ich das alleine und äh gestalte mit Kindern und Jugendlichen den Alltag. In den Ferien hab ich äh.. äh ja Teenager, Jugendliche, die gerne halt die Arbeit auch mit Kindern machen wollen in den Ferien und dann halt auch so Ferienaktionen planen und so das was halt bisher halt auch erlebt so mit Ferienfreizeiten, Ferienprogramm, Kooperationen mit anderen Einrichtungen, also die typische Arbeit halt in einem Jugendzentrum.“

Erneut spricht Achim davon, mit seinen Klient*innen ,den Alltag zu gestalten“ diese pädagogische Betreuung auf Augenhöhe scheint seiner Idealvorstellung eines Berufs sehr nahe zu kommen. Zusätzlich antizipiert er jedoch selbstverständlich eine Leitungsposition. Das Studium ist für ihn in diesem Rahmen nur ein Mittel zum Zweck, wie er weiter ausführt:

„Aber das is.. ja eigentlich halt auch so der eigentliche Grund warum ich das halt auch mache [das Studium der Sozialen Arbeit, L.L.]. Also nich“ nur um den Abschluss zu haben sondern weil da möcht ich hin [zur Stelle als Jugendzentrumsleiter, L.L.], das is" mein Ziel und wenn ich das erreicht hab kann sein, dass ich später dann so vielleicht en neues Ziel halt suche, vielleicht irgendwie so ne Weiterbildung irgendwas komplett in nem andern Bereich irgendwie so ne Fortbildung mache, aber das is so, da möchte ich hin, das macht mich glücklich. Dafür möcht ich halt den Bachelor haben, der reicht da auch, ich brauch keinen Master oder ich möcht, muss keinen Weg gehen der darüber hinausgeht.. könnt" ich das halt als Erzieher schon machen, würd" ich das halt auch nur Erzieherqualifikation machen, muss aber halt en Studium haben und deswegen den Bachelor. Und da bin ich halt auch schon glücklich. Würden andere sagen ich würde aber gerne den Master haben oder en Doktortitel oder wie die Möglichkeiten sind, dann ja die anderen, sollen die das machen, ich bin da.. nich so anspruchsvoll was jetzt so den Grad angeht.“ 
Hier wird Achims Abgrenzung von einem status- und prestigeorientierten Denken noch einmal sehr deutlich. Seine beruflichen Vorstellungen sind davon geprägt, dass er seinen Weg Schritt für Schritt gehen will und sein Beruf mit keiner speziellen Position verbunden sein muss, sondern er ihn zufrieden machen soll. Achims Wünsche wirken damit überschaubar und scheinen für ihn realistisch erreichbar zu sein. Gleichzeitig hält er sich auf seinem Weg weitere Umentscheidungen offen: Er scheint sich nicht auf bestimmte Ziele oder ein bestimmtes Lebensmodell festlegen zu wollen, was für eine Offenheit seinerseits steht, aber auch auf eine gewisse Orientierungslosigkeit hindeutet. Außerdem grenzt er sich von ,anderen “ ab, die einen Master- oder Doktortitel erlangen wollen, da ist Achim nicht so „anspruchsvoll“. Eine Abwertung beinhaltet diese Abgrenzung zugleich nicht. Das mögliche Prestige eines Studiums oder entsprechende Aufstiegsmöglichkeiten spielen für ihn keine Rolle.

Was für Achim aber durchaus eine Rolle spielt in seiner beruflichen Zukunft, ist das Gehalt: Für ihn wäre es ein „Glück“, einmal eine Vollzeitstelle zu haben. Durch die könnte er sich etwa Reisen finanzieren, für die er bislang kein Geld hatte. Eine städtische Anstellung wäre ihm außerdem lieber als eine kirchliche, denn die ist „sicherer" und bringt „mehr Geld“. Geld ,beruhigt ungemein “ und Geld „ermöglicht“ Dinge - so lässt sich sein Verhältnis dazu auf den Punkt bringen.

,[I]ch hab en Auto und das fährt mich von A nach B, das ist für mich halt schon Luxus. Es muss jetzt kein Neuwagen sein, aber ich brauch irgendwann, meiner fährt auch noch lange. Oder auch für später ich.. also nicht nur weil ich finde das macht so von der Sauberkeit enormen Aufwand, aber ich brauch halt auch kein Haus, ich brauch auch keinen, keine Eigentumswohnung, also klar für viele is das.. bestimmt ne Sicherheit und halt auch was Beruhigendes, aber.. ich brauch halt nurn Dach überm Kopf.“

Achims Bescheidenheit ist offensichtlich, für ihn sind ökonomischer Besitz und materieller Gewinn nicht handlungsleitend - aber Geld bedeutet für ihn Sicherheit. Gleichzeitig zeigen sich innerhalb dieser Vorstellungen auch hedonistische Züge: So kommt er auf das Thema der Familiengründung selbst zu sprechen, als es um seine Zukunftsvorstellungen geht und er sagt dazu, er möchte nach dem Berufseinstieg erst einmal sein Geld „(...) für mich auszugeben, muss jetzt nicht direkt schon Nachwuchs haben oder so, sondern einfach halt so die Welt sehen, wofür halt einmal halt auch bis dato immer so das Geld gefehlt hat sag ich jetzt mal. " Achims Erfahrung der finanziellen Begrenzung und Notwendigkeit in Kindheit und Jugend führt dazu, dass er Geld jetzt als Mittel zur Unabhängigkeit und Freiheit sieht und die entsprechenden Vorteile ausnutzen möchte, sobald sie 
ihm zur Verfügung stehen. Familiengründung steht in dieser Planung an zweiter Stelle. An späterer Stelle wird sogar klar, dass sie gar nicht zwangsläufig zu seiner Lebensplanung gehört: In seinem Umfeld beobachtet Achim, dass viele seiner Freunde heiraten und teilweise auch schon ein Haus bauen. Davon distanziert er sich und betont mit Blick auf seine Pläne zur Familiengründung: „, Wenns passiert, passierts“ und „alles kann, nix $\underline{\text { muss “. }}$

Gleichzeitig antizipiert er, später einmal ein „, super Papa“ zu sein, nur ,viel zu nett “ und nicht konsequent genug (,[W]ahrscheinlich würd“ ich so dieses Ganze was ich in der Ausbildung gelernt hab total vergessen und sagen so ,Ja klar, hier haste noch zwei Becher Schokoladeneis“"). Jedoch wünscht er sich, seinen Kindern mehr „Disziplin und Eigenmotivation“ mitzugeben - „weil ich das selbst nicht kannte“, wie er betont. Er möchte seine Kinder hinsichtlich ihrer Noten stärker fördern als es seine Mutter getan hat, damit sie nach ihrer Schulzeit ihren weiteren Weg möglichst frei bestimmen können: „[M]an is halt nunmal dazu ich sag jetzt mal verdammt irgendwie aus der Schule rauszukommen und zu arbeiten und diesbezüglich sollte man, wenn man halt wirklich halt auch frei das machen möchte was man halt will, muss man halt auch leider Gottes dementsprechend halt die Noten mitbringen, es sei denn man hat dann halt auch die Ausdauer wie zum Beispiel in meinem Fall." Erwachsenwerden und die Pflicht, zu arbeiten, sind in dieser Darstellung eine ,Verdammnis‘. Einerseits folgen Achims Vorstellungen einer hedonistischen, lustbetonten Orientierung, in deren Rahmen er sich von der Ernsthaftigkeit und den Pflichten des Lebens distanziert. Andererseits nimmt er diese Pflichten durchaus an legt eine gewisse Disziplin an den Tag, um beispielsweise seinen Schulabschluss zu absolvieren. Beides - Genuss und Disziplin - scheint so von Achim , ausbalanciert' zu werden. Durch sein Durchhaltevermögen und seine Ausdauer will sich Achim den Weg in eine Berufslaufbahn erarbeiten, in der er frei und eigenständig Entscheidungen treffen kann, in der er mit Klient*innen ,den Alltag gestalten “ und etwa Ferienaktionen planen kann. Sein beschwerlicher Weg zu dem Beruf als Jugendzentrumsleiter ist sozusagen die Gegenleistung für einen Beruf, der Freiräume und selbstständiges Arbeiten ermöglicht. Diese Perspektiven will er auch an seine Kinder weitergeben.

Dieses handlungsleitende Credo wird auch zum Abschluss des Interviews noch einmal deutlich, als Achim darüber erzählt, worauf es ihm im Leben ankommt: Für ihn ist besonders bedeutsam, dass er ,klar im bestimmten Rahmen, aber eigentlich halt immer das machen konnte was ich halt wollte, halt auch irgendwie.. also mein, mein Weg halt auch frei wählen konnte. (...) [D]ann kommt dann halt auch hinzu was muss man dafür leisten, aber einfach halt grundsätzlich auch von Familie oder Freundeskreis, immer die Möglichkeit gehabt zu haben, das frei zu machen was ich halt machen wollte." Einen bescheidenen Handlungsspielraum 
zu haben, den eigenen Weg ,frei zu wählen“, sich diese Möglichkeiten durch eigene Leistung zu erarbeiten und dabei auf den Rückhalt aus der Gemeinschaft vertrauen zu können, ist für Achim zentral.

Abschließend formuliert er noch seine drei Wünsche, über die er verhältnismäßig lange nachdenkt:

„... (13 sec) Also ein Wunsch ist leicht, also es is` sehr kitschig aber ich hätt halt schon den Wunsch halt einfach meinen äh meinen Vater kennenzulernen, weil ich einfach.. zwei Jahre war wo er gestorben is'.. und da hab ich halt schon wo ich kleiner war halt.. schon sehr gelitten, dass ich halt so, ich hab en paar Fotos von ihm, aber ich wusst" oder ich weiß äh gar nich" wie hat er agiert oder wie hat er gelacht, wie war überhaupt die Stimme. Das wär dann halt wirklich irgendwie, halt so etwas wo ich sagen würde ja das wär, das wärn Wunsch.. auch einfach jetzt so aufgrund meiner jetzigen Situation wärs halt schon angenehmer haltn bisschen mehr Geld in der Tasche zu haben ((lacht)), das wär halt einfach jetztn Wunsch. Der dritte... ach en dritten bräucht" ich eigentlich auch ehrlich gesagt nich". Also es is jetzt nich“ so.. halt wie gesagt so des Geld weils dann halt einfach entspannter wäre und ne gewisse Sicherheit, man hat halt nunmal gewisse.. Fixkosten die man jeden Monat bezahlen muss. Aber ansonsten.. ich, ich bräucht' jetzt halt auch nich ' mehr also nötig oder halt auch nich" mehr irgendwie.. ansonsten Wünsche hab ich halt nich“. Ich hoff halt natürlich dass das Studium erfolgreich is aber.. des schaff ich aus eigener Kraft, dafür brauch ich keinen Wunsch also irgendwie, ne, eigentlich.. Nö, ich bräucht" nur, ich würd" nur die zwei nehmen."

Hier wird erstens erneut deutlich, dass Achims Aufwachsen durch den Tod seines Vaters von schwierigen Phasen emotionaler Belastung geprägt war (,sehr gelitten"). Bezeichnend ist, wie er den Wunsch äußert, seinen Vater kennenzulernen: Er betont Details der zwischenmenschlichen Interaktion (,wie hat er agiert“, ,wie hat er gelacht", „wie war überhaupt die Stimme“) und scheint sich ein genaues Bild von diesem Mann machen zu wollen, den er nie wirklich kennenlernen konnte. Sein wertschätzender Blick auf soziale Beziehungen und die Wichtigkeit enger Bindungen schlägt sich hier noch einmal nieder.

Zweitens impliziert Achims Wunsch nach ,mehr Geld in der Tasche“, um die „Fixkosten“ zu zahlen und ,entspannter“ zu sein, dass dieser Aspekt der finanziellen Versorgung für ihn mit Sorgen und einem gewissen Druck verbunden ist. Er scheint zu wissen, wie es ist, keine finanzielle Sicherheit zu haben. Drittens äußert er auf manifester Ebene seine Selbstsicherheit in Bezug auf das Studium, die jedoch möglicherweise von unrealistischen Vorstellungen geprägt sein mag, wie es sich auch bei seinen Vorstellungen von Geophysik und Jura der Fall war. An einer akademischen Prüfung hat er bislang schließlich nicht teilgenommen. Und viertens verweist sein Verzicht auf einen dritten Wunsch auf seine Bescheidenheit. 


\section{Habitus, Studien(fach)wahl und Milieuspezifika}

Achims Weg in die Soziale Arbeit ist zwar von Umwegen über zwei verschiedene Studiengänge und die Erzieherausbildung geprägt, von der fachlichen Ausrichtung her ist er allerdings ein sehr geradliniger. Schon früh hat Achim Erfahrungen in der pädagogischen Arbeit mit Jugendlichen gemacht, mit ihnen gemeinsam den „Alltag gestaltet“, was auf einen niedrigschwelligen und partizipativen Umgang auf Augenhöhe hinweist, und Begeisterung dafür entwickelt. Diese Form der pädagogischen Begleitung betont er daher auch bei all seinen daran anknüpfenden Tätigkeiten - sei es in der Behindertenwerkstatt oder in seiner antizipierten Leitungsfunktion eines Jugendzentrums.

So ist es auch dieser konkrete Traumberuf, für den er „verbissen “ an der Sozialen Arbeit festhält, strategisch vorgeht, Wartesemester in Kauf nimmt und letztendlich eine fünfjährige Ausbildung absolviert, um zugelassen zu werden mit Erfolg. Der akademische Abschluss oder mögliche Bildungstitel spielen für ihn dabei keine Rolle, von Status- und Prestigedenken grenzt er sich grundlegend ab. Auch materieller Besitz treibt ihn nicht an, von Bescheidenheit geprägt möchte er nur ein „Dach über dem Kopf“ haben. Diese handlungsleitenden Werte zeigen Parallelen zu Achims Erfahrungen in seiner Herkunftsfamilie: Der Umgang mit begrenzten finanziellen Mitteln und die Möglichkeit, sich in diesem Rahmen die größtmögliche Handlungsfreiheit zu nehmen, haben ihn geprägt. Geld bedeutet daher für ihn zum einen Sicherheit, zum anderen aber auch die Möglichkeit, eine gewisse Genussorientierung auszuleben, auf Reisen zu gehen das spätere Gehalt erst einmal ,für mich" auszugeben. Diese durchaus bescheidene Genussorientierung scheint gleichzeitig ,in Balance" zu sein mit Achims strategischem und ausdauerndem Weg hin zu seinem Wunschstudium, für das er mehrere Jahre Wartezeit und sogar eine dreijährige Ausbildung in Kauf nimmt.

Seine schulische und berufliche Orientierung vollzog sich ohne Leistungsdruck oder das elterliche Ziel eines bestimmten Abschlusses oder Berufs. Stattdessen wurde er durch sein soziales Umfeld ergebnisoffen unterstützt - ob er nun „Anwalt“, „Tanzlehrer" oder „Architekt" werden wollte. Diese Handlungsfreiheiten prägen auch seine Berufsvorstellungen, denn die Möglichkeit, ,frei das machen möchte was man halt will", möchte er auch seinen Kindern weitergeben und orientiert sich damit am Wert von Autonomie. Zudem spielen fürsorglich konnotierte Tätigkeiten jenseits von finanziellem Gewinndenken eine zentrale und positiv besetzte Rolle in der Herkunftsfamilie, in der seine Mutter für ihn die Bezugsperson war und ist: Mit der Pflege ihres Vaters, der anschließenden Erziehung ihrer Söhne und ihrem ehrenamtlichen Engagement in den Schulen ihrer Söhne lebt sie außerhalb der Sphäre von Erwerbsarbeit vor, was ihre Söhne 
als Altenpfleger und angehende Sozialarbeiter dann zu professionalisieren scheinen. Nicht nur in dieser fachlich-beruflichen Disposition, sondern auch in Achims Blick auf sein soziales Umfeld, seinen Vater und sein positives Selbstbild als Elternteil schlägt sich mehrfach nieder, dass die Gemeinschaft für ihn eine zentrale Rolle spielt.

Die zentrale Rolle seiner Mutter und die dadurch beförderte Nähe zu fürsorglichen Tätigkeiten prägt auch die Dimension der Vergeschlechtlichung von Achims Studien(fach)wahl: Das Interviewmaterial belegt, wie bedeutsam seine Mutter für Achim ist als Betreuungsperson, Bezugsperson und Orientierungsfolie. Das Zusammenleben mit ihr, dem Bruder und dem für Achim weniger bedeutsamen Lebensgefährten war von gemeinschaftlichen Aushandlungsprozessen und einer gleichmäßigen Verteilung der Haushaltstätigkeiten geprägt, so Achims Rückblick. Vor diesem Hintergrund hat er ein tendenziell egalitäres Bild entwickelt von der Aufteilung reproduktiver Tätigkeiten. Im Ergebnis scheinen Achims berufliche Orientierung und seine Vorstellungen von Familiengründung und von Familienorganisation vergleichsweise wenig von binär-vergeschlechtlichten Einflüssen geprägt zu sein.

In dieses Bild fügen sich Achims Vorstellungen von Familiengründung ein: Er sieht sich als späteren ,guten Papa“, möchte sich aber nicht darauf festlegen, unbedingt eine Familie zu gründen. Auch hier hält er sich alle Möglichkeiten offen. Die Antizipation der familiären Versorgerrolle spielt in seinen Ausführungen keine Rolle. Gleichzeitig möchte er seinen potentiellen Kindern mehr Disziplin vermitteln, als er selbst erfahren hat, damit sie nach dem Schulabschluss mit weniger Aufwand als ihr Vater ihr Leben frei gestalten können. Achims von Notwendigkeiten geprägte Herkunftserfahrungen tragen somit zu einer eher methodisch-planenden und disziplinierten Orientierung bei, mit der er auch selbst bei seiner Zulassung zur Sozialen Arbeit erfolgreich war. Die wiederkehrende Offenheit von Achims Zukunftsvorstellungen - sei es bei seinen beruflichen Möglichkeiten oder der Familiengründung - gehen Hand in Hand mit seinem schrittweisen Vorgehen. Er setzt sich überschaubare, mittelfristige Ziele und eine langfristige, von festen Zielen geprägte Lebensplanung kommt für ihn nicht in Frage.

Zusammenfassend ist es das Zusammenspiel von Achims Abgrenzung von Prestige- und Statusdenken, seiner Bescheidenheit, seiner offenen Vorstellungen von Familiengründung, seiner tendenziell egalitären Vorstellungen von der Aufteilung reproduktiver Aufgaben, die hohe Bedeutung von Gemeinschaft und zwischenmenschlichen Beziehungen und die positive Orientierung an seiner Mutter, die stets fürsorgliche Tätigkeiten ausgeübt hat, das seine hohe fachliche Passung zur Sozialen Arbeit maßgeblich prägt. Achims Fall zeigt damit einige 
Parallelen zu dem Tabeas, aber ebenso einige Unterschiede: Auch bei Achim findet sich eine Abgrenzung von Status- und Prestigedenken, er hat ein partizipatives und egalitäres Verständnis von seiner Tätigkeit als Sozialarbeiter und ordnet seine Vorstellungen von Genuss der beruflichen Sphäre nicht völlig unter. Gleichzeitig findet sich bei ihm ein größerer Bildungsaufstieg ohne Eltern als erwerbsbezogene Vorbilder und ohne familiäre Unterstützung während der Schulzeit. Zudem zeichnen sich bei Achim keinerlei Spuren von Distinktion ab, wie es bei Tabea der Fall ist. All dies verweist in Kombination mit Achims Wunsch nach freien Entscheidungsmöglichkeiten auf eine Verortung von Achims Fall in ähnlicher horizontaler Lage wie der von Tabea, aber eher im vertikal-unteren Bereich. Allerdings entsprechen Achims Habituszüge nur teilweise den Spezifika des Leistungsorientierten Arbeitnehmermilieus und stattdessen sind in seinen Handlungsorientierungen auch Hinweise auf das Hedonistische Milieu erkennbar. Eine schlüssige Milieuhypothese ist für diesen Fall deshalb nicht möglich und seine Verortung erfolgt vorrangig vor dem Hintergrund der Relationen zu den anderen Fällen.

\subsection{Fall Michael: „Samstag, Sonntag wird durchgearbeitet.. Also des is immer so"}

\section{Reflexion der Interviewsituation}

Mit etwas über einer Stunde Dauer ist das Interview mit Michael durchschnittlich lang. Die Gesprächssituation ist von einem präsentationsfreudigen, selbstbewussten Auftreten Michaels geprägt: Er spricht flüssig, antwortet überwiegend ohne lange Überlegungen und setzt Betonungen so, dass seine Erzählungen eine gewisse Dynamik enthalten und ihnen gut gefolgt werden kann. Seine Körperhaltung spricht von Gelassenheit, er lehnt sich zurück und scheint die Befragungssituation zu ,genießen“. Teilweise erinnern Passagen an erzählerische Anekdoten, in denen Michael einen Spannungsbogen aufbaut oder spezielle Äußerungen besonders betont und vor dem Weitererzählen auf eine Reaktion der Interviewerin zu warten scheint. Die Interviewerin begibt sich in die Rolle der interessierten Zuhörerin und reagiert auf Michaels Pointen intuitiv und bestärkend, um sich seinem Erzählduktus anzupassen und die Gesprächsdynamik aufrecht zu erhalten. So folgt auf die von ihm betonte Äußerung ,[M]it 14 Jahren hatt ich mein erstes Auto gekauft ((lacht))" etwa eine rhetorische Nachfrage der Interviewerin (,Was?“), auf die hin Michael den für ihn wichtigen Inhalt nochmal bestätigen kann (,Ja ((lacht))“). 
Nach Ende der Aufnahme beginnt er einen Austausch darüber, wie viele Interviews geführt werden, bezeichnet Michael das Vorhaben als „spannend“ und kommentiert anerkennend, dass die Forscherin dadurch sicher ,viele interessante Menschen" kennenlernen würde. Michael begibt sich so auf Augenhöhe der For-

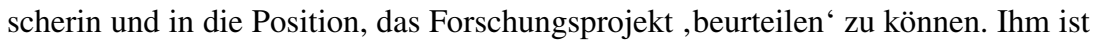
es wichtig, Wertschätzung der Interviewerin gegenüber zu zeigen und gleichzeitig impliziert sein Kommentar, dass er zum Kreis dieser ,interessanten Menschen“ gehört.

Insgesamt nutzt Michael das Interview damit wie eine Bühne: Er präsentiert sich gekonnt und scheine eine ,Geschichte' zu haben, die er erzählen will. Zugleich lässt er sich auf sämtliche Fragen der Interviewerin ein und überlässt ihr die Kontrolle über das Gespräch. Dieses selbstbewusste Auftreten von Michael ist zwar auffällig, wirkt aber zugleich authentisch. So lässt auch sein Sprachstil als umgangssprachlich bezeichnen und ist von einem leichten hessischen Dialekt geprägt, den er auch nicht zu verstecken sucht.

\section{Kurzeinführung in den Fall}

Michael studiert im ersten Semester Bauingenieurwesen und ist zum Zeitpunkt des Interviews 20 Jahre alt. Er hat einen älteren Bruder, der ein Studium in Betriebswirtschaftslehre absolviert hat, und eine jüngere Schwester, die ihr Lehramtsstudium zurzeit pausiert, weil sie ein Kind bekommen hat. Michaels Eltern sind selbstständig im Autohandel und in der Immobilienbranche. Sein Vater hat einen Volksschulabschluss und sich mit achtzehn Jahren selbstständig gemacht. Seine Mutter ist ausgebildete Fremdsprachenkorrespondentin, hat diesen Beruf allerdings früh verlassen und ist in die Selbstständigkeit ihres Mannes eingestiegen, wo sie für die Buchhaltung zuständig ist.

Michael selbst wurde in die „Exotenszene reingeboren“, wie er den Handel mit Hochklassewagen nennt. Michael schraubt an den exotischen Autos auch selbst herum, dies allerdings eher als Hobby. Seine Tätigkeit im Familienunternehmen fokussiert sich auf den Handel. Er hat ein Gymnasium besucht und nach der elften Klasse die Schule abgebrochen. Im Anschluss hat er die Ausbildungen zum Maurer und zum Maurermeister durchlaufen. Für ein Universitätsstudium im Wirtschaftsingenieurwesen wurde Michael bei zwei Versuchen nicht zugelassen und hat stattdessen das Bauingenieurstudium an einer Hochschule für Angewandte Wissenschaften begonnen. Neben seinem Studium arbeitet Michael zusammen mit seinem Bruder, mit dem er sich in seinem siebzehnten Lebensjahr selbstständig gemacht hat - ebenfalls im Autohandel. Zusätzlich ist Michael in einem Ingenieurbüro tätig. 
Michael lebt mit seiner Freundin zusammen, die Architektur studiert. Die beiden sind seit Michaels vierzehntem Lebensjahr ein Paar und wohnen seit einem Jahr in einer gemeinsamen Wohnung und haben einen Hund.

\title{
Studien(fach)wahl im Kontext der Herkunftsfamilie
}

Als Intervieweinstieg auf die Frage hin, wie er zu seinem Bauingenieurstudium gekommen ist, nimmt Michael eine thematische Setzung jenseits der konkreten Studienfachwahl vor und bezieht sich auf seine ersten Arbeitserfahrungen in seiner Jugend: „Also angefangen bei mir hats alles mal so mit, mit 14, 13-14 Jahren, war damals schon ziemlich, ziemlich, sach ich mal es hat mir sehr viel Spaß gemacht viel zu arbeiten oder generell in die Arbeit einzusteigen.. und hab auch damals schon sehr viel gemacht. " Dieser Einstieg steht sinnbildlich für etwas, das Michael und seine Herkunftsfamilie ausmacht: die gemeinsame Selbstständigkeit. So ist Michael mit seinem Studium beschäftigt, er ist einmal die Woche in einem Ingenieurbüro tätig und er ist gemeinsam mit seinem Bruder selbstständig im Handel mit Hochklasseautos - und "Samstag, Sonntag wird durchgearbeitet.. Also des is immer so. Aber des immer schon so gewesen die letzten drei Jahre. Des is nix Neues ". Michaels Alltag ist auf seine verschiedenen Formen der erwerbsbezogenen Arbeit ausgerichtet, sie nehmen den zentralen Stellenwert der Lebensführung für ihn ein. Die Begründung, warum Michael so viel Zeit in das Arbeiten investiert, verweist zum einen auf die positive Besetzung von Arbeit für ihn und zum anderen auf die prägenden Bedingungen in seiner Herkunftsfamilie:

\begin{abstract}
„Des macht mir Spaß. (...) Des is die Motivation. Es is wirklich, es is wirklich die Motivation, ich weiß auch nich wieso, aber äh.. meine Eltern sind genauso. Wir ham des so vorgelebt bekommen. Unser Vadder is so, mein Bruder is so, meine Schwester.. naja gut des is die einzigste, es einzigste Mädchen in der Familie, die wurd halt immer en bisschen.. geschont. Aber unser Vadder hat uns da sehr zu ge-, ich will net sagen gedrillt, des klingt so als hätt er uns gezwungen. Anfangs natürlich hatten wer manchmal schon kein Bock, da sagt er Jungs wir machen jetzt mal was."
\end{abstract}

Der zentrale Wert von Disziplin und Arbeit scheint in Michaels Familie nicht nur angelegt zu sein, sondern sie wird entlang einer patriarchalen Linie sozial vererbt. Michael schreibt zwar seinen beiden Eltern hohes Engagement für die Arbeit zu, erwähnt aber nur seinen Vater explizit, während er seine Schwester völlig aus der Einbindung in die gemeinsame Selbstständigkeit ausklammert. Sie wurde als „einzigstes Mädchen" schließlich ,geschont“, wodurch Frauen eine Schutzbedürftigkeit vor den Belastungen der Erwerbsarbeit zugeschrieben wird; ein Schutz, den die Männer der Familie offensichtlich bieten. Der Vater wiederum hat hier die 
führende Rolle eingenommen und seine Söhne ,gedrillt“, wobei Michael hier, seinen Habitusmustern und dem Wert von Eigenständigkeit entsprechend, die eigene Freiwilligkeit hervorhebt. Die enge Verknüpfung von Männlichkeit und beruflicher Leistung schlägt sich auch in Michaels frühem Einsatz in der familiären Selbstständigkeit wieder, bei dem er sich an seinem älteren Bruder orientiert hat: „Also, lag aber auch en großer Teil daran, dass ich mit 13-14 en Bruder hatte der dann 18 war und dann auch voll dann mitten drin schon war. Man will natürlich als kleinerer Bruder immer es selbe machen wie der ältere Bruder. Und da wurd" man dann en bisschen mitgerissen".

Diese Begeisterung für die Arbeit im Autohandel gibt Michael heute ebenso patriarchal weiter: „, [M]eine Freundin hat zwei kleine Geschwister, die sind acht und zehn, elf isser jetzt geworden, und der Elfjährige der hat da richtig Bock drauf. Der liebt Autos und der is ähnlich wie ich. " Seinen Neffen in spe bindet er in die Arbeit an den Autos ein und nimmt ihn zu Veranstaltungen mit - so wie Michael von seinem Vater einst zu Lamborghinitreffen mitgenommen wurde.

Die schwerpunktmäßige männliche Zuständigkeit für Erwerbsarbeit in der Familie spiegelt sich auch ebenso der Arbeitsteilung der Eltern und der gleichzeitigen Doppelbelastung der Mutter wieder: Während Michaels Mutter für die Erziehung ihrer Söhne und die Buchhaltung im gemeinsamen Autohandel zuständig war, war sein Vater in seiner Kindheit häufig, teilweise sogar ,dauerhaft unterwegs " auf Geschäftsreisen. In diesen Zeiten war auch die Großmutter in die Erziehung involviert. Die familiäre Selbstständigkeit wird so durch eine funktional ausdifferenzierte Arbeitsteilung möglich, durch die dem Vater die Rolle , an der Front' des Familienunternehmens zugewiesen wird - der diese wiederum aktiv übernimmt und ausfüllt -, während die Mutter (auch gemeinsam mit anderen Frauen der Familie) im Hintergrund für Unternehmens- und Familienarbeit zuständig ist. Auch der Alltag von Michaels Familie ist geprägt von der ständigen Präsenz der beruflichen Selbstständigkeit: „,[D]a wird Arbeit und privat kaum getrennt weil des geht nicht. Weil da is' die Küche und nebendran isses Büro und dann wenn man ausm Büro rauskommt in die Küche dann isses privat, dann wird ständig über die Firma diskutiert. " Das Bild der Familie als funktionale unternehmerische Einheit wird ergänzt durch Michaels Perspektive auf das heutige Verhältnis zu seinen Eltern, in dem er keine Hierarchie sieht, sondern eine Partnerschaft auf Augenhöhe: „Zwischen unsern Eltern und uns isses nich“ Eltern-Kinder, des is entweder firmentechnisch gesehn.. fast wie.. sach ich mal Partner, Kollegen und äh familiär gesehn sind des wie Freunde. (...) Aber des is “ ne ganz andere Beziehung, wenn ich mir jetzt Freunde von mir anguck: “

Ein Hauptgrund für die familiäre Zentrierung um die Selbstständigkeit ist die Sicherung von ökonomischem Kapital. So betont Michael, dass er ,nie so der Typ [war] der irgendwie sich hinsetzt und jetzt Konsole spielt oder so, ich hatt 
immer sehr viel Spaß dran gehabt da was zu machen, was zu sehn was ich mach und dann bisschen Geld zu verdienen." Dieses Verhalten wurde von den Eltern gefördert: Wenn Michael etwa als Jugendlicher verreisen wollte, wurde dieser Urlaub nicht von den Eltern finanziert, sondern er sollte sich das Geld selbst erarbeiten. Sobald er sein eigenes Geld verdient hat, haben seine Eltern ihn dafür gelobt und doch die Hälfte des Urlaubs bezahlt - ,einfach so, als Motivationsschub." Man sieht hier, dass für Michaels Eltern die Beteiligung an Arbeit und das eigenständige Erarbeiten von Geld positiv besetzt sind und sie das ihrem Sohn ,schmackhaft' gemacht haben. Sich anzustrengen und Dinge selbst zu bezahlen, wurde bereits in der Kindheit positiv honoriert. Disziplin, eigenständige Leistung und der finanzielle Gewinn scheinen für ihn so schon früh identitätsstiftend gewesen zu sein. Auf dieses Prinzip, sich nichts schenken zu lassen, sondern sich selbst für seinen Erfolg anzustrengen, scheint Michael stolz zu sein und orientiert sich noch heute daran. Diese Prioritäten sieht er auch in den Werten, die ihm seine Eltern - auch diesmal ausschließlich adressiert an die Söhne - vermittelt haben und die auch auf einer Abgrenzung von einer hedonistischen, genussorientierten Lebensweise beruhen:

\begin{abstract}
„Und ähm.. ja wie soll mans sagen, wir wurden nich“ geldfixiert großgezogen aber unsre Eltern ham gesagt ,Jungs, wenn ihr Geld verdient hab ihrs einfacher. Macht euch darüber Gedanken. In'en Tag reinleben macht keinen Sinn, weil irgendwann macht ihr euch Gedanken wie zahl ich des, wie zahl ich des, wie zahl ich des." Und im Endeffekt kommts eigentlich immer darauf an.“
\end{abstract}

Die familiäre Selbstständigkeit entlang dieser Praktiken wurde von entsprechendem finanziellem Erfolg gekrönt, so Michaels Darstellung - denn der Autohandel lief während seiner Kindheit „bombastisch“. Dabei besteht Michael zwar darauf, dass die Bedeutung von Geld nicht die zentrale Rolle in seiner Erziehung eingenommen habe, aber es scheint doch einen immensen Stellenwert für ihn einzunehmen - denn ,im Endeffekt" kommt es doch ,immer darauf an“. In der Folge grenzt sich Michael mit seiner Familie nicht nur von anderen Familien ab, in denen die Eltern ,en anderen Job [machen]“, sondern seine Eltern vermitteln ihm auch den Wert einer gewissen Diskretion:

„[W]as ich früh gemerkt hab is“, dass man mit diesem Autohandel oder beziehungsweise mit diesen Autos aufpassen muss was man seinen Freunden erzählt. Des hat man schnell gemerkt, weil wenn man dann, für mich war des normal, als ich ganz klein war, diese Autos. Klar wusst" ich, andere ham die vielleicht nicht, aber es war erstmal normal. (...) [D]a muss mer halt echt aufpassen, des ham wer halt relativ früh gelernt, dass man, also des ham unsere Eltern immer gesacht, ,Redet 
bitte net dadrüber' oder.. ich wurde auch in meinem Leben nicht ein einzigstes Mal mit so nem Fahrzeug in die Schule oder sonst was gefahrn. Also da ham meine Eltern sehr viel Wert drauf gelegt, des wollten die nich. Besonders meine Mutter ((lacht)).“

Es findet sich damit durchaus ein exklusiver Lebensstil in Michaels Familie, was ihren ökonomischen Besitz angeht, aber zugleich das Streben, damit in bestimmten Kontexten nicht aufzufallen - vor allem von Seiten der Mutter aus. Ihr Verhältnis zum familiären Autohandel beschreibt Michael nochmal an anderer Stelle: „[M]eine Mudder is eine, die is.. SEHR SEHR bodenständig. Wirklich sehr sehr bodenständig. Die hasst diese Autos, die hasst des Generell. Die sitzt im Büro und fährt auch nich in diesen Autos mit. Und mein Vadder is jemand der genießt des, der sacht ,Ich arbeit dafür '“. Die Kontrastierung von Michaels ,sehr bodenständiger", asketischer Mutter und seinem Vater, bei dem auf Arbeitsdiszplin der , verdiente Genuss` folgt, verweist auf deren unterschiedlichen Umgang mit Statussymbolen. Während sich seine Mutter von dieser Art der Demonstration von Status und ökonomischem Kapital abgrenzt, wird diese vom Vater in ausgewählten Kontexten ${ }^{14}$ bewusst betrieben.

Vor diesem Hintergrund der Herkunftsfamilie als erfolgreiche unternehmerische Einheit mit funktionaler vergeschlechtlichter Arbeitsteilung und beruflicher Erfolgsorientierung auf männlicher Seite wird nachvollziehbar, wie Michaels Weg in das Bauingenieurstudium zustande $\mathrm{kam}^{15}$ :

„,[A]nfangs (...) wars en Wunsch meiner Eltern, mein Bruder hat auch was ganz anderes gemacht, und meine Schwester auch. Und meine- mein Vadder sacht ,Jungs, ich mach das seit 40 Jahren, ich weiß wie die Branche is. Ihr macht das, ihr könnt das gern machen, hab ich nich degegen, wenns euch Spaß macht immer gern. Aber äh ich kenn die Branche und ich möcht" dass ihr was macht, wo ihr immer noch en zweites Standbein habt ${ }^{\prime} . "$

Das Studium war also in erster Linie eine Empfehlung der Eltern (auch hier primär gerichtet vom Vater an die Söhne) mit dem Ziel, den Status der Familie abzusichern. Dass der Vater „weiß wie die Branche is “ und seinen Söhnen die

\footnotetext{
${ }^{14}$ Seine Kinder etwa mit den statusträchtigen Autos in die Schule zu fahren, ist schließlich auch für den Vater nicht in Frage gekommen.

${ }^{15}$ Es mag verwundern, dass erst an dieser Stelle der analytische Blick konkret auf das Bauingenieurwesen gelegt wird. Damit wurde allerdings Michaels Themensetzung gefolgt, der zuerst über die Bedeutung von Arbeit für ihn und seine Familie erzählt und daran seinen Weg in das Studium aufspannt. Indem Michaels Perspektive in dieser Weise gefolgt wird, kann die Bedeutung des Studiums für ihn am ehesten erschlossen werden.
} 
Absicherung durch eine andere Tätigkeit empfiehlt, spricht für dessen strategische und langfristige Perspektive auf den Automobilsektor, bei dem er aufgrund seiner Erfahrungen Änderungen in der Wirtschaftslage vermutet. Indem Michael seine Erzählungen mit dem Rekurs auf seine Arbeitserfahrungen beginnt und auch die Frage nach dem Zustandekommen seines Studiums mit der elterlichen Empfehlung beantwortet, wird offenbar, dass ebendiese familial erwerbsbezogenen Praktiken maßgebend und rahmend für seinen Weg in das Studium sind. Wie es fachlich zum Bauingenieurstudium an einer Hochschule für Angewandte Wissenschaften kam, lässt sich anhand von Michaels Stationen vor dem Studium rekonstruieren.

\section{Weg hin zum Studium}

Als Michael etwa 15 Jahre alt war, entwickelte er den Wunsch, Architektur zu studieren (,Des fand ich sehr intressant irgendwie, weil ich immer fasziniert von Häusern war und des Ganze drumherum, des hat mir einfach gefallen (...), da sieht man was, was man so erschaffen hat"). Allerdings hat er seine Schullaufbahn auf dem Gymnasium nach der elften Klasse abgebrochen und eine Ausbildung begonnen. Den Grund dafür sieht er in seinem eigenen Verhalten, das er als durchgängig „lernfaul“ beschreibt. Die familiären Reaktionen auf seinen Schulabbruch weisen erneut das Geschlecht als strukturierendes Element aus: „Meine Mutter hat sich schwer gegen gewehrt, dass ich Schule abgebrochen hab. Mein Vadder hat (...) gesacht wenn dir was Spaß macht, machs.. und meine Mudder hat gesagt sie möchte es nich'. Dann kam mein Onkel noch dezu, der is 'äh auch Diplomingenieur und auch Handwerker. Also ihr Bruder, von meiner Mudder der Bruder. Hat gesagt zu meiner Mudder, wenn ihm des Spaß macht, lassmer ihn mal machen, mal gucken was dabei rauskommt. Dann kam mein Schwiegervater noch dezu, der hat genau es selbe gesacht." Es ergibt sich ein Bild von den Männern der Familie - auch der Herkunftsfamilie von Michaels Mutter -, die im Einklang und in Gelassenheit die Partei des jugendlichen Michael ergreifen und sich für seine freie Wahl entgegen des Abiturs einsetzen und der Mutter, die einen größeren Wert auf die Schulbildung ihres Sohnes legt. Dieser vergeschlechtlichte Umgang mit institutionalisierter Bildung schlägt sich später in Michaels Erzählungen erneut nieder.

Was die fachliche Richtung der Ausbildung anging, wollte Michael „, [i]rgendne Ausbildung “ machen, hat allerdings keinen Ausbildungsplatz gefunden und war deshalb ein Jahr lang bei der Handwerkskammer angestellt. Dort war er „Klassenbester“, wurde in die Ausbildung zum Maurer vermittelt und entdeckte in seinem Ausbildungsbetrieb die Freude an dieser Tätigkeit („, [U]nd hab dann gewusst alles klar, das is definitiv die richtige Richtung, das macht dir 
sehr viel Spaß und äh du lernst tolle Leute kennen, es is "äh des is 'perfekt"). Parallel dazu hat er mit 17 Jahren gemeinsam mit seinem Bruder die eigene Autohandelsfirma gegründet. Schließlich absolvierte er noch seinen Meister als „,beste[r] Jungmeister" in der Stadt, wie er betont. Seine Mutter habe sich über diese Entwicklung ,natürlich riesig gefreut“.

Von der Architektur war er zu dem Zeitpunkt wieder abgekommen, da seine Freundin vor ihm mit einem Architekturstudium begonnen hat und er gemerkt hat, dass ihm das „zu künstlerisch“ ist. Auch von der theoretischen Mathematik grenzt er sich ab, denn diese habe „keinen Realitätsbezug“. Im Ergebnis nähert sich Michael einem greifbareren, praxisnahen, angewandten Fach zu, bei dem man ebenfalls ,sieht(...), was man so erschaffen hat" und das eine Nähe zu seinem Meisterfach aufweist - dem Bauingenieurwesen, das er mit einem Wirtschaftsstudium ergänzen will. Nach seiner Meistertitelverleihung bewarb er sich so in zwei Semestern in Folge an einer Universität für das Wirtschaftsingenieurwesen mit Schwerpunkt Bauingenieurwesen, allerdings erfolglos. Während dem Jahr des Wartens auf einen Studienplatz war Michael in Vollzeit in seinem Unternehmen tätig. Bei der ersten Universitätsbewerbung wurde er aus formellen Gründen nicht zugelassen (,[W]ar alles ,ne ganz komische Geschichte, des hat dann doch nich' funktioniert, hatte alles bisschen was mit dem Verzug vom Meisterkursende zum Studienanfang zu tun gehabt") und beim zweiten Versuch nicht, weil es zu viele Bewerber*innen mit besseren Voraussetzungen gab. Deshalb bewarb er sich am letzten Tag der Bewerbungsfrist für Bauingenieurwesen an der Hochschule für Angewandte Wissenschaften und wurde zugelassen - was er im Rückblick als „,die wesentlich bessere Entscheidung “ darstellt. Michael kehrt seine Geschichte von seinem selbstkritischen Schulabbruch über seine zufällig ausgewählte Ausbildung bis zum besten Jungmeister und der passgenauen Hochschule damit zur Erfolgsgeschichte um. Seine Erzählungen machen zwar seinen Kampf in den letzten Jahren deutlich, den er aber mit Selbstsicherheit schildert und dabei unklare Übergänge im Nachhinein als Erfolge erzählt. Diese Sicherheit haben nicht alle seiner Familienmitglieder geteilt: „Es ham viele Angst gehabt, meine Mutter, mein Vater, mein Vater eigentlich nich, aber meine Mutter hat viel Angst gehabt, dass ich danach nich wieder dahinkomm. Also, das war auch immer mehr meine Mutter die sich darum gekümmert hat. Des is' also, er is' sehr viel unterwegs, mein Vadder (...). “ Resultierend aus ihrer Zuständigkeit für die Kindererziehung, so auch für deren Schulbildung, verdichtet sich so das Bild von Michaels Mutter als sorgende Akteurin der Familie mit einem Fokus auf dem Erlangen von kulturellem Kapital.

Was die Fachwahl hin zum Bauingenieurwesen betrifft, spielen wie bereits dargestellt Michaels fachlicher Einstieg über die Maurermeisterausbildung eine Rolle 
sowie die elterliche Empfehlung, in eine Branche außerhalb des Automobilsektors einzusteigen. Dabei wirft Michael auf die Immobilien- und Automobilbranche einen ähnlichen Blick: Er betont, dass man in beiden Branchen ,en langen Atem ham [muss], dass man sich da hin arbeitet wo man hinwill". Nur durch harte Arbeit kann man sich den Erfolg dort also verdienen. Zwar schraubt Michael auch an den Autos herum und genießt diese Tätigkeit, allerdings fokussieren sich seine Erzählungen weit mehr auf den Aspekt des Handels. Er versteht seine Tätigkeit in der Automobil- wie auch künftig in der Immobilienbranche als ein Business: „Die Leute haben Geld, die Leute wollen was ausgeben, die wollen investieren, manche investieren in Immobilien, manche in Autos, manche in beides ((lacht) $)$ “. Sichtlich stolz berichtet er vor dem Hintergrund, dass sein Vater, sein Bruder und er kürzlich ein Auto an den Besitzer des , größten Straßenbauunternehmen [s] der Welt" verkauft haben und „Politiker hatten wir auch schon “ als Kunden. Sogar „an den Gründer von Whats App“ haben sie ein Auto verkauft. An diesem Beispiel beschreibt Michael die Arbeitsteilung des Verkaufsprozesses so, dass , ich[das Auto] reingeholt [hab]“, „,mein Bruder hat sich en bisschen um die Vermarktung gekümmert“, „vermarktet ham wirs dann zusammen“ und „,den Deal [abgeschlossen]" hat sein Vater. Dass Michael an dieser Stelle die exklusiven Kunden der Familienfirma mit ihren exklusiven Autos derart hervorhebt, verweist erneut auf seine ausgeprägte Statusorientierung. Das Familienunternehmen ist etwas Besonderes, Michael hat dort mit besonderen Menschen zu tun und wird dadurch letztlich selbst zu etwas Besonderem. Der prestigereiche Abschluss des Geschäfts wiederum gebührt in patriarchaler Logik dem ,Oberhaupt der Familie'.

Der Erfolg des Handels scheint beruht dabei insbesondere auf dem gekonnten Umgang mit den Kund*innen- ein Umgang, den Michael und sein Bruder von klein auf gelernt haben: ,[D]ass wir auf äh in der Automobilbranche gro $\beta$ geworden sind oder Autoverkauf isses.. des Problem dass wir, dass wir uns mit Kunden nich unterhalten können ham wir glaub ich nich ((Michael lacht - I lacht)). " Dabei besteht Michael drauf, dass der Beruf des Autohändlers ein ehrlicher Beruf ist. Er wehrt sich gegen das negative Image, das dem Autohandel auch seiner Wahrnehmung nach zugeschrieben wird und hebt hervor, dass er die Bedingungen des Geschäftsabschlusses seinen Kund*innen transparent erläutert:

„[D]ie meisten Leute die zu uns kommen, denken, wenn man des so ausdrücken darf, wir verarschen die. Denken die alle, hundertprozentig. Dass wir irgendwelche Ganoven wärn oder sowas (...). [A]lso da reden wir aber auch offen mit denen und sagen, Wir ham dann und dann des und des und des wär unsre Marge, des würd ich dabei verdienen und hab den und den Aufwand'. Des verstehn die Leute auch, 
aber die dies nicht verstehn, weiß nicht.. also warum mans nich versteht irgendwie, man muss ja auch von irgendwas leben ((lacht)).“

Trotz seines geübten Umgangs mit Kund*innen hat Michael also nicht in jedem Fall Erfolg, was er mit seinem Verständnis vom Autohandel als grundehrliches Geschäft nicht nachvollziehen kann.

\title{
Studien(fach)wahl und antizipierte Zukunft
}

Auf die Frage hin, wie er sich sein Leben in zehn Jahren wünscht, äußert Michael konkrete Zukunftsvorstellungen:

\begin{abstract}
„((Schmunzelt)) In zehn Jahren.. da werd“ ich 31. Da hätt‘ ich gern schon mein eigenes Haus gebaut. (I: Okay) Also, da würd“ ich gern hinkommen. Mein eigenes Haus gekauft äh selbst gebaut und irgendwie natürlich im Beruf erfolgreich. Spaß daran haben, den Autohandel immer noch machen und eventuell auch was wir jetzt schon en bisschen angefangen ham, mein Bruder und ich, uns so.. ja dann irgendwie so ne kleine Autosammlung aufzubauen die rentabel is auf Langzeit gesehn. Dass man dann so auch paar Sachen hat an denen man Spaß hat, sagen wers mal so. Aber hoffentlich immer noch genau so motiviert wie heute, was die Arbeit angeht.“
\end{abstract}

Neben den ,Früchten“ der eigenen Arbeit und materiellem Besitz (,Haus gebaut“, „Autosammlung“) wünscht er sich vor allem nach wie vor Freude an der Arbeit, also die Beständigkeit seiner positiv besetzten beruflichen Disziplin. Der von ihm als wichtig dargestellte ,Spaß“ im Leben wiederum fokussiert sich ganz auf die Freude am materiellen Besitz, symbolisiert durch eine Sammlung an statushohen Luxusautos. Dass Michael an dieser Stelle nicht von sich auf seine Partnerschaft oder Familiengründung thematisiert, mag damit $\mathrm{zu}$ tun haben, dass es im vorigen Interviewverlauf überwiegend um seine Studienfachwahl ging. Es ist aber auch ein Hinweis auf seine Prioritäten. Auf Nachfrage der Interviewerin hin geht Michael auf seine Pläne zur Familiengründung ein:

\footnotetext{
„Also Kinder will ich auf jeden Fall haben (...). Aber ich hätte mehr Lust drauf, dass wenn ich sag ich bin jetzt Ende 20, Anfang 30, wo ich schon mein Leben sag ich mal in diesen, auf den Schienen hab wo ich hinwill, dann en Kind zu bekommen. Dass ich mir schon dieses Standbein oder dieses ganze Fundament aufgebaut hab.“
}

Über eine mögliche Familiengründung hat er auch schon mit seiner Freundin gesprochen: „[K]lar planen wir, sie studiert Architektur, klar planen wir, irgendwann mal alles zusammen zu machen. (...) [I]rgendwann mal zusammen ne Firma zu machen, was in diese Immobilienbranche reingeht. “ 
Michaels antizipierte Familiengründung ist ebenso von festen Vorstellungen geprägt wie seine berufliche Zukunft. Gleichzeitig sieht er den beruflichen Erfolg als Voraussetzung dafür, eine Familie zu gründen - dabei verwendet auch er den von seinem Vater angeführten Begriff des „Standbein[s]“. Der Einbezug seiner Freundin wiederum verweist auf die Erfahrungen in seiner Herkunftsfamilie: Eine gemeinsame Selbstständigkeit mit ihr ist Michaels Ziel. Allgemein deuten Michaels überzeugte und selbstsichere Antworten, in denen er den gut durchdachten Plan für sein Leben darstellt, auf die hohe Bedeutung für ihn hin, einen solchen zu haben und sich feste Ziele im Leben zu setzen - und diese durch Arbeit zu erreichen.

Im weiteren Verlauf geht Michael darauf ein, dass sich das Thema Kinderbetreuung schon jetzt in seiner Partnerschaft andeutet - und bezieht sich dabei auf die Betreuung des gemeinsamen Hundes:

„[D]a merkt man schon son bisschen wie sich des Ganze entwickelt. Klar bin ich mehr unterwegs, klar hab ich weniger Zeit für den Hund. Aber wenn ich mal da bin nehm ich mir auch Zeit für ihn. (...) also sie pusht mich da teilweise aber sie is da noch strenger. (...) Wenn meine Freundin jetzt irgendwann mal en Kind kriegen würde, dann des, sie wär nur noch für des Kind da. Also nur noch.“

Hier führt Michael den gemeinsamen Hund als Beispiel an, das die Fürsorge seiner Freundin verdeutlicht. Michaels beruflich bedingte Abwesenheit wiederum erinnert an die seines Vaters - seine Freundin scheint ihn dabei zu mehr Sorgearbeit anzuhalten. Es findet eine klare Zuschreibung von Zuständigkeit und Verantwortung statt, die Michael positiv formuliert und die an das Bild der, geborenen Mutter' erinnert, die gar nicht anders kann, als nur noch für ihr Kind da zu sein. Michael selbst dagegen würde seine Berufstätigkeit nicht zu Erziehungszwecken unterbrechen (,Ne, würd' ich auch nie machen. (...) Gehen.. würds schon, aber ich würds meinem Bruder gegenüber nich machen, weil dann er da allein steht"). Während das Engagement seiner Freundin in der Erziehung außer Frage steht und er ihren Beruf in diesem Kontext nicht thematisiert, knüpft Michael seine Beteiligung an der Kindererziehung auch hier an seinen beruflichen Erfolg: „[I]ch hoff dass ich irgendwie, dass wenn ich Kinder krieg so erfolgreich bin, dass ich mir Zeit nehmen kann, des Ganze dann so mitzukriegen."

Wie Michael über seine Freundin erzählt, deutet jedoch nicht nur auf die vergeschlechtlichte Zuschreibung von Fürsorge hin, sondern auch auf gemeinsame Habitusmuster. Als er über seine Einstellung zur Arbeit spricht, kommentiert er: „Meine Freundin is genauso“. Auch sie arbeitet etwa regelmäßig von zu Hause 
aus weiter an ihren Projekten in der Architektur, sie ,lernt sehrviel für ihr Studium" und auch bei ihr wird ,samstags direkt (...) wieder gearbeitet und sonntags auch. Also des passt ganz gut zusammen." Dass es zwischen Michael und seiner Freundin so gut ,passt“, beruht - so eine sich aufdrängende Lesart - auch auf ihrer habitusspezifischen Passung entlang der milieuspezifischen Werte von Leistung und Disziplin.

Abschließend bringen Michaels Antworten auf die ,Standardfragen“ des Interviews zentrale Aspekte seiner Bewertungs- und Handlungsmuster noch einmal auf den Punkt:

I: Worauf kommts dir im Leben an?

M: (5 sec)... Unabhängigkeit. Große Unabhängigkeit. Im Leben sach ich mal, so viel.. so erfolgreich zu sein, dass man so viel Spaß am Leben und so viel Zeit sich nehmen kann wie man will. Ich leg sehr sehr viel Wert drauf sagen zu können irgendwann mal ich will jetzt, jetzt in diesem Moment machen was ich will. (...) Also jetzt net irgendwie Geld oder sowas, weil, wobei des dazugehört in diesem Fall, des spielt halt immer so ne Rolle mit.

I: Dann die letzte Frage: Stell dir vor du hättest drei Wünsche. Was würdest du dir wünschen?

M: WOW ((lacht))... Was würd ich mir wünschen (5 sec). Also sehr viel Gesundheit auf jeden Fall mal für die Familie und Freunde. (...) Ansonsten ähm.. pff.. schwer, des, des is eine der schwersten Fragen jetzt. (...) Weil.. den Rest den.. da muss ich ehrlich sein, da bin ich so drauf, dass ich sag des kann ich mir nicht wünschen, weil da muss ich mich hinarbeiten. (I: Okay) Also ich würd mir jetzt irgendwas wünschen, sagen wir mal, ich will mal Millionär werden. (I: Okay) Klar äh sag ich mal, hat man den Gedanken dass man, oder zumindest isses bei mir so, dass man irgendwann mal hinwill, aber ich würd mir jetzt nich wünschen dass ich sag hoffentlich bin ichs irgendwann mal. (...) Den Rest kann man beeinflussen, des muss man sich nich wünschen.

Unabhängigkeit nennt Michael als leitendes Ziel, das er seines Erachtens durch beruflichen Erfolg und entsprechenden finanziellen Gewinn erreichen kann. Hier deutet sich ein Widerspruch an, denn der von ihm benannte Stellenwert von Spontanität findet sich in keiner anderen Passage des Interviews wieder und mag an dieser Stelle eine Inszenierungsstrategie sein, die seinen dominanten disziplinierten Habitusmustern eigentlich nur wenig entsprechen. Seine geäußerten Wünsche wiederum sind von Selbstsicherheit und Eigenständigkeit geprägt: Sein einziger zentraler Wunsch ist die Gesundheit für seine Familie und seine Freunde, da er diese nicht selbst beeinflussen kann. Millionär zu sein, wäre zwar grundsätzlich auch ein Wunsch - womit noch einmal der Stellenwert von ökonomischem 
Kapital deutlich wird - aber dieses Ziel kann und muss er sich selbst erarbeiten. Grundsätzlich lehnt Michael das Konzept vom „Wünschen“ eher ab, was aufgrund seiner disziplinierten Einstellung nicht verwundert, denn seine Erfolge will er selbst erarbeiten und nichts, geschenkt haben".

\section{Habitus, Studien(fach)wahl und Milieuspezifika}

Michaels Weg in das Studium des Bauingenieurwesens ist kein geradliniger, sondern durchzogen von Brüchen (wie seinem Schulabbruch), Unsicherheiten (wie der notwendigen Anstellung bei der Handelskammer auf der Suche nach einem Ausbildungsplatz) und Umwegen (wie der Umorientierung hin zum hochschulischen Bauingenieurwesen nach den universitären Absagen im Wirtschaftsingenieurwesen). Seine Darstellung dieses Weges zeugt jedoch nur von geringen Spuren dieser Unwägbarkeiten - Michael erzählt seine Geschichte als Erfolgsgeschichte. Die ,Rückschläge', die er rückblickend überwiegend als Erfolge konstruiert, zeigen zum einen seine Grenzen, etwa das Abitur zu absolvieren oder ein Universitätsstudium aufzunehmen. Sie zeigen aber auch seine Disziplin, mit der er etwa seine Selbstständigkeit seit seinem siebzehnten Lebensjahr vorantreibt oder mit er seinen Plan, zu studieren, verfolgt.

Angetrieben wird er dabei vom Wert der eigenständigen Leistung und Arbeit, der die Praktiken seiner Herkunftsfamilie maßgeblich prägt. Ist schon sein Vater ein Selfmademan und lebt ihm auch sein Bruder die völlige Hingabe an die selbstständige Arbeit vor, folgt Michael diesem Ideal und die Zentrierung um die berufliche Leistung wird in der Familie so patriarchal vererbt. Dass jeglicher beruflicher Erfolg des Familienunternehmens nicht geschenkt, sondern hart erarbeitet ist, wird von Michael mehrfach betont. Die elterliche (insbesondere väterliche) Empfehlung wiederum, ein Studium als ,zweites Standbein“ aufzunehmen, zeugt von einem strategischen Vorgehen und dem Ziel des Studiums, den Status der Familie abzusichern. Der Status spielt auch eine besondere Rolle in Michaels Verständnis vom Autohandel, denn er hat bereits Autos an erfolgreiche Geschäftsleute und Prominente wie den „Gründer von Whats App“ verkauft. Dieser Umgang mit einer speziellen Klientel und die Exklusivität dessen prägen Michaels Faszination für diese Tätigkeit. Auch seine künftige Tätigkeit als Bauingenieur betrachtet er stets vor dem Hintergrund der "Immobilienbranche“, also verstanden als ein Business. Michaels Zukunftsvision von sich als Bauingenieur scheint weniger davon geprägt zu sein, tüftelnde Konstruktionsarbeit am Computer oder koordinierende Leitungsaufgaben auf einer Baustelle auszuüben, sondern vielmehr von der Antizipation einer gewinnbringenden Selbstständigkeit als erfolgreicher Immobilienmagnat im Sinne seiner Selfmademan-Philosophie. 
Einen Fokus auf das Erlangen von institutionalisiertem kulturellem Kapital legt besonders Michaels Mutter, die im Rahmen der vergeschlechtlichten funktionalen Aufgabenteilung in der Familie schwerpunktmäßig für die Sorgearbeit und Buchhaltung des Unternehmens zuständig ist. Die gesamte ,Unternehmerfamilie ‘ funktioniert nur auf der Grundlage dieser vergeschlechtlichen Zuständigkeiten und Einstellungen, innerhalb der männlich-vergeschlechtlichte Part an die Front des Unternehmens tritt und der weiblich-vergeschlechtlichte Part die Hintergrundarbeit ausführt. Entsprechend unterschiedliche Habitusmuster von Hedonismus des ,genießenden ' Vaters und Askese der ,bodenständigen' Mutter klingen hier an.

Vor diesem Hintergrund antizipiert auch Michael selbst eine Zukunft als Unternehmer mit eigener Autosammlung und beruflichem wie finanziellem Erfolg - seine Orientierung an selbst erarbeitetem Status und Prestige ist augenscheinlich - in gemeinsamer Selbstständigkeit mit seiner Freundin. Diese wiederum teilt mit Michael zentrale Habitusmuster entlang von Leistung und Disziplin, so Michaels Darstellung. Dabei deutet sich einerseits die Reproduktion der elterlichen Arbeitsteilung an, denn Michael sieht die Zuständigkeit für die Sorgearbeit bei seiner Partnerin, während er seinen Schwerpunkt auf die Erwerbsarbeit legt. Gleichzeitig deutet sich ein - wenn auch begrenzter - Wandel des milieuspezifischen Geschlechterverhältnisses an: Während Michaels Mutter ihren ursprünglichen Beruf als Fremdsprachenkorrespondentin verlassen hat, um die Buchhaltung des Unternehmens ihres Mannes zu übernehmen - also eine für sie fachfremde Tätigkeit auszuüben - wäre Michaels Freundin als Architektin in ihrem hochqualifizierten Beruf tätig, was ihre soziale Position vergleichsweise besser absichern würde. Dieser intergenerationale Wandel und die damit einhergehende Verlagerung auf kulturelles Kapital trägt wiederum zur Statussicherung bei - die Geschlechterpraktiken sind damit konstitutiv für die sozialen Positionen der Familie.

Zusammengefasst könnten sich Michaels studienfachwahlbezogene Habitusmuster von denen Achims kaum mehr unterscheiden: Der zentrale Wert der eigenständigen Leistung, von diszipliniertem, erwerbsorientiertem Vorgehen, seine Orientierung an materiellem Besitz und Status und Prestige sowie die patriarchale Organisation seiner erfolgreichen Familie von Selbstständigen verweisen auf eine Verortung im oberen Bereich des Leistungsorientierten Arbeitnehmermilieus mit Nähe zur ständisch-kleinbürgerlichen Traditionslinie (siehe auch Vester 
2015: 162 ff.). ${ }^{16}$ Michaels materialistische und an Status und Exklusivität ausgerichtete Habituszüge könnten auch für eine Verortung in der Traditionslinie von „Macht und Besitz“ sprechen, ebenso die patriarchale und familiäre Organisation der gemeinsamen Selbstständigkeit, die Michael von nicht hinterfragt wird. Spuren der Autoritäts- und Hierarchiegebundenheit zeichnen sich in seinem Habitus also durchaus ab. Im Vergleich dazu sind die hohe Bedeutung des Leistungsprinzips und der handlungsleitende Wert von Eigenständigkeit jedoch derart ausgeprägt, während sich kein distinktives Verhalten abzeichnet, sodass eine Verortung des Falls in der Traditionslinie von „Facharbeit und praktischer Intelligenz“ naheliegt.

\subsection{Fall Dominic: „Ich hab sowohl von Freunden als auch Familie, Bekannten gesacht gekriegt, hier des Soziale liegt dir doch"}

\section{Reflexion der Interviewsituation}

Das Gespräch mit Dominic dauert etwa eine Stunde. Dieses Interview wurde auf die gleiche Weise angebahnt wie das Interview mit Achim, da auch Dominic an der Online-Umfrage nicht teilgenommen hatte: Mit der Begründung, gezielt auf männliche Studenten zuzugehen, hat die Forscherin Dominic aktiv angemailt und sich danach erkundigt, ob noch Interesse an einer Interviewteilnahme bestehe. Noch am gleichen Tag antwortet Dominic und drückt sowohl seine Bereitschaft aus, der Forscherin , zu helfen" wie auch seine Freude darüber, dass sie sich ,persönlich an [ihn] gewendet" hat. Nach einigen Tagen muss der Termin jedoch wegen eines Arztbesuchs auf seiner Seite verschoben werden, worüber er per Mail sein Bedauern ausdrückt und umgehend einen Ersatztermin anbietet. Durch diese verbindliche und wertschätzende Kommunikation wird bereits im Vorfeld deutlich, dass Dominic gerne und sehr bereitwillig an der Befragung teilnimmt. Durch die gezielte Kontaktaufnahme durch die Interviewerin scheint er sich ,geehrt` zu fühlen, möglicherweise im Sinne eines besonderen, , ausgewählten ‘ Interviewpartners.

Die Interviewsituation selbst ist auch von einer betont positiven Haltung von Dominic geprägt. Die Rolle des Interviewten scheint er sehr ernst zu nehmen und

\footnotetext{
${ }^{16}$ Zugleich eint Michael und Achim ein Habituszug, der auch ihre Studienfachwahl prägt, allerdings bei beiden in unterschiedlichem Ausmaß und unterschiedlicher Kombination mit weiteren Habituszüge vorliegt - ihre Orientierung an Autonomie.
} 
war darum bemüht, diese gut zu erfüllen. Nachfragen der Interviewerin nimmt er ernst, denkt darüber länger nach und antwortet ausführlich und detailreich. Es erscheint ihm wichtig, ein , kompetenter' Gesprächspartner zu sein und dafür strengt er sich an.

\section{Kurzeinführung in den Fall}

Dominic ist zum Zeitpunkt des Interviews 20 Jahre alt und studiert im ersten Semester Soziale Arbeit. Seine Eltern haben als höchsten Bildungsabschluss beide das Abitur, seine Mutter ist Intensivkrankenschwester und sein Vater Finanzbeamter. Dominics zwei Jahre älterer Bruder hat sein Abitur auf einem Gymnasium gemacht und studiert im dritten Semester Jura.

Seine Schullaufbahn auf einem Gymnasium hat Dominic nach der zehnten Klasse abgebrochen und ist auf eine Fachoberschule mit dem Schwerpunkt Sozialwesen gewechselt. Dort hat er sein Fachabitur absolviert, sich im Anschluss für das Studium der Sozialen Arbeit beworben und wurde zugelassen.

Dominic wohnt noch bei seinen Eltern im Umkreis seines Studienortes, plant aber, mit seinem besten Freund eine Wohngemeinschaft zu gründen, wenn dieser aus seinem Auslandsjahr zurückkehrt. In einer Partnerschaft befindet sich Dominic zurzeit nicht. Seine Freizeit ist vor allem durch sein ehrenamtliches Engagement im Fußballverein der Stadt geprägt, wo er jedes Spiel besucht und als Verkaufsleiter für Öffentlichkeitsmaterial während der Spiele tätig ist.

\section{Weg hin zum Studium}

Dominic beginnt die Erzählung über seinen Weg in die Soziale Arbeit damit, dass er eigentlich den Beruf des Polizisten ergreifen wollte (,Ja des is eigentlich so gekommen, dass ich ursprünglich zur Polizei gehen wollte.. Des is mein.. Traum eigentlich schon gewesen seitdem ich denken kann"). Dieser Berufswunsch taucht mehrere Male im Interviewmaterial auf, er spielt für ihn eine zentrale Rolle: Seit seiner Kindheit hatte er den Plan verfolgt, Polizist zu werden, ihn „hats schon eigentlich immer intressiert ja mit Blaulicht irgendwie über die Straße irgendwie zu fahrn “, er hat Polizeiberichte in der Zeitung gelesen, Serien wie Cobra11 und SoKo Leipzig geschaut und bei denen es ihm wichtig ist, wie „realistisch“ die Polizeiarbeit dargestellt wird. Außerdem hat Dominic selbst Bekannte bei der Polizei, mit denen er sich über deren Arbeit austauscht. Zusätzlich hat Dominic auch einen realen Einblick in die Polizeiarbeit erhalten, als er dort ein Schülerpraktikum absolviert hat. Der entsprechende Bewerbungsprozess sei besonders hürdenreich gewesen und Dominic ist stolz, mit seiner Bewerbung erfolgreich gewesen zu sein (,,[D]da muss man (...) circa anderthalb Jahre bevors Praktikum stattfindet, dort ne Bewerbung hinschicken (...). Für meinen Zeitraum haben 
sich 250 Schüler beworben.. und zehn Stück hamse genommen (...) und ich war dabei“). Das Praktikum selbst war „des beste Praktikum was ich je in meinem Leben äh erlebt hab“: Von der Pferdestaffel über die Arbeit der Bundespolizei am Flughafen, von der Teilnahme am sportlichen Einstellungstest über Seminare zum Thema Drogen bis hin zu Besuchen an Schießständen und bei der Hundestaffel - Dominic hat zahlreiche Facetten des Polizeialltags kennengelernt und bezeichnet diese Erfahrung als „Schritt zum Beruf“. Dominics , besondere Eignung' für diesen Beruf hat ihm auch sein Praktikumsbetreuer bestätigt, so seine Darstellung: „Und mein damaliger ähm.. Praktikumsbetreuer sagte dann zu mir weil ich der. Interessierteste war in der Gruppe, sachte, Ich will von dir nach dem Abitur ne Bewerbung aufm Tisch ham “". Letztendlich hat er sich aber wegen seiner Gehörlosigkeit auf einem Ohr nicht beworben. Dass dies ein definitives Ausschlusskriterium für den Polizeidienst ist, ließ er sich von einem Polizeiarzt bestätigen.

Diese Erzählungen über die Polizei verweisen auf Dominics große Leidenschaft für diesen Beruf, die er durch mehrere Informationskanäle fundiert und die auf einer starken antizipierten Passung beruht. Indem Dominic das strenge Auswahlverfahren sowie die persönliche Aufforderung zur späteren Bewerbung betont, hebt er seine besondere Eignung für den Polizeiberuf - die ihm so auch durch die polizeiliche Instanz selbst bestätigt wurde - zusätzlich hervor. Der Kern seines Interesses für die Polizeiarbeit wiederum bleibt an dieser Stelle eher diffus - die Vielfalt des Berufs scheint hier eine Rolle zu spielen, möglicherweise auch Aspekte von Status und Macht (,Blaulicht“), was im weiteren Material jedoch noch geprüft werden muss. Dominics methodisches Vorgehen hin zu diesem Berufswunsch zeigt sich letztendlich auch in seinem letzten desbezüglichen Schritt, sich die fehlende körperliche Eignung dafür polizeiärztlich bestätigen zu lassen.

Deshalb „musste“ sich Dominic eine berufliche Alternative suchen. Zeitgleich zu dieser beruflichen Umorientierung fand bei ihm auch eine schulische Umorientierung vom Gymnasium hin zur Fachoberschule statt. Die Entscheidung, nach der Grundschule ein Gymnasium zu besuchen, war maßgeblich von Dominic selbst ausgegangen, wie er erzählt: ,, [M]eine Eltern ham auch erst überlegt ob sie mich auf ne Realschule äh schicken oder auf ne Gesamtschule.. aber ich wollte halt eben unbedingt auch auf die [Gymnasialschule A] gehen weil mein Bruder äh da halt eben auch war." Weshalb die Eltern diese Überlegungen angestellt haben, bleibt offen: Möglicherweise waren sie aufgrund seiner bisherigen Grundschulleistungen davon ausgegangen, Dominic könnte auf einer Gesamt- oder Realschule besser aufgehoben sein. Das würde dafür sprechen, dass seine Eltern nicht um jeden Preis einen möglichst hohen Schulabschluss für ihn 
angestrebt haben. Stattdessen haben sie sich an Dominics Wünschen orientiert, der unbedingt auf die Gymnasialschule wollte, auf der bereits sein zwei Jahre älterer Bruder war. Der Weg hin zur allgemeinen Hochschulreife war außerdem Voraussetzung für Dominics Ziel, Polizist zu werden. Die Zeit auf dem Gymnasium beschreibt Dominic als anstrengende, ,harte Zeit“: Er gehörte zum ersten G8-Jahrgang seiner Schule und bezeichnet diesen als „Versuchskaninchen“. Seine Freizeit verbringt er überwiegend mit Lernen, um in der Schule mithalten zu können (,[U]nd ich bin von der Schule heimgekommen, saß bis abends um sechs, bis es Abendessen gab, am Schreibtisch und mit Freunde treffen war nich so viel, generell in der ganzen.. G8-Zeit“). Er musste sich „zusammenreißen“ und „durchbeißen“ und die neunte Klasse wiederholen. Gleichzeitig kritisiert er auch den sozialen Umgang in der Schule: Dort gab es zwischen den Schüler*innen viel „Mobbing“, der Umgang mit den Lehrkräften war distanziert (,[M]an hat sich aufm Gang begrüßs, mehr aber auch nich“) und sogar gleichgültig: „,[I]ch bin hintenrunter gefallen und des hat die Lehrer im Prinzip nich so wirklich gejuckt.“

Positiv an der Gymnasialzeit erinnert Dominic, dass er dort seinen heute besten Freund kennengelernt hat (,[W]ar der Erste der mich.. aufgenommen hat") und mit dem eine ,wunderbare Freundschaft entstanden “ ist. Dominic betont, dass er „,wirklich der allerbeste Freund is, den ich hab“ und dass dieser ihn ,auch in dem Weg, den ich (...) eingeschlagen hab, auch äh großartig unterstützt" - dafür ist er ihm „dankbar“. Auch im weiteren Verlauf thematisiert Dominic seinen besten ,Kumpel' immer wieder - diese Freundschaft scheint für ihn sehr wichtig zu sein. Besonders fällt auf, wie positiv und emotional diese Erzählpassagen sind. Dass er diese Freundschaft derart wertschätzt, wie er sie beschreibt und immer wieder erwähnt verdeutlicht Dominics Orientierung hin zu Gemeinschaft und Zusammenhalt.

Nach der für ihn schwierigen Zeit auf dem Gymnasium wechselt er nach der zehnten Klasse auf eine Fachoberschule. Er hat sich also schon mit etwa siebzehn Jahren für die Fachrichtung entschieden, in der er sein Fachabitur absolvieren will. Für ihn ist schnell klar, dass er einen sozialen Abschluss machen will, denn ihm wurde „...sowohl von Freunden als auch Familie, Bekannten gesacht gekriegt, hier des Soziale liegt dir doch, geh doch ins Sozialwesen als.. Fachrichtung“, was er bereits in seiner Eingangserzählung betont. Diese Empfehlung und Einschätzung seines Umfelds, dass ihm eine soziale Fachrichtung so läge, erwähnt er während des Interviews immer wieder (,,[D]es Soziale ham mir so viele Leute gesagt, des würde mir liegen“; „Er [der beste Freund, L.L.] war zum Beispiel auch einer derjenigen, die gesacht ham du bist so sozial eingestellt“). Die Rückmeldungen aus der Gemeinschaft prägen seine Entscheidung maßgeblich 
und bestärken ihn. Gleichzeitig informiert er sich auch über andere Fachrichtungen, allerdings glaubt er, „was Elektrotechnik und so weiter angeht des is mir zu hoch, da bin ich irgendwie nich ganz aufm Level“. Letztendlich macht er sein soziales Fachabitur ,mit nem Schnitt von 2,1 wo man... sehr zufrieden sein kann.“ Damit zeichnet sich auf mehreren Ebenen ab, dass Dominic mehrmals an seine Grenzen gestoßen ist und diese realistisch akzeptiert hat, nicht zwangsläufig nach dem höchsten Abschluss strebt, sondern sich nach seinen Interessen und der Einschätzung seines Umfeld richtet und so den Weg hin zur Fachhochschulreife im sozialen Bereich wählt. Mit Rückblick auf die Überlegung seiner Eltern, ihn direkt nach der Grundschule auf eine Gesamt- oder Realschule zu schicken, verdichtet auch der Schulwechsel die Vermutung, dass sie seine geringe Passung für ein Gymnasium möglicherweise schon früher, geahnt' haben.

Seine Schulerfahrungen an der Fachoberschule unterscheiden sich grundlegend von denen im Gymnasium: Dort sei „,alles komplett anders, war viel lockerer“ und die praxisorientierte Abwechslung von Schulunterricht und Praktikum - in seinem Fall in der Schulbetreuung - gefällt Dominic besonders gut (,,[D]dann drei Tage Praktikum, zwei Tage Schule in der Woche gehabt, da war immer Montag bis Mittwoch Praktikum und Donnerstag Freitag war Schule.. und das fand ich war relativ entspannt gewesen"). Zum anderen seien auch die Lehrkräfte völlig anders gewesen, ,, alle total entspannt drauf“ und was ihn ,,dort an der Schule so begeistert hat war. dass jeder Lehrer drauf geachtet hat dass kein Schüler hintenrunter fällt"،, indem beispielsweise Themen im Unterricht für Einzelpersonen wiederholt werden. Auf der ehemaligen Gymnasialschule sei das ,nie möglich gewesen", schätzt Dominic ein. Das unterstützende und zugewandte Verhältnis zwischen Lehrkräften und Schüler*innen, gegenseitige Rücksichtnahme und der Gemeinschaftssinn in der Fachoberschule scheinen zu Dominic viel besser zu ,passen“ als die auf Leistung und das Erlangen des Abiturs gerichtete Pädagogik seines Gymnasiums.

Einige seiner ehemaligen Schulkamerad*innen von der Fachoberschule trifft er im ersten Semester des Studiums wieder:

„(...) [U]nd ähm des hat auf jeden Fall schon mich sehr gefreut.. und da hat man halt eben auch son Anker, okay da is man jetzt nich komplett alleine und.. an der Hochschule [Hierstadt], die is ja bekannt äh dass sie relativ groß is, da geht man ja teilweise vielleicht auchn Stückchen unter weil so viele Menschenmassen da sind, werde teilweise in der Bahn auch angesprochen ,Hier du warst doch äh bei mir in der und der Vorlesung', ich guck ihn dann an, ,Woher kennen wir uns $i$, , ja seis vom Stadion oder sonstwas, ich kenn so viele Leute und.. durch die Hochschule isses halt eben noch mehr geworden.. und dadurch, dass man halt eben dort viele äh noch von der alten Schule her kennt, kann man sich halt eben auch besser austauschen, 
ne.. und hat vielleicht dann auchn Anker, Okay lass doch mal zusammen lernen".

Und natürlich hab ich auch viele neue nette Leute kenngelernt und joa.“

Dominic bezeichnet die alten Schulkamerad*innen zwei Mal als „Anker“, die für ihn eine Unterstützung an der neuen Hochschule sind, wo er Angst hat, in den „Menschenmassen unterzugehen“. Es schwingt deutlicher Stolz mit, wenn er davon berichtet, dass er „so viele Leute kennt“", sei es durch die Schule, Hochschule oder das Fußballstadion (in dem er ehrenamtlich tätig ist). Es wirkt beinahe, als stelle er sich als ,Lokalprominenz' dar, die sogar schon in der Bahn von Fremden angesprochen wird. Das Gesehen-werden und Eingebunden-sein in eine Gemeinschaft bedeuten für Dominic gleichzeitig Sicherheit, Aufwertung und Anerkennung und sind für ihn zentrale Orientierungspunkte.

\section{Studien(fach)wahl im Kontext der Herkunftsfamilie}

Wie sich schon in Dominics Übergang auf die weiterführende Schule angedeutet hat, wird in seiner Herkunftsfamilie ein kooperativer Umgang mit bildungsbezogenen Entscheidungen gepflegt, in dessen Rahmen sich seine Eltern an seinen Wünschen orientieren. Das zeigt sich auch in seiner krisenhaften Zeit am Gymnasium: Dort haben sie „zusammen als Familie ne Schullaufbahnberatung (...) wahrgenommen“ um „als Familie en neuen Weg zu finden“. Die Entscheidung, auf eine Fachoberschule mit sozialer Fachausrichtung zu wechseln, nimmt Dominic rückblickend ebenso als Überlegung wahr, die „zusammen“ angestellt wurde. Dass seine Eltern ihn in der Schullaufbahnberatung und bei dem Wechsel auf die Fachoberschule unterstützen, bestärkt den Eindruck eines gemeinschaftlichen, kooperativen Umgangs mit ihren Kindern. Sie treffen Bildungsentscheidungen mit ihnen gemeinsam und orientieren sich dabei nicht an einem möglichst hohen Abschluss, sondern den Ressourcen ihrer Söhne.

Auch die an die Fachoberschule anschließende Entscheidung von Dominic, Soziale Arbeit zu studieren, befürworten seine Eltern. Nicht nur wegen ihrer Einschätzung, dass dieser Bereich ihm besonders läge, sondern auch ,[w]eil.. meine Eltern wollten gar nich, dass ich zur Polizei geh. Meine Mutter hatte da.. Riesenangst wenn ich zur Polizei gegangen wär, mein Vater. hat von Anfang an gesagt, dass es.. bei mir nich möglich wär zur Polizei zugehen. Der hat mir des eher auch son bisschen kaputt geredet, zumindest versucht. Auch wo ich des Praktikum bei der Polizei machen wollte war er auch.. strikt dagegen, hats aber dann dennoch zugelassen Gott sei Dank". Hier zeichnet sich ab, dass seine Eltern ihm aus Fürsorge vom Polizeiberuf abraten: Seiner Mutter schreibt Dominic hier eine beschützende Perspektive zu, sein Vater dagegen wollte womöglich eine Enttäuschung vermeiden, da er die einseitige Gehörlosigkeit seines Sohns schon als 
Grund für eine Ablehnung bei der Polizei vermutete. An späterer Stelle schätzt Dominic außerdem, sein Vater habe ihm vom Polizeiberuf auch aus eigener Erfahrung abgeraten: Er hatte nach seiner Schulzeit am verpflichtenden Wehrdienst teilgenommen und wisse daher, bezogen auf den militärischen Bereich, ,was da in dem Beruf abgehen kann ". Im Resultat sehen die Eltern Dominic nicht (gerne) in der Position eines Polizisten. Was sich im Umgang mit seiner Schullaufbahn angedeutet hat - der gemeinschaftliche Entscheidungsprozess und die Unterstützung der Entscheidungen von Dominic - findet hier also zum Teil seine Grenzen, gerade was die Darstellung des Vaters angeht, der von Dominic in einer restriktiven, bestimmenden Rolle gezeichnet wird (,,kaputt geredet“, „strikt dagegen“). Im Gegensatz zur Mutter wird ihm damit eine maßgebliche Entscheidungsposition zugeschrieben. Im Endeffekt lassen beide Eltern aber Dominics Wunsch zu, sich für ein Polizeipraktikum zu bewerben - später sichtbar erleichtert, dass er für diesen Beruf aus genannten gesundheitlichen Gründen nicht zugelassen wird und stattdessen das Studium der Sozialen Arbeit beginnt.

Die Einbettung von Dominics Studien(fach)wahl in seine Herkunftsfamilie deutet darauf hin, dass bildungsbezogene Praktiken, die einer akademischen Ausbildung nahe sind, in seiner Familie bereits angelegt sind und entsprechende Bildungswege von den Eltern nicht erwartet, aber unterstützt werden: Sie beraten und begleiten Dominic umfassend und gehen mit ihm so den Weg zur Hochschule sozusagen gemeinsam.

Erkenntnisreich ist außerdem noch Dominics Perspektive auf seinen älteren Bruder, der im dritten Semester Jura studiert, was für Dominic ein „sehr anspruchsvoller Studiengang “ ist. Dieses Fach hätte er sich auch für sein Studium grundsätzlich vorstellen können, weil er viele Schnittstellen zur Polizeiarbeit sieht, aber auch hier sind Ratschläge aus seinem sozialen Umfeld maßgeblich für ihn: „, [A]ber da mir so viele Leute gesagt haben, Jura das issn furztrockenes Fach und wirklich nur Paragraphen und Paragraphen' und ähm, da hamse gesagt ich soll mir doch lieber etwas lebhafteres.. aussuchen und da ich wie gesagt durch des ähm Fachabitur so viel Spaß an der Sozialen Arbeit bekommen hab, wärs für mich überhaupt gar kein Thema mehr gewesen jetzt ins Jurastudium einzusteigen. "Zum einen zeigt sich hier ein anerkennender Blick von Dominic hin zum juristischen Studium, zum anderen schließt er sich den Ratschlägen seines sozialen Umfeld an und grenzt sich von den abstrakten Inhalten des Jurastudiums ab und plausibiliert so seinen bereits begonnenen Weg in die Soziale Arbeit als "lebhafteres" Fach als den passenden für ihn - ein Begriff, der an dieser Stelle nicht konkretisiert wird. Möglicherweise basiert diese Bewertung auf der Unterscheidung von praxisnahen und anwendungsbezogenen Fächern und Berufen (Soziale Arbeit, Polizei), die nach Dominics sozialem Umfeld gut zu ihm 
passen, und von eher abstrakten bzw. voraussetzungsvollen Fächern, die diszipliniertes Lernen erfordern und in denen auch Dominic selbst sich nicht sieht (Jura, Elektrotechnik).

\section{Studien(fach)wahl und antizipierte Zukunft}

Auf die Frage, wie sich Dominic seinen Traumjob in der Sozialen Arbeit vorstelle, antwortet er ohne langes Überlegen mit drei möglichen Handlungsfeldern: Zum einen könnte er sich vorstellen, in der Familienhilfe zu arbeiten. Diese Tätigkeit wurde erst in der vorigen Woche in einer Vorlesung thematisiert und hat ihn offensichtlich begeistert. Er beschreibt, dass er in der Familienhilfe ,... mit in die Familien gehen [könnte],..die Probleme zum Beispiel mit Kindererziehung haben oder sei es wenn ein Elternteil verstorben is un.. der andere Elternteil momentan überfordert is, dass man einfach Unterstützung hat". Zum anderen benennt Dominic ein „Jugendhaus“ als potentielles Betätigungsfeld: Dort würde er mit Kindern und Jugendlichen arbeiten, ,, sei es wenn irgendwelche Jugendliche aus (...) dem Familienhaus rausgehen müssen.. oder. Waisenkinder geworden sind". Und schließlich kommt für ihn als dritter ,Traumjob" noch in Frage, im „Fanprojekt“ des örtlichen Fußballvereins mitzuwirken. Dort sind mehrere Sozialarbeiter*innen hauptamtlich beschäftigt und organisieren verschiedene soziale und kulturelle Angebote und Veranstaltungen für die Fangemeinschaft, insbesondere für Kinder und Jugendliche. Dominic hofft, dass er in diesem Beruf „Fußball und Arbeit in einem " verbinden kann.

Diese Berufsvorstellungen weisen auf Mehreres hin: Dominic orientiert sich an aktuellen Vorlesungsinhalten in seinem Studium; er ist also noch nicht festgelegt, was seine berufliche Zukunft angeht, sondern lässt sich von neuen Informationen und Einblicken im Studium leiten. Seine beruflichen Vorstellungen sind - etwa im Vergleich zu Achim, der eine konkrete Position und Tätigkeit in einem bestimmten Handlungsfeld vor Augen hat - nur grob begrenzt. Verbindendes Element der drei genannten Tätigkeit ist wiederum die Zielgruppe von Kindern und Jugendlichen, die er schon in seinem Praktikum in der Schulbetreuung kennengelernt hat und in dem er "riesenviel Spaß (...) entwickelt hat mit der Arbeit mit den Kindern“. Was genau er sich von dieser Arbeit erhofft, beschreibt er folgendermaßen:

„Ich stell mir im Prinzip vor, dass ich an dem Tag jemandem helfen konnte, dass ich en guten Job gemacht habe und dass meine Hilfe auch angenommen wird und auch des Gefühl zu haben, man wird im, im Prinzip gebraucht. Und.. anderen Menschen zu helfen, des.. des gibt ja en ganz besonderes Gefühl. In.. zum Beispiel Familien die ziemliche Probleme ham, wenn die in ein, zwei Jahren ihr Leben wieder komplett im Griff haben, wieder auf beiden Beinen stehen, und wenn man 
ich nenns mal Projekt, wenn man dieses fertige Projekt dann wieder äh entlässt, dann sieht man okay, des hab ich jetzt geleistet.“

Dominic möchte ,helfen“, was für ihn bedeutet: Er möchte ,gebraucht" werden und beschreibt dabei die antizipierte Arbeit mit seinen Klient*innen als „Projekt“, das er vorantreibt und dessen Erfolg er als das Ergebnis seiner eigenen Leistung betrachtet. Zugleich spielt auch hier ein emotionaler Aspekt von gemeinschaftlicher Unterstützung eine Rolle für ihn. Im Vergleich zu Achim sind Dominics Vorstellungen von der Sozialen Arbeit allerdings nicht derart ergebnisoffen, sondern normativer geprägt und er wirft einen eher defizitären Blick auf seine Klient*innen, deren Probleme er bearbeiten will. Dominic konstruiert hier durchaus ein hierarchisches Verhältnis, innerhalb dessen er seine Klient*innen als „fertige[s] Projekt (...) entlässt“ und sich als ,Freund und Helfer' zeichnet, dessen Hilfe dankbar angenommen wird - der möglichen Interpretation der Position eines Polizisten nicht unähnlich. Zusätzlich schwingt ein Verständnis von seiner Tätigkeit als Sozialarbeiter mit einer Ordnungsfunktion mit: In einigen der von Dominic erwähnten Tätigkeiten (Familienhelfer, Jugendheim) sieht er sich in einem sozialen Kontext, der , aus den Fugen geraten' ist und den er wieder ,richten“ würde. Sein Blick auf die Klient*innen als „Projekt“ bestärkt diesen Eindruck.

Dieses Motiv prägt auch seine Überlegung, im Fanprojekt des Fußballvereins tätig zu sein. In diesem Verein engagiert er sich ehrenamtlich und leitet dort seit einigen Jahren den Verkauf von Öffentlichkeitsmaterial im Stadion. Er hat ein „feststehendes Team “ und „fünf Stände zu betreuen“ und investiert viele Stunden wöchentlich in diese Tätigkeit, die ihn von der Arbeit im Fußballverein begeistert. Warum er sich dort so einbringt, bringt er auf den Punkt: Das ist für ihn ,Ausgleich“ und „Freude“, denn im Stadion ,,werd ich anerkannt“. Dominic möchte gesehen und anerkannt werden - eine gewisse Disposition hin zu Macht und Status schwingt erneut mit.

Was sein Privatleben in zehn Jahren angeht, hat Dominic klare Vorstellungen: Bis dahin möchte er ,,hoffentlich [eine] Frau“ haben und vielleicht ist ,dann auch (...) des erste Kind unterwegs “. Auf die Frage hin, ob er zur Erziehung zu Hause bleiben möchte, antwortet er:

„Würde mir auf jeden Fall auch äh Elternzeit auch nehmen, um natürlich auch dann meine Frau äh auch zu unterstützen, grade auch dann in der Anfangszeit äh was äh ziemlich schwer is, wenn grade halt eben son Neugeborenes da is und da is ja Familienzusammenhalt wirklich sehr sehr wichtig. Und mir persönlich ist jetzt auch äh Familienzusammenhalt und Freunde auch sehr wichtig. Von daher würde 
ich des natürlich auch weiterleben wollen.. äh den engen Familienzusammenhalt und.. da hab ich dann schon meine Prioritäten."

Dominics Vorstellungen über die gemeinsame Erziehung zeigen zum einen, dass hier heteronormative Zuständigkeitszuschreibungen wirken, wenn Dominic davon spricht, seine Frau ,, unterstützen“ zu wollen, womit er impliziert, dass die Hauptverantwortung für die Familienarbeit bei ihr liegt. Gleichzeitig möchte er sich in diese Aufgaben einbringen, was zwar keine egalitäre, aber zumindest eine beteiligende Vorstellung der Familienarbeit ist. Auch hier ist wieder deutlich, wie sehr Dominic den Wert von Gemeinschaft in den Vordergrund rückt: Dass „,Familienzusammenhalt sehr sehr wichtig“ und „Freunde auch sehr wichtig“ sind, betont und wiederholt er mehrere Male. Es ist klar: Dominic hat - wie er selbst sagt - seine „Prioritäten“, die auf einem funktionierenden sozialen Netz, Rückhalt, Unterstützung und seiner Rolle als anerkannter, unterstützender Teil dieser Gemeinschaft liegen. Gleichzeitig sind materielle Güter nicht in Dominics Fokus, denn er „,brauche keinen Lamborghini vor der Tür“, sondern es genügt ihm der Luxus, hin und wieder zwei Wochen Urlaub in Kroatien zu verbringen - materiell präsentiert Dominic sich als bescheiden.

Diese Prioritäten und eine gewisse Bescheidenheit kommen auch zum Tragen, wenn er beschreibt, dass es ihm im Leben darauf ankommt, „(...) zufrieden zu sein mit dem was man tut, was man vor allem auch hat. Und.. dass man auch.. emotionale Nähe hat, sei es von Freunden, sei es von Familie.. und auch Rückhalt hat." Auch seine drei Wünsche orientieren sich maßgeblich an den Werten von Gemeinschaft und Rückhalt: Zum einen wünscht er sich, „wirklich eine glückliche Familie zu haben“, zum anderen, „, die Freunde die man jetzt hat bis zum Lebensende zu haben " - hier erwähnt er noch explizit seinen besten Freund - und schließlich, dass „Hierstadt die Championsleague gewinnt ((lacht))“.

\section{Habitus, Studien(fach)wahl und Milieuspezifika}

Für Dominic ist die Soziale Arbeit der ,Plan B', weil er seinen Traumberuf des Polizisten aus gesundheitlichen Gründen nicht ergreifen kann. Sie ist außerdem das Resultat seiner schulischen Umorientierung weg vom Abitur an einem Gymnasium hin zu einer Fachoberschule mit sozialem Schwerpunkt eine Umorientierung, die von seinen Eltern in einem kooperativen Umgang unterstützt wurde. Für sie war nicht die Orientierung an einem möglichst hohen Bildungstitel ihres Sohnes handlungsleitend, sondern an seinen Ressourcen und Interessen. Diese Disposition hin zu einem kooperativen Miteinander spiegelt sich auch in Dominics Bewertungen der beiden Schulsysteme wieder, bei denen er 
besonders den egalitären, rücksichtsvollen Umgang der Lehrkräfte an der Fachoberschule schätzt und sich von der leistungsorientierten, Ellbogenmentalität ' der Gymnasialschule distanziert. Die Gemeinschaft spielt für Dominic allgemein eine zentrale Rolle: Sie ist für sie ein „Anker“, verkörpert durch die ehemaligen Mitschüler*innen an der Hochschule, und strukturiert sein Leben maßgeblich mit, wie etwa die für ihn sehr bedeutsame Beziehung zu seinem besten Freund. Ratschläge von den ihm nahestehenden Personen prägen auch sein Selbstbild und seinen beruflichen Weg: Dass ihm „,das Soziale liegt“, wird ihm mehrfach bestätigt und er geht deshalb, unterstützt von Freund*innen und Familie, nach seiner krisenhaften Gymnasialzeit den Weg hin zum Studium der Sozialen Arbeit.

Elemente der Vergeschlechtlichung von Dominics Studien(fach)wahl zeigen sich erstens darin, dass er seinen Vater im Kontext des Polizeiberufs in einer vergleichsweise restriktiveren Entscheidungsposition wahrgenommen hat als seine Mutter - letztendlich fand aber auch hier eine Orientierung an Dominics Wünschen von Seiten des Vaters statt. Zweitens ist die Gründung einer eigenen Familie für Dominic ein fester Wunsch, in deren Rahmen er die schwerpunktmäßige Zuständigkeit für Sorgearbeit auf der Seite seiner künftigen Frau sieht. Gleichzeitig ist seine Beteiligung daran eine fixe Größe, denn auch hier kommt seine Orientierung an Familienzusammenhalt und Gemeinschaft zum Tragen. So lassen sich zwar Tendenzen der vergeschlechtlichten Arbeitsteilung erkennen, die aber weit entfernt sind von klaren Zuständigkeiten und Kompetenzzuschreibungen wie im Fall von Michael - und gleichzeitig weniger offen sind als die von Achim.

In die Antizipation seiner beruflichen Zukunft dagegen tritt noch eine weitere Dimension jenseits von der Orientierung an Gemeinschaft und Zusammenhalt: Dominic möchte seinen Klient*innen „,helfen“, will aber auch dass diese Hilfe „angenommen“ wird und dass er ,gebraucht" wird - die Anerkennung seiner Hilfe ist damit für ihn ein entscheidendes Element seiner Berufsvorstellungen. Zugleich zeichnet er sich hier in einer Machtposition, nach der er den möglichen ,Erfolg' seiner Klient*innen seiner eigenen Leistung zuschreibt. Diese Anerkennung ist für ihn auch Antrieb, sich so zeitintensiv seinem Ehrenamt im Fußballstadion zu widmen. Eine Disposition hin zu Macht und Status ist also durchaus erkennbar und sie hat das Potential zum Widerspruch mit Dominics kooperativen und gemeinschaftlichen Handlungsorientierungen - so kommen all diese Habituszüge zusammen in seinen beiden Berufswünschen des Polizisten und des Sozialarbeiters, die vor diesem Hintergrund in der Figur des ,Freund und Helfers', der von seiner Umgebung gebraucht und anerkannt wird, kumulieren. Dabei scheint er die Welt seiner Klient*innen wieder, in Ordnung ' zu bringen, indem er sie unterstützt und dann als ,fertige[s] Projekt" wieder entlässt. 
Damit ist die Offenheit der beruflichen Entwicklung im Kontext von vergeschlechtlichten Habitusmustern bei Dominic größer als bei Michael, dessen Weg als ,Mann der Familie' schon vorgezeichnet scheint, aber kleiner als bei Achim, dessen Berufswahl nicht von den Dimensionen von Macht und Status strukturiert ist.

Zusammenfassend sprechen Dominics habitusspezifische Muster für eine Verortung des Falls ,zwischen' den anderen beiden männlichen Fällen Achim und Michael: Auch bei Dominic zeichnet sich eine Orientierung am Leistungsprinzip ab und prägt seine Berufsvorstellungen. Gleichzeitig spielt die Orientierung an Anerkennung von außen, an Status und Macht eine gewisse Rolle. Diese Habituszüge führen mit Dominics Disposition hin zu einem kooperativen, gemeinschaftlichen Umgang und mit den zentralen Werten von Freundschaft und Familie zur Schlussfolgerung, dass er im mittleren Bereich des Leistungsorientierten Arbeitnehmermilieus (siehe auch Vester 2015: 162 ff.) zu verorten ist, gleichwohl sich bei ihm auch Spuren eines ständisch-kleinbürgerlichen Habitus abzeichnen.

\subsection{Fall Rebecca: „[W]eil viele einfach nur wirklich Kindergärtnerin oder Lehrer im Kopf ham und (...) des is furchtbar"}

\section{Kurzeinführung in den Fall}

Das Interview mit Rebecca dauert etwa 70 Minuten. Das Gespräch war allgemein von Rebeccas eindringlichem und emotionalem Sprachstil geprägt: Sie setzt häufig Betonungen, unterstreicht ihre Aussagen durch entsprechende Gestiken, sie ,schnaubt' und , seufzt' mehrmals. An einigen Stellen scheint sie besonders emotional involviert, etwa wenn es um Situationen in ihrem Freiwilligem Sozialen Jahr in einer Schule ging, auf die sie mit Fassungslosigkeit zurückblickt: „[E]s war erschreckend, wie viele Kinder da einfach schon richtig großeProbleme ham. Wir hatten ein Kind, des hat uns gedroht sich UMZUBRINGEN. In der zweit-ne es war in der DRITTEN KLASSE. “ Ihr auffälliger Sprachstil beim Berichten von Situationen, in denen die Welt für sie ,nicht in Ordnung ist", durchzieht mehrere Passagen des Interviews.

Davon abgesehen ringt Rebecca auch immer wieder um Worte: Sie vertauscht gegensätzliche Adjektive (beschreibt etwa die Soziologie als ,zu praktisch ' und korrigiert dies dann zu ,theoretisch ' oder wählt zuerst den Begriff ,Zukunft', wenn sie sich auf ihre, Vergangenheit' bezieht), bricht Worte ab und präzisiert Begriffe. 
Rebecca scheint, etwas zu sagen` zu haben, ihre (Über-)Betonungen und langen, emotionalen Erzählpassagen lassen ihre Erzählungen teilweise dramatisch und eindringlich wirken.

\section{Kurzeinführung in den Fall}

Rebecca ist zum Zeitpunkt des Interviews 20 Jahre alt und studiert im ersten Semester Soziale Arbeit. Ihr Vater hat als höchsten Bildungsabschluss die Fachhochschulreife und Kunststofftechnik an der gleichen Hochschule studiert, an der auch Rebecca eingeschrieben ist. Heute ist er als Kunststoffingenieur selbstständig tätig. Rebeccas Mutter hat die allgemeine Hochschulreife und eine Ausbildung zur Chemielaborantin abgeschlossen. Nachdem sie einige Jahre in diesem Beruf gearbeitet hat, musste sie sich aus gesundheitlichen Gründen beruflich umorientieren. Sie hat sich zur Steuerfachkraft weiterbilden lassen und ist heute ebenfalls selbstständig, mit einem eigenen Handarbeitsladen.

Rebecca hat noch eine ältere Schwester, die ihre Mittlere Reife und im Anschluss eine Ausbildung zur Bürokauffrau absolviert hat. In diesem Beruf wollte sie allerdings nicht bleiben, sondern hat ihr Fachabitur nachgeholt und die Ausbildung zur staatlich anerkannten Grafikdesignerin gemacht. In diesem Feld ist sie nun tätig.

Rebecca selbst hat ihr Abitur auf einem Gymnasium absolviert, anschließend ein Freiwilliges Soziales Jahr in einer Schule durchlaufen und danach ihr Studium begonnen. Sie wohnt zurzeit noch bei ihren Eltern, will aber mit ihrem Partner zusammenziehen, mit dem sie seit acht Monaten eine Beziehung führt. Er studiert Informationsrecht im dritten Semester - ein Studiengang mit juristischem Abschluss - an der gleichen Hochschule wie Rebecca.

\section{Weg hin zum Studium}

Rebecca beginnt ihre Erzählungen damit, dass ihre Wahl auf die Soziale Arbeit erst seit Kurzem feststeht - vorher hatte sie überlegt, Kommunikationsdesign zu studieren. Wie sie dazu kommt, erläutert sie im späteren Gesprächsverlauf: „,II]ch bin künstlerisch halt sehr viel tätig und mach des auch sehr gerne und ähm.. da kam ich dann halt auf die Idee, als ich nach Studiengängen gesucht hab in dem Bereich Kommunikationsdesign zu studiern." Ihre künstlerischen Tätigkeiten konkretisiert sie anschließend mit ,fotografieren" und ,zeichnen“, was ihr „Spaß“" macht, weil „man dann hinterher en Ergebnis hat, was halt auch andere toll finden." Die Freude sowie die Anerkennung durch andere spielt für Rebeccas künstlerische Betätigung also eine Rolle. Gleichzeitig betont sie, das Künstlerische und Handwerkliche sei in ihrer Familie häufig zu finden - von ihrer Mutter über ihren Vater bis hin zum Opa seien viele Personen „handwerklich“ begabt. 
Besonders hebt sie hier ihre Schwester vor: „[S]ie is nochmehr künstlerisch begabt als ich, also die zeichnet einem aus, siehtn Foto und zeichnet es einem getreu ab, also es is wirklich dann, es sieht aus wien Foto. Also die is da richtig gut drin (...). “

Während diese Nähe zu künstlerisch-kreativen Betätigungen Rebeccas Studienfachwahl in Richtung Kommunikationsdesign prägt, entscheidet sie sich letztendlich doch gegen diesen Studiengang, weil ihr die Berufsaussichten in diesem Feld zu unsicher sind (,,Und ähm aber da kam, kam mir relativ schnell nach näherem Überlegen in den Sinn: Na die Berufschancen sind jetzt nich soprickelnd hinterher"). Um eine Alternative zu finden, greift sie auf ihre anderen Erfahrungen mit Tätigkeiten zurück, die ihr ,Spa ${ }^{\text {“ }}$ machen und kommt zu dem Ergebnis: „Und dann hab ich halt so überlegt, was mir sonst noch Spaß macht und ähm seit en paar Jahren hab ich mich halt engagiert ehrenamtlich mit Kindern (...). [U]nd so bin ich dann halt in die Richtung gekommen so man könnte was in dem Bereich machen und ähm ja da hab ich dann halt mal geguckt was es für Bereiche gibt." So kam Rebecca auf „Pädagogik, Soziale Arbeit, Soziologie“ und hat sich für diese Studiengänge an der Universität und der Hochschule für Angewandte Wissenschaften in ihrer Heimatstadt beworben. Sie wurde für alle drei Studiengänge zugelassen, für die Soziale Arbeit allerdings erst im Nachrückverfahren - eine Woche vor Semesterbeginn - und entscheidet sich für dieses Fach. Um diese Entscheidung zu treffen, hat sie vorab die Lehrpläne der drei Fächer recherchiert und der Lehrplan in der Sozialen Arbeit hat sie „wesentlichmehr angesprochen“, weil er „,breitgefächert“ war und Bereiche wie Soziologie, Psychologie und Recht umfasst. Diese Vielfalt habe sie im Lehrplan der Pädagogik nicht gefunden, ,da war wirklich rein theoretisch Pädagogik, Pädagogik, Pädagogik“, während sie in der Soziologie die „Forschung“ zu gesellschaftlichen Fragestellungen spannend fand (,"[W]iehalt die Gesellschaft sich verhält, was man, also wiees zu den ganzen Zuständen kommt, dass zum Beispiel jetzt Traditionen entstanden sind (...)“), ihr dieser Studiengang allerdings „,zu theoretisch“ erschien, denn $\mathrm{zu}$ viel Theorie „langweilt mich, ehrlich gesagt“.

Für Rebeccas Studienfachwahl von Bedeutung ist sowohl ein Sicherheitsdenken wie auch die Freude an der antizipierten beruflichen Tätigkeit. Sie trifft ihre Wahl auf der Grundlage ihrer eigenen Erfahrungen und geht dabei strategisch und planend vor, indem sie unterschiedliche Studieninhalte detailliert vergleicht. Schließlich grenzt sich ab von zu theoretischen, abstrakten Studieninhalten und tendiert hin zu einem praxisorientierten Studium, das ihr eine spätere Tätigkeit mit Kindern und Jugendlichen in Aussicht stellt. Die Soziale Arbeit war dabei also keine willkürliche Entscheidung oder ein Plan B, sondern ihre erste Wahl. Zugleich zieht sie die universitäre Ausbildung nicht der fachhochschulischen 
vor, sondern folgt ihren Interessen und den recherchierten Studieninhalten - das Prestige der Bildungseinrichtung ist für sie nicht maßgeblich.

In ihrem ehrenamtlichen Engagement hat Rebecca zehn Jahre Kinder und Jugendliche in einem Reitverein trainiert. Ihre Erzählungen darüber sind vor allem durch ihre Erfahrung mit ihrer ehemals besten Freundin geprägt, durch die sie zu diesem Verein gekommen ist, mit der sie aber in Streit geraten ist. Sie äußert kritisch darüber, dass diese ehemalige Freundin ein „, absolut verwöhntes Einzelkind“ und „respektlos “ geworden sei ,gegenüber Leuten, die wesentlich ältersind“. Der Umfang dieser Passagen und ihre hohe Erzähldichte weisen auf die Bedeutsamkeit dieses Themenkomplexes für Rebecca hin. Ihre Ausführungen dazu lassen sich als erster Hinweis auf ihre Orientierung an Respekt und Autorität deuten ein Hinweis, dem im weiteren Interview nachgegangen werden soll. Außerdem lässt sich im Reitverein - zu dem sie durch ihre Freundin gekommen ist und in dem Entschluss zur Sozialen Arbeit, der zumindest teilweise von dieser Ehrenamtserfahrung geprägt war, eine Linie der Vergeschlechtlichung in Rebeccas Biografie erahnen, im Rahmen derer sie diese weiblich konnotierten und zahlenmäßig weiblich dominierten Tätigkeiten ausübt. Auch dieser Zusammenhang wird im Folgenden weiterverfolgt.

Parallel zu ihrem ehrenamtlichen Engagement ist Rebecca nach der Grundschule auf ein Gymnasium gewechselt und hat dort ihr Abitur absolviert. Auf die Nachfrage der Interviewerin hin, ob der Wunsch zu studieren für Rebecca sicher war antwortet diese: „Doch, das war mir eigentlich schon von klein auf klar, ja ich bin nach der Vierten direkt aufs Gymnasium gegangen, das wollt ich unbedingt.. und (...) also ich hatte damals schon den Plan, dass ich wirklich Abitur machen möchte.. und dann studieren. "Die Betonung der Sicherheit und der Unbedingtheit ihres „Plans“, zu studieren, könnte sowohl auf ihre Selbstsicherheit hindeuten wie auch eine Inszenierungsstrategie derselben. Der genauere Blick auf ihre Schullaufbahn in der Analyse von Rebeccas Studien(fach)wahl im Kontext ihrer Herkunftsfamilie wird diesen Punkt erneut aufgreifen.

Nach ihrem Abitur schließlich durchläuft Rebecca ein Freiwilliges Soziales Jahr in einer Schule, „um zu wissen, halt ich des überhaupt den ganzen Tag aus, Kinder zu ertragen ((lacht))“ und stellt dort fest: „[I]ch kannden ganzen Tag schreiende Kinder um mich haben und es lässt mich eigentlich relativ locker. " Auch hier konstruiert sie das Bild eines geplanten, methodischen Vorgehens, indem sie ihre Eignung für die Arbeit mit Kindern und Jugendlichen geprüft habe um ihre beruflichen Überlegungen abzusichern. Gleichzeitig kommt sie in der Arbeit mit den Schulklassen an ihre Grenzen, zum einen aufgrund der Menge an 25 Schüler*innen, zum anderen weil sie einige Schüler*innen als

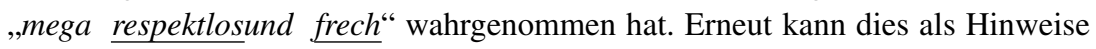


auf Rebeccas Orientierung an Respekt und klaren Hierarchien gelesen werden, allerdings wäre auch möglich, dass sie das Verhalten der Schüler*innen vor dem Hintergrund eines egalitären Anspruchs kritisiert. Im Ergebnis beschließt sie, beruflich lieber mit kleineren Gruppen oder Einzelpersonen arbeiten zu wollen.

Schließlich sichert Rebecca ihre Berufswahl und den Übergang nach der Schule nicht nur durch ihr FSJ und ihre Bewerbung für drei unterschiedliche Studiengänge $\mathrm{ab}$, sondern sie hatte früher auch einen alternativen Berufsplan, falls sie für ein Studium gar nicht aufgenommen werden sollte. Dann hätte sie Polizistin werden wollen (was ihr wegen eines Bänderrisses allerdings zum potentiellen Zeitpunkt der Bewerbung nicht möglich war), ,[w]eil ich will dann nich ohnewas dastehen und nixmachen “, ,, das is mir zu unsicher “. Die Polizei bezeichnet sie als „spannende Alternative“, weil sie auch dort „,mit Menschen arbeiten “ könne und auch diese Arbeit einen „sozialen Hintergrund“ habe. Sie konstruiert den Polizeiberuf hier im Sinne eines ,Freund und Helfers', während die Machtposition einer Polizistin verknüpft sein mag mit Rebeccas bereits angeklungener Orientierung an Respekt, Autoritäten, Ordnung und klaren Hierarchien: In einer Position als Lehrerin ist der Respekt der Schüler*innen nicht selbstverständlich, sondern ein Resultat von Aushandlungs- und Beziehungsarbeit. Die Position der Polizistin dagegen ist von staatlicher Seite aus mit einem entsprechenden Status und Handlungsbefugnissen versehen, die dazu ermächtigen, , für Ordnung zu sorgen`.

\section{Studien(fach)wahl im Kontext der Herkunftsfamilie}

Die nähere Betrachtung von Rebeccas Schullaufbahn verweist auf die Rolle ihrer Eltern und auf ein - wenn nicht das - zentrale Thema ihrer Erzählungen: die ADHS-Diagnose in ihrer Kindheit. Ihre Erkrankung thematisiert sie immer wieder und betont, wie schwierig deshalb ihre Schulzeit war. Sie beschreibt, dass sie ,extremst verhaltensauffällig “ war, ,also wirklich ziemlich stark“. Es war für sie „extremst schwierig mim Lernen“ und „das Ganze ging so weit, dass [sie] im Unterricht aufgestanden [ist], weil [sie] nicht mehr sitzen konnte". Rebeccas Sozialleben wurde dadurch stark belastet: Sie spricht von ,[heftigem] Mobbing“ durch ihre Mitschüler*innen, das sich durch ihre gesamte Grundschulzeit gezogen hat. Rebecca versucht an dieser Stelle, das Zustandekommen ihres Interesses an Psychologie durch ihre ,Mobbingerfahrungen“ zu erklären (,[ [ $\underline{\text { ] }}$ arummachen die des eigentlich, warumähm mobben die sich jetzt gegenseitig. (...) Des sind dann auch schon so Sachen, die mich auch in dem Alter schon intressiert hatten. Wo ich dann eigentlich dann mich auch sehr für Psychologie intressiert hab"). Möglicherweise lässt sich ihre distanzierte Fragestellung ,, Warum machen die des eigentlich “ vor dem Hintergrund dieser biografischen Erfahrung eher als personalisierte Frage deuten und sie will eigentlich wissen: ,Warum machen die des 
eigentlich mit mir $\underset{i}{.}$. Ihr Interesse an Psychologie wirkt in diesem Licht wie ein Interesse an Erklärungen für ihren eigenen Biografieverlauf.

Die Krankheit wurde bei ihr in der ersten Klasse diagnostiziert, woraufhin ihre Eltern „,nich (...) lange gewartet [haben] mit irgendwelchen Therapien, die hams wirklich gleich angegangen“. Sie haben „,dafür gekämpft, dass ich auf ne normale (...) Schule gehen kann “ und dass sie ,, in den Verein gut integriert “ ist. Rebeccas Engagement im Reitverein wurde also auch von ihren Eltern gefördert. Rebecca hat so von der ersten bis zur achten Klasse durchgängig Therapien besucht und wurde mit Ritalin behandelt. Ihre Eltern haben „Zusatzunterricht organisiert“ und ihre Mutter hat mit ihr „sehr viel gelernt" und „lesen geübt“. Auch eine „Kunsttherapie“ hat sie gemacht und habe so ihr Verhältnis zu künstlerischer Betätigung nochmals intensiviert. Rückblickend stellt Rebecca in Anbetracht der vielfältigen Unterstützung durch ihre Eltern fest: „Ohne die ganzen Sachen hätt ich auchs Abi nie gepackt. (...) [D]es Ganze hat halt wirklich im Nachhinein kann ich da einfach nur dankbar drüber sein, weil.. des Ganze hat dazu geholfen, dass ich dann einfach (...) in der Oberstufe einfach überall mitgekommen bin“.

All diese Hinweise darauf, wie Rebeccas Eltern mit ihrer ADHS-Erkrankung umgegangen sind und wie Rebecca das heute bewertet, sind sehr aufschlussreich was den Stellenwert von (institutionalisierter) Bildung und die konkrete Bildungspraxis in der Familie angeht. Ihre Eltern haben dafür ,gekämpft", dass Rebecca auf eine Regelschule gehen kann und dass sie in ihren Sportverein ,gut integriert“ ist - sie haben ,nicht lange gewartet“ mit Therapien und Unterstützungsangeboten: Offenbar haben Rebeccas Eltern eine spezifische soziale Laufbahn für sie antizipiert, diese durch das ADHS bedroht gesehen und in der Folge umfangreihe Stützmaßnahmen initiiert. Dieser ,Kampf " spricht auch für eine gewisse Unsicherheit. Dies lässt sich als Kontrast zum familiären Umgang mit schulischer Bildung im Fall von Dominic und Achim feststellen: Während es bei Achim nur wenige familiäre Unterstützungsmöglichkeiten gab - und weitere Förderung auch nicht von der Mutter initiiert werden konnte - und Dominics Eltern gemeinschaftlich mit ihm über seinen weiteren Schulweg entschieden haben, der dann letztendlich vom Gymnasium weggeführt hat, deutet sich bei Rebecca der unbedingte elterliche Wille eines möglichst hohen Schulabschlusses an einem Gymnasium an.

Rebecca betont vor dem Hintergrund ihrer Schullaufbahn auch, dass sie sich selbst als Kämpferin sieht und sich durchgesetzt hat: Denn ,es hätte jetzt keiner vermutet, dass ich wirklich Abi mach und studier" - weder ihre Lehrer*innen noch ihre Therapeut*innen - und Rebecca hat sich in der Schule besonders angestrengt, ,vier Wochen vor ner Klausur da gehockt und hab gelernt " und 
„es hat sich gelohnt“ - sie hat trotz aller Hürden und wider mancher Erwartungen das Abitur absolviert. Durchsetzungsvermögen, Disziplin und eigene Leistung haben ihr diesen, Sieg' möglich gemacht. Dieser Sieg wurde zwar durch ihre Eltern gefördert, war aber in erster Linie das Ergebnis ihrer eigenen Anstrengung und es entsteht so der Eindruck von Rebecca als individualistische Einzelkämpferin.

Interessant ist in diesem Zusammenhang auch, wie Rebecca dem Bildungshintergrund ihrer Eltern eine Bedeutung zumisst:

„Ja, meine Eltern hatten aber auch einfach die Möglichkeit, mich zu unterstützen. Also (...) meine Eltern haben beide auch Abitur gemacht, die hatten halt auch den Hintergrund dahinter. Ich mein, des hatten wir jetzt auch schon alles (...) in den ganzen Vorlesungen, jemand deren Eltern die halt selber nicht ganz so gut in der Schule warn, die können ihren Kindern ja auch nich so viel helfen. Oder wenn sie jetzt nich so gut verdienen, meine Eltern ham, mein Vater hat verdammt gut verdient früher, dadurch konnten die ganzen (...) Zusatzsachen bezahlt werden (...). Und des war halt mein Glück.“

Rebecca führt an, dass ihre Eltern einen hohen Bildungshintergrund und genügend finanzielle Ressourcen haben und dass sie ihre Tochter deshalb so wirksam bei der Krankheitsbewältigung unterstützen konnten. Zum einen nutzt sie ihr akademisches Wissen aus den ersten Wochen des Studiums als Argumentationsgrundlage und betont damit die Stichfestigkeit ihrer These, die damit wissenschaftlich belegt scheint. Zum anderen grenzt sie sich und ihre soziale Herkunft von , bildungsferneren" Familien ab, deren Kindern vergleichsweise weniger Unterstützung zu Gute kommt. Sie betont dabei nicht nur die (geschlechtlich strukturierten) finanziellen Ressourcen ihres Elternhauses - denn der Vater habe früher „verdammt gut verdient" - sondern auch die kulturellen Ressourcen, nämlich das Abitur als Nachweis für den hohen elterlichen Bildungshintergrund. Rebecca hebt ihren sozialen Hintergrund von der ,Masse" ab und weiß den theoretischen Wissensbestand aus ihrem ersten Studiensemester dabei gekonnt einzubringen.

Nach dem gemeinsamen Erfolg von Rebeccas Abitur betrachten ihre Eltern ihre Studienfachwahl allerdings mit Skepsis:

„Mein Vater macht sich regelmäßig darüber lustig, wie so ziemlich jeder Mensch der erfährt, dass man Soziale Arbeit studiert (I: Echt, so schlimm?). Also in meinem Umfeld ja, leider. Weil irgendwie, keine Ahnung, isses nich so hoch angesehn, weil viele einfach wirklich nur Kindergärtnerin oder Lehrer im Kopf ham (I: Ja gut, okay) und des is ei-, des is furchtbar. Also ich hab da am Anfang wirklich sehr damit zu kämpfen gehabt und echt, bin ins Zweifeln gekommen ob des überhaupt die richtige Wahl is, weil sich einfach alle drüber lustig gemacht ham. Also, wenn 
man sich dann überlegt, über Psychiater macht sich keiner lustig, aber es is.. nich $\underline{\text { so }}$ weit entfernt davon. Wir sind zwar.. eher in der Praxis, aber viele Sachen werden auch in Zusammenarbeit gelöst. Und äh, also ich finds halt, es war richtig, es war richtig anstrengend, da auch mal klar zu machen, dass des eigentlich en total wichtiger Beruf is, der eben nich nur, dass man im Kindergarten endet. Weil ganz ehrlich, ich studier" jetz nich, um dann im Kindergarten zu arbeiten."

Rebeccas Studienfachwahl wird von ihrem Umfeld - explizit ihrem Vater - abgewertet, dort scheint kein konkretes Wissen über die Soziale Arbeit vorhanden zu sein. Im Gegenzug wertet Rebecca die Soziale Arbeit auf und setzt sie mit dem prestigeträchtigeren Feld der Psychiatrie gleich. Die Anerkennung ihrer Arbeit und der gesellschaftliche Wert der Sozialen Arbeit sind ihr wichtig. Zugleich schließt sie sich in ihren Ausführungen allerdings implizit der Abwertung der Berufe der ,Kindergärtnerin" und der „Lehrer" an, denn vor allem im Kindergarten möchte sie nicht ,ende[n]“. Vor diesem Hintergrund der familiären Reaktion auf ihre Studienfachwahl lässt sich vermuten, dass in der Familie eher vage, teilweise stereotype Vorstellungen über pädagogische existieren und eine fachliche Disposition dahingehend ist nicht erkennbar. Möglicherweise hätte Rebecca die Soziale Arbeit ohne ihre biografischen Erfahrungen mit Psycholog*innen und Sozialarbeiter*innen gar nicht gekannt. Auch eine (familiäre) Orientierung an Status und Prestige bei der Bewertung von Berufen zeichnet sich hier ab.

Um die Abwertung der Sozialen Arbeit aus ihrem Umfeld nachzuvollziehen, lohnt ein Blick auf Rebeccas Vater, der im Interview mehr Raum einnimmt und häufiger von ihr benannt wird als ihre Mutter. Ihr Vater ist selbstständiger Kunststoffingenieur, hat in den Hochzeiten seiner Selbstständigkeit laut Rebecca „verdammt gut verdient", hatte aber ursprünglichen einen anderen Berufswunsch: Er wollte Anwalt werden. Letztendlich habe er sich jedoch „,anders entschieden“wie es dazu kam, wird im Interview nicht deutlich; möglicherweise ist der Vater aber mit diesem Wunsch an seine Grenzen gekommen, denn mit seiner Fachhochschulreife hätte er ein Jurastudium nicht beginnen können. Aussagekräftig ist bereits, dass Rebecca über diesen Berufswunsch weiß und ihn als berichtenswert einstuft. Über den Vater erzählt Rebecca des Weiteren etwas belächelnd und zugleich bewundernd, dass er ein breites historisches Wissen hat, dieses Wissen gut zu transportieren weiß und daraus regelmäßig längere Gespräche entstehen: „Weil der kann sich auch alles Mögliche merken, als der hat auch da.. en unglaubliches Gedächtnis und kriegt dann, wenn man dann über ein Thema, was sogar in der heutigenZeit is, anfängt zu reden, schafft er es irgendwie, so abzuschweifen ((schmunzelt)), dass er irgendwann im Mittelalter oder in der Richtung endet." Der Vater scheint also nicht nur in Anbetracht des potenziellen Jurastudiums, sondern auch was sein informelles Bildungsverhalten angeht 
eine Leidenschaft für gesellschaftlich-historische Themen zu hegen und dieses Interesse im familiären Austausch einzubringen. Dieser Einfluss prägt Rebeccas Neugier für rechtliche und soziale Fragestellungen, denn sie will daraufhin wissen, ,warum gibt es Gesetze, für was sind sie gut.. und was bringt es der Gesellschaft und (...) washats überhaupt dazu gebracht, dass die Gesellschaft (...) sich da überhaupt dran hält. " Diese rechtlichen Fragestellungen haben auch Rebeccas besonderes Interesse für die Soziale Arbeit begründet, im Vergleich etwa zur Pädagogik. Dass ihr Vater ihre Studienwahl derart belächelt, spricht vor diesem Hintergrund für eine distinktive Perspektive seinerseits: Mit seiner Selbstständigkeit in der Ingenieursbranche und dem ursprünglichen Berufswunsch des Anwalts, beurteilt er Berufe offenbar primär nach deren Prestige und schätzt soziale (und weiblich konnotierte) Berufe gering, die weder mit hohem gesellschaftlichen Ansehen noch mit großem Verdienst einhergehen. Dieser distinktive Blick seinerseits kann durchaus auch als Prätention gelesen werden.

Der Bezug zu rechtlichen Themen findet sich auch bei Rebeccas Partner wieder, der einen rechtswissenschaftlichen Studiengang (Informationsrecht) im dritten Semester studiert. Er „hat [Rebecca] auch eigentlich schon ziemlich in'en

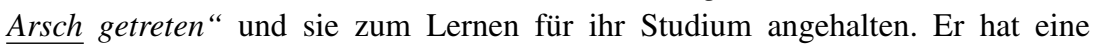
längere Studienerfahrung vorzuweisen und nimmt Rebecca gegenüber eine Expertenrolle ein, innerhalb derer er ihr Ratschläge für ihr eigenes Bildungsverhalten erteilt. Umgekehrt scheint Rebecca den Druck, von außen' zu brauchen, um die Anforderungen im Studium zu bewältigen. Der Blick von Rebecca ,hoch` zu ihrem versierten Vater und das Verhältnis zu ihrem studienerfahrenen Freund deutet auf eine gewisse hierarchische Strukturierung der entsprechenden Geschlechterpraktiken hin. Die familial Verankerung von beruflichen Aspekten von Gesetz und Ordnung ${ }^{17}$ und Rebeccas entsprechende Dispositionen werden ebenso nachvollziehbar.

Ihre Mutter nimmt im Interview vergleichsweise weniger Raum ein, was die berufliche Sphäre angeht. So berichtet Rebecca zwar von der mütterlichen Unterstützung ihrer Schullaufbahn, aber weniger von ihrer Rolle in der Entwicklung von Rebeccas beruflichen Interessen oder im Hinblick auf ihre Studienfachwahl. Zugleich grenzt sich Rebecca vom Beruf der Mutter selbst ab: Ihr Handarbeitsladen sei nämlich ein "Saisongeschäft", wodurch sie kein durchgehend sicheres Gehalt bezieht (,,[I]m Sommer ist da en riesenstarker Rückgang “). Diese

\footnotetext{
${ }^{17}$ Die sich nicht nur bei ihrem Vater und Partner zeigt, sondern bis zum Großvater zurückreicht, der Berufsfeuerwehrmann war und damit ebenso Ordnungsperson (und Helfer zugleich) war.
} 
Situation will Rebecca für sich selbst nicht, sondern möchte ein ,gesichertes Einkommen“", das ,regelmäßig aufm Konto is".

Schließlich soll noch die vergeschlechtlichte Arbeitsteilung in Rebeccas Herkunftsfamilie beleuchtet werden: Ihre Mutter war die erste Zeit der Kindererziehung zu Hause, bis ihre Töchter in den Kindergarten gegangen sind ${ }^{18}$. Vom Kindergarten wurde Rebecca von ihrer Großmutter abgeholt, die im gleichen Haus wohnt. Was die Grundschulzeit angeht, betont Rebecca, ,wir mussten früh auch sehr selbstständig sein, ich kam aus der Schule nach Hause und es war keiner zu Hause, meine Oma hat mir zwar die Tür aufgemacht, aber in der Wohnung oben war ich alleine." Ihre Oma besucht habe sie seltener, da ihr zu dem Zeitpunkt bereits verstorbener Opa „eher so die Bezugsperson“ für sie war. In der Mittagspause wiederum kam ihre Mutter nach Hause, um zu kochen und bei den Hausaufgaben zu unterstützen, bevor sie wieder zur Arbeit ging. Das macht deutlich, dass Rebecca durchaus betreut wurde und sie nach der Schule nicht völlig allein im Haus war. Möglicherweise will sie hier also eine Selbstständigkeit konstruieren, die in dem Maße nicht vorhanden war.

\title{
Studien(fach)wahl und antizipierte Zukunft
}

Was eine mögliche berufliche Zukunft in der Sozialen Arbeit angeht, könnte sich Rebecca gut vorstellen, ,im Jugendamt“ oder ,im Gericht“ tätig zu sein. Die Zielgruppe ist dabei für sie klar, das hat sich bereits angedeutet - sie möchte mit Kindern und Jugendlichen arbeiten. Weshalb es gerade diese Zielgruppe sein soll, begründet sie im Interviewverlauf nicht nur mit ihrer Erfahrung im Voltigieren - wie in der Eingangssequenz - sondern auch mit Rückgriff auf ihre eigene Erfahrung mit pädagogischen Fachkräften:

\begin{abstract}
„Ähm liegt es daran, weil ich halt selber viel mit das heißt Psychologen, Sozialarbeitern und so weiter zu tun hatte.. und ähm ich mirs aber auch eher vorstellen kann, weil man auch einfach.. man kann da noch was ändern, man kann denen im Leben noch weiterhelfen, sodass die dann hinterher das Leben genießen können oder ihre Probleme halt ähm verbessern können. Ich find bei Erwachsenen ist des dann oft so.. keine langfristige Hilfe, man hilft denen kurz, aber sie schaffens dann halt oft einfach auch nichts mehr zu ändern, weil halt eben ähm der Aspekt sag ich jetzt mal von Erziehung und Umstellung von seinem Leben einfach nich mehr so gegeben ist, weil es einfach an sich schon so gefestigt ist."
\end{abstract}

Diese Berufsvorstellungen lassen sich als Reproduktion ihrer eigenen Biografie deuten: Rebecca hat gelernt, dass das Leben ein Kampf ist und sie sich

\footnotetext{
${ }^{18}$ Wann genau das der Fall war, wird in Rebeccas Ausführungen nicht ersichtlich.
} 
gegen äußere Umstände - negative Zuschreibungen durch Lehrkräfte, ihre ADHSsymptomatischen Defizite, die subjektiv erfahrende soziale Ausgrenzung durch die Mitschüler*innen - durchsetzen muss. Diesen Kampf hat Rebecca, so ihre Geschichte, gewonnen: Mit Hilfe ihrer Eltern und durch Therapien konnte sie „ihre Probleme verbessern“, hat den Anschluss in der Schule gefunden und ihr Abitur gemacht. Dass sie daraufhin erfolgreich ihr Wunschstudium aufgenommen hat, passt zu dieser Erzählung ihrer Erfolgsgeschichte. Ihren damit verbundenen Blick auf die Welt möchte sie offensichtlich durch ihren Beruf weitergeben: Wer sich genug anstrengt und dabei unterstützt wird - in diesem Fall durch Rebeccas zukünftige Arbeit - der schafft es, stark zu werden, ,mithalten`zu können und etwas aus sich zu machen. Rebeccas Orientierung an einem individualistischen Leistungsprinzip schlägt sich damit auch maßgeblich in ihren beruflichen Vorstellungen nieder.

Diese gehen noch einen Schritt weiter, denn Rebeccas Zukunftspläne bleiben nicht bei der Sozialen Arbeit stehen. Eigentlich hat sie einen anderen Traumberuf, den sie auch explizit als solchen benennt: „Also ich will hinterher [nach dem Studium, L.L.] noch ne Ausbildung machen zum Kinder- und Jugendtherapeuten, des wär so der absolute Traum wenn des klappt." Vor diesem Hintergrund wäre das Studium der Sozialen Arbeit, so Rebeccas Wunsch, nur eine Zwischenstation auf dem Weg zur Therapeutin. In Kombination mit ihren oben beschriebenen individualistischen und leistungsorientierten Vorstellungen von der Arbeit mit Kindern und Jugendlichen entsteht ein Bild von ihr als künftige Therapeutin in einer Machtposition und mit dem Sendungsbewusstsein, ihr milieuspezifisches Credo von Disziplin und Leistung weiterzugeben. Diese Interpretation verdeutlicht das Risiko, dass sie die Problemlagen ihrer Klient*innen womöglich auf individuelles Fehlverhalten zurückführen würde, was ein empathisches Einfühlen erschweren könnte.

Was ihr privaten Zukunftsvorstellungen angeht, möchte Rebecca später eine Familie gründen, ,wenns halt passt, wenn man den richtigen Partner hat (...) und man auch weiß, man kann en Kind finanzieren. " Erneut ist für sie Geld hier eine wichtige Sicherheit. Auf die Frage der Interviewerin hin, ob nach Rebeccas Vorstellungen sie oder ihr Partner zur Erziehung zu Hause bleiben würde, antwortet sie:

„Also ich denk mal, es wär schon denkbar, dass ich die erste Zeit zu Hause bleibe, aber lange wird das nicht gutgehn, weil ich auch sag ich muss was machen. (...) Und ähm ja also ich denk schon wenn des Kind in "en Kindergarten gehen kann, will ich auch schon wieder arbeiten, weil.. ich mag auch nich ' den ganzen Tag zu Hause sitzen und ich hab auch keine Lust die Hausfrau zu spielen ((lacht)). Also des ähm wär auch nichts für mich.“ 
Vehement grenzt sich Rebecca von der Rolle der „Hausfrau“ ab, die nach ihren Vorstellungen von Untätigkeit geprägt ist und die sie abwertet. Damit distanziert sie sich zugleich von einem spezifischen, weiblichen' Lebensmodell, das nicht ihrem milieuspezifischen Credo von Leistung und Disziplin entspricht. Die Eingebundenheit in Erwerbsarbeit scheint dabei maßgeblich für ihre Definition von Leistung, während sie Reproduktionsarbeit als Untätigkeit abwertet. Gleichzeitig antizipiert sie selbstverständlich für sich die Übernahme der Erziehungsarbeit, eine Elternzeit auf Seiten ihres Partners erwähnt sie von sich aus nicht. Erst auf Nachfrage der Interviewerin sagt sie dazu:

\begin{abstract}
„Wenn mein Geld reichen würde vom Job her, wärs eher nich so des Problem, wenn er sagt er kümmert sich um die Kinder.., wär für mich jetzt ähm nich des Problem, wenns Geld halt reicht, wenn nicht dann halt nicht, weil äh ja. Aber ich fänds jetzt auch nich gut, wenn er dann den ganzen Tag zu Hause sitzt und die Kinder schon groß und selbstständig sind (...). Weil deswegen, wenn er sagt ja er will sich jetzt um die Kinder kümmern, sag ich okay, is ok, dann hab ich kein Problem damit wenns Geld reicht, aber ansonsten sag ich wärs mir auch lieber wenn er arbeiten geht.. und man dann halt den Haushalt irgendwie aufteilt."
\end{abstract}

Rebecca würde die Elternzeit ihres Partners höchstens akzeptieren (, dann hab ich kein Problem damit"), aber nicht erwarten oder einfordern. Dieses Arrangement knüpft sie außerdem an die Bedingung, selbst genügend Geld im Beruf zu verdienen - umgekehrt erwähnt sie diese Bedingung nicht, wenn es darum geht, dass sie zur Erziehung zu Hause bleibt, was auf die Selbstverständlichkeit eines Gehaltsgefälles verweist. Und erneut grenzt sie sich hier von ihrer Vorstellung von Trägheit ab, die sie mit der Übernahme von Reproduktionsarbeit verbindet. Auch von ihrem Partner erwartet sie, ihrem erwerbsfokussierten Leistungscredo zu folgen. Schließlich zeigt sich so, dass Rebecca zwar in der Theorie die Erziehungsarbeit durch ihren Partner zulässt - in der Praxis allerdings ist es wahrscheinlich, dass ihr aktueller Partner mit seinem Abschluss im Informationsrecht mehr Gehalt beziehen wird als Rebecca in der Sozialen Arbeit oder als Kinder- und Jugendtherapeutin. Eine Aufgabenteilung hin zur Sorgearbeit auf Rebeccas Seite wäre in dieser Konstellation wahrscheinlich.

Rebeccas finanzielle Zukunftsvorstellungen wiederum sind geprägt von ihrer bereits erwähnten Sicherheitsorientierung (,,[W]o ich weiß, es kommt da-, es kommt die und die Summe, darauf kann ich mich verlassen,.. davon kann ich meine Miete zahlen“), von einer gewissen Bescheidenheit (,,[E]s wär natürlich toll wenn dann halt auch mal son, ich sag jetzt mal son paar Luxusartikeldabei sind, dass ich jetzt mal unbekümmert in die Stadt gehen kann und sag ich kauf mir ne neue Hose oder so") und davon, dass sie ihre Freude am Beruf über dessen 
finanziellen Gewinn stellt - wobei sie diesem gegenüber auch nicht gleichgültig ist: „,[E]s wär natürlich schön, wenn man en Job kriegt wo man richtig viel verdient, aber ich sag des is jetzt kein Muss für mich, solange ich Spaßam Job hab. “

Auf diese Dimension der Erfüllung im Beruf kommt sie auch wieder bei den Abschlussfragen zu sprechen, zum einen als sie darüber erzählt, worauf es ihr im Leben ankommt: „Das is wirklich schwierig. Ähm, ja wirklich en Job zu haben der einem Spaß macht, dass man halt auch wirklich gerne aufsteht, gerne lebt, Freunde haben (...). Einfach nur, dass es halt wirklich passt. "Sinn und Freude im Beruflichen wie Privaten prägen Rebeccas Vorstellungen. Auch die drei Wünsche, die sie bei der letzten Frage des Interviews äußern kann, beziehen sich auf diese Aspekte: Sie möchte ,ne Familie ham, in der man sich wohlfühlt, wo man auch glücklich mit is“, sie wünscht sich, dass mit ihrer Ausbildung „alles so klappt, wie ichs mir erhoffe, also dass das Geld dann für die Ausbildung da is, dass das klappt weil,.. so zehntausend bis fünfzehntausend kann die nämlich schon kosten “ und sie wünscht sich,

„,...dass ich dann halt einfach wirklich meinen Traumjob.. äh finde.. und was noch. Keine Ahnung ((lacht)). Ähm.. ja dass es halt dann auch hinterher mit dem Job einfach funktioniert einfach alles,.. dass man eben, dass ich halt einfach wirklich.. zufrieden sein kann mit meinem Leben, das is eigentlich auch so der Wunsch, dass.. einfach alles irgendwie funktioniert und ich einfach zufrieden bin.“

Diese mehrfache Erwähnung von Zufriedenheit, ihre Wunschvorstellungen und ihr Blick auf die Kosten ihrer Therapeutinnenausbildung betonen nochmal ihren Realismus und ihre relative Bescheidenheit.

\section{Habitus, Studien(fach)wahl und Milieuspezifika}

Rebeccas Weg in die Soziale Arbeit ist maßgeblich geprägt durch ihre biografischen Erfahrungen mit ihrer ADHS-Diagnose, durch die sie sozialarbeiterische Tätigkeiten überhaupt kennengelernt hat, und den Weg zum Abitur, der für sie ein seit ihrer Kindheit fest gehegter Wunsch war und den als ,Kampf ' erlebt hat. Ihre Eltern reagieren auf ihre Diagnose mit vielfältigen Unterstützungsleistungen, die ihren Weg zum Abitur absichern sollen: Vom gemeinsamen Lernen über Nachhilfe bis hin zu mehreren Therapien wirken sie darauf ein, dass Rebecca im Gymnasium mithalten kann und in ihren Reitverein integriert ist. Rebecca weiß diese Unterstützung zu schätzen, unternimmt enorme Anstrengungen, geht diszipliniert vor und schafft so schließlich ihren Schulabschluss. Geprägt von ihrem Sicherheitsdenken und geplanten Vorgehen erfolgen ihre Bewerbungen 
für drei Studiengänge, von denen die Soziale Arbeit ihr Wunschstudiengang ist erstens aufgrund der sicheren Berufsaussichten, zweitens wegen der fachlichen Vielfalt, die auch Rechtsgrundlagen umfasst und drittens, um eine Grundlage zur Therapeutinnenausbildung zu legen.

Ihr Ziel ist es, mit Kindern und Jugendlichen zu arbeiten, deren „Probleme zu verbessern“ und ihnen zur „Umstellung und Erziehung“ zu verhelfen. Kurzum: Sie möchte ihr milieuspezifisches Credo von individualistischer Leistung, Disziplin und Teilhabe weitergeben. Flankiert wird ihre Studien(fach)wahl (und auch ihr alternativer Berufswunsch der Polizistin) von ihrer Disposition hin zu Ordnung, Hierarchien und Respekt. Sie vergleicht die Soziale Arbeit mit der Psychiatrie, betont zudem ihre juristischen Inhalte und bemängelt die ,Respektlosigkeit' und das ,Verwöhnt sein' ihrer ehemals besten Freundin. Zudem lenkt Rebecca immer wieder ihren ,Blick nach oben': Sie wertet die Soziale Arbeit auf, grenzt sich von „Kindergärtnerinnen“ und „Lehrern“ ab, sie bewundert ihren aus ihrer Sicht gebildeten Vater und antizipiert für sich den erstrebenswerten Beruf der Therapeutin. Ihre Orientierung , hin zu Höherem` ist unverkennbar, wobei das Ziel nicht unbedingt den höchsten materiellen Gewinn, sondern mindestens genauso Freude am Beruf bedeuten muss. Ob die Soziale Arbeit dementsprechend nur eine Zwischenstation hin zu ihrem Traumberuf sein wird oder ob sie doch in ein sozialarbeiterisches Handlungsfeld einmündet - besonders die Arbeit im Jugendamt oder im Gericht könnte sie sich vorstellen - muss zum aktuellen Zeitpunkt offengelassen werden.

Allgemein zeichnet sich ab, dass Rebeccas Familie von Such- und Aufstiegsbewegungen geprägt ist: die Schwester, die von der Bürokauffrau zur Grafikdesignerin umgeschult hat, ihr Vater, der als Kunststoffingenieur selbstständig, aber doch nicht Anwalt geworden ist und ihre Mutter, die zwei Ausbildungen absolviert und sich letztendlich mit einem Handarbeitsladen selbstständig gemacht hat. Möglicherweise kommt Rebecca mit dem Therapeutinnenberuf an ihre Grenzen, wie es bei ihrem Vater und dem Anwaltsberuf der Fall war; möglicherweise gelingt ihr aber auch der anvisierte berufliche Aufstieg. In jedem Fall passt zu Rebeccas leistungsorientierter, disziplinierter und erwerbsorientierter Lebensführung keine ,traditionelle' Aufgabenteilung, in deren Rahmen sie ihren Beruf für die Erziehung ihrer Kinder längere Zeit pausieren oder gar aufgeben würde. Im Gegenteil scheint für sie Leistung und Anerkennung maßgeblich mit der Sphäre von Erwerbsarbeit verknüpft zu sein - Sorgearbeit wertet sie als Untätigkeit ab und „Hausfrau zu spielen“ kommt für sie nicht in Frage. Entsprechend antizipiert sie eine Partnerschaft, in der ihr Partner ebenso ihren Werten folgt. Egalitär sind die Geschlechterpraktiken, die sich bei Rebecca finden und die sie in ihren Zukunftsvorstellungen beschreibt, indes nicht: Die Beteiligung ihres Partners an 
der Kindererziehung macht sie von ihrem eigenen Gehalt abhängig, das - folgt man ihrer aktuellen Paarkonstellation - höchstwahrscheinlich geringer als das des Partners selbst ausfallen würde. Die grundsätzliche Zuständigkeit für die Kindererziehung nimmt sie selbstverständlich für sich ein. Diese vorreflexiven Geschlechterpraktiken verweisen auf ein durchaus hierarchisch strukturiertes Geschlechterverhältnis in Rebeccas Lebensführung. Damit hängt womöglich auch zusammen, dass ihr Interview auffällig von der Präsenz von männlichen Orientierungs- und Vorbildpersonen durchzogen ist - sei es ihr bewundernder Blick zum Vater, die antreibende Funktion ihres Partners oder die enge Beziehung zu ihrem Großvater: Sie sind für Rebecca stärker mit der Sphäre von Erwerbsarbeit verknüpft, die für ihren Leistungsanspruch die maßgebliche ist. ${ }^{19}$ Vor dem Hintergrund eines wachsenden Gleichheitsanspruchs in ihrem Milieu entsprechen diese erwerbsfokussierten und männlich vergeschlechtlichten Biografien für Rebecca näher an ihren Zukunftsvorstellungen, wodurch künftige Widersprüche zwischen ihrer Zuständigkeit für die Kindererziehung mit ihren leistungs- und teilhabeorientierten Handlungsmustern gut vorstellbar sind.

Zusammengefasst unterscheidet sich Rebeccas Fall besonders von den bereits vorgestellten sozialarbeiterischen Fällen von Tabea und Achim, die von Gemeinschaft, Egalität und einer Abkehr von Prestige- und Statusdenken geprägt sind: Bei Rebecca spielt ihre Disposition hin zu Aufstiegsstreben, zu Statusdenken und ihre Orientierung an erwerbstätigkeitsbezogener Anerkennung eine tragende Rolle in ihrer Studien(fach)wahl. Sie scheint damit eher dem Fall von Michael nah zu sein und teilt mit ihm einen spezifischen Blick auf die tragenden Werte von Leistung und Erfolg, der mit einem wettbewerbsorientierten Aufstiegsstreben verknüpft ist. Zusammengenommen mit ihrem prätentiösen ,Blick nach oben' und der Individualisierung von strukturellen Problemen, die sich in ihren Bewertungen abzeichnet, liegt eine Verortung des Falls im vertikalmittleren Bereich des Leistungsorientierten Arbeitnehmermilieus mit Nähe zur ständisch-kleinbürgerlichen Traditionslinie nahe (siehe auch ebd.).

\footnotetext{
${ }^{19}$ Obwohl auch die Mutter berufstätig und selbstständig ist, aber eine geringere Rolle in Rebeccas Erzählungen einnimmt.
} 


\subsection{Fall Jennifer: „[W]ar vielleicht der anstrengendere Weg (...), aber der bessere denk ich im Nachhinein"}

\section{Reflexion der Interviewsituation}

Das Interview mit Jennifer dauert gut eine Stunde. Die Atmosphäre ist von Beginn an auffallend gelöst und Jennifers Antwortverhalten lässt sich als spontan und gesprächsnah beschreiben. Sie scheint sich gleich wohl zu fühlen, greift zu Kaffee und Keksen und wirkt nicht nervös.

Am Ende des Interviews stellt Jennifer noch mehrere Fragen zum Forschungsprojekt, sowohl methodische wie auch inhaltliche. Besonders die untersuchten Studienfächer scheinen sie zu interessieren, da sie selbst Soziale Arbeit und ihr Partner Bauingenieurwesen studiert. Nachdem die Interviewerin berichtet, dass die Akquise von Interviewpartner*innen im Bauingenieurwesen schwieriger war als in der Sozialen Arbeit, antwortet Jennifer, ,das hab ich mir schon gedacht" und solidarisiert sich anschließend mit der Forscherin: „Also ich find so, man kommt ja vielleicht selber mal in die Lage, ne, dass man Leute braucht und Interviews führen muss." Damit betont Jennifer zum einen ihre Kenntnis der beiden Fachkulturen und begründet zum anderen ihre Gesprächsbereitschaft mit einer Vorstellung gegenseitiger Hilfsbereitschaft (,Geben und Nehmen' als Prinzip wechselseitiger Unterstützung).

\section{Kurzeinführung in den Fall}

Jennifer ist 26 Jahre alt und studiert im ersten Semester Soziale Arbeit. Sie ist in Hierstadt und Umgebung aufgewachsen und während ihrer Kindheit vier Mal umgezogen. Ihr Vater ist verstorben, als sie ein Jahr alt war. Anschließend war ihre Mutter zuerst alleinerziehend, hatte dann einen neuen Partner, war anschließend wieder alleinerziehend und hat mittlerweile schon seit längerem wieder einen Lebenspartner. Jennifer hat vier Geschwister, davon sind zwei etwa in ihrem Alter (24 und 21) und zwei sind deutlich jünger (15 und 13). Die fünf Kinder stammen von drei Vätern ab.

Jennifers Mutter hat einen Realschulabschluss und eine Berufsausbildung zur Bürokauffrau absolviert, in diesem Bereich ist sie angestellt. Während Jennifers Kindheit war ihre Mutter zeitweise nicht erwerbstätig, etwa wenn sie einen Partner hatte, der die Familie finanziert hat, und zeitweise war sie in Teilzeitanstellungen beschäftigt, wenn sie alleinerziehend war. Ihr verstorbener Mann hatte einen Hauptschulabschluss, mehr ist über ihn nicht bekannt. Jennifers Stiefvater ist KfZ-Mechaniker. Jennifer selbst hat ihren Hauptschulabschluss absolviert und anschließend eine Ausbildung zur Bürokauffrau durchlaufen beim gleichen Arbeitgeber, bei dem auch ihre Mutter zu dem Zeitpunkt war. Dort hat sie 
einige Jahre gearbeitet. Anschließend hat sie sich umorientiert, ihren Realschulabschluss und ihr Fachabitur auf einer Berufsschule nachgeholt und das Studium der Sozialen Arbeit begonnen.

Jennifer ist die Erste in der Familie, die studiert, was ein präsentes Thema für sie ist, wie sich in der weiteren Analyse noch zeigen wird. Ihre Geschwister haben teilweise eine Ausbildung absolviert, die Jüngeren gehen noch zur Schule und denken daran, später einmal zu studieren. Dazu sagt Jennifer: „Find ich auch total schön, ja... Dass sie sich trauen und des machen. Weil man kriegts ja schon anders vorgelebt zu Hause."

Seit einigen Jahren wohnt sie gemeinsam mit ihrem Partner in einem Vorort von Hierstadt und arbeitet neben dem Studium zehn Wochenstunden in der Behindertenhilfe. Ihr Freund studiert an der gleichen Hochschule wie Jennifer Bauingenieurwesen im Master.

\section{Weg hin zum Studium}

Jennifer leitet ihre Erzählungen damit ein, dass sie vor ihrem Studium der Sozialen Arbeit in einem anderen Bereich Berufserfahrung gesammelt hat: Sie hat eine Ausbildung zur Bürokauffrau bei der städtischen Verwaltung absolviert und war dort insgesamt sechs Jahre tätig. Diese Tätigkeit kontrastiert Jennifer zur ihrem jetzigen Studium der Sozialen Arbeit (,,[I]ch hab ja vorher, ähm, was ganz anderes gemacht") und erläutert, weshalb sie ihren alten Beruf verlassen hat:

„,[U]nd hab dann aber gemerkt ähm dass des nicht des Richtige für mich is, also es is einfach immer desselbe. Und hab auch an, ich hab an verschiedenen Stellen gesessen und es hat auch mal mehr und mal weniger Spaß gemacht, aber es is halt im Endeffekt trotzdem immer desselbe. Und dann kam so die Phase,.. ähm des will ich nich mehr machen aber was denn stattdessen?"

Für Jennifer waren die verwalterischen Tätigkeiten im Büro monoton und diese Monotonie verursacht bei ihr eine wachsende Unzufriedenheit. Zugleich scheint ihr dieser Beruf doch bis zu einem gewissen Maß entsprochen zu haben, schließlich hat sie erst nach mehreren Jahren Alternativen in Erwägung gezogen. Zudem zeigen ihre Ausführungen an dieser Stelle, dass es ihr wichtig ist, einen Beruf zu finden, der zu ihr passt (,,.. dass des nicht des Richtige für mich is“) und abwechslungsreich ist (,im Endeffekt immer desselbe“).

Für sie resultiert die offene Frage, welche Tätigkeit für sie stattdessen in Frage kommt und sie bezeichnet die anschließende Orientierungsphase als ,schwierig“ und führt aus, dass es „dann auch nochn bisschen demotivierender [war], was 
die Arbeit anging, weil da musste man ja trotzdem jeden Tag hingehn“. Möglicherweise sind es finanzielle Gründe, die Jennifer dazu bewegen, jeden Tag dem aus ihrer Sicht unbefriedigenden Job im Büro nachzugehen, vielleicht spielen hier aber auch Motive von Disziplin und Pflichtbewusstsein eine Rolle. In jedem Fall klingt an, dass Jennifer in eine krisenhafte Berufs(orientierungs)phase eintritt.

Um einen alternativen Beruf für sich zu finden, orientiert sie sich an ihrem sozialen Umfeld: Da sie „so viele Freunde [hat], die im sozialen Bereich arbeiten" - größtenteils als Heilerziehungspfleger*innen, teilweise im Rahmen eines Studiums der Sozialen Arbeit - rückt ihr Blick schnell auf dieses Tätigkeitsfeld. Sie informiert sich über den Beruf der Heilerziehungspflegerin und stellt fest, dass sie dafür entweder eine staatliche Ausbildung zur Sozialassistentin absolvieren müsste - wofür sie mit ihren zu diesem Zeitpunkt 24 Jahren zu alt war, um zugelassen zu werden - oder eine gleichwertige Ausbildung in einer privaten Institution selbst finanzieren müsste, was für sie nicht in Frage kommt (,Die Alternative dazu wär gewesen, ans [Hospital] zu gehen und da hätt ich kein Geld für bekommen und hätte bezahlen müssen"). Schließlich ist es ihr Freund, durch den sie ein mögliches Studium der Sozialen Arbeit für sich ernsthaft in Betracht zieht:

„Und da hatte mein Freund die Idee, dass ich doch Soziale Arbeit studieren kann, weil ich in den gleichen Bereichen arbeiten kann, aber höher qualifiziert bin und des kostet mich äh zumindest bis zum Bachelor keine fünf Jahre Ausbildung, sondern nur drei Jahre.“

Die Argumente des Freundes, durch das Studium sowohl eine höhere Qualifizierung zu erreichen wie auch weniger Zeit investieren zu müssen, scheinen Jennifer zu überzeugen und sie entscheidet sich, das Studium anzustreben. Dafür muss sie ihr Fachabitur nachholen und vorab eine Feststellungsprüfung ablegen (,....weil ich zu lang aus der Schule draußen war, Mathe, Deutsch, Englisch wurde geprüft ((räuspert sich)), hat aber ganz gut funktioniert“). Als Bereiche für das Fachabitur kommt aufgrund ihrer Ausbildung ausschließlich Wirtschaft und Verwaltung in Frage, ,was jetzt auch nochmal, also des war ja nun wiedernich der Bereich den ich wollte, aber ums in einem Jahr machen zu können musstich halt Wirtschaft und Verwaltung wählen, hab des auch äh gut abgeschlossen ". Wie Jennifer betont, nimmt sie also weitere Jahre der Beschäftigung mit den Fächern in Kauf, mit denen sie sich eigentlich nicht mehr beschäftigen will, weil sie diesen Abschluss als Voraussetzung für ihr Studium braucht. Sie geht hier strategisch und diszipliniert vor und zeigt Durchhaltevermögen, um ihr 
Ziel zu erreichen. Auch der Abschluss ihrer Eingangserzählung verweist auf ihre Bereitschaft, Hürden in Kauf zu nehmen, um Soziale Arbeit studieren zu können:

„Des is äh, so so der Weg, also eigentlich wär ich auch mit ner Ausbildung zufrieden gewesen, aber da einem da so unnötig Steine in den Weg gelegt wurden, (...) war vielleicht der anstrengendere Weg ähm, aber der bessere denk ich im Nachhinein, ja.“

Damit war das Studium der Sozialen Arbeit die ,zweite Wahl' nach einer möglichen Ausbildung, die aufgrund der Rahmenbedingungen, die Jennifer als „Steine“ in ihrem „Weg“ bezeichnet, für sie nicht oder nur schwer machbar ist. Das Prestige bzw. der Status des Studiums und der anschließenden Berufstätigkeit spielen für sie keine dominante Rolle, sie setzt beides in ihrer Anerkennung gleich.

Schaut man genauer auf die Frage, warum Jennifer nicht mehr in ihrem Ausbildungsberuf arbeiten wollte, tritt nicht nur der Wunsch nach mehr Abwechslung in den Vordergrund, sondern auch nach Forderung und Anerkennung im Beruf: So war sie zuerst in einem hochschulischen Fachbereichssekretariat tätig und hat viel mit Studierenden zusammengearbeitet, was ihr auch ,,viel Spaß gemacht" hat, allerdings war sie anschließend in anderen Institutionen „Assistentin der Geschäftsleitung “ und „Assistentin vom Direktor“, was aus Jennifers Sicht ,immer nur so.. Kaffeekochen, äh Teekochen, Tisch eindecken für irgendwelche wichtigen Leute" war und weshalb sie sich ,wie der Handlanger gefühlt" habe. Dort hatte sie außerdem den Eindruck, dass auf sie „als Vorzimmersekretärin oft auch schon son bisschen auf einen hinabgeschaut [wurde] und des hat mir eigentlich nicht so viel Spaß, also des war.. nich son tolles Gefühl." Die abhängige, zuarbeitende Position der Assistentin und die geringe Wertschätzung, die sie in dieser erfährt, beeinflussen Jennifers Entscheidung, diesen Beruf zu verlassen, maßgeblich. Dieser Schritt bedeutet für sie aber auch, die bis dahin gewonnene Unabhängigkeit und finanzielle Sicherheit aufzugeben und Risiken einzugehen - ein Schritt, bei dem sie ihr Freund begleitet und unterstützt hat:

„[D]es is dann einfach so passiert und dann verdient man Geld und man baut sichn eigenes Leben auf, man zieht und man finanziert en Auto, so hab ichs gemacht, und dann hat man einfach dieses Geld und es is schon en Schritt dann zu sagen ich verzichte auf des Geld das ich jeden Monat hab und äh.. ja, aber da hat mich mein Freund halt son bisschen hin, ja der hat dann gesagt ,Des kriegen wir schon und des schaffen wir schon" und, ja, des ja, war richtig ((lacht)).“ 
Von selbst kommt Jennifer anschließend darauf zu sprechen, dass ihr Partner einen ähnlichen sozialen Hintergrund habe wie sie - in beiden Familien sind sie die Ersten, die studieren: „Er kommt aus ner Familie da wurde auch nich studiert, die Mutter hat zwar Abitur, der Vater nich, aber studiert wurde auch nich und er is auch der Erste, der gesagt hat er schlägt diesen Studienweg ein.. und sich des quasi getraut hat. " Offensichtlich verbinden Jennifer und ihren Partner ähnliche habitusspezifische (Bildungs-)Erfahrungen und sie lässt sich von ihm darin unterstützen, sich in ein Studium zu ,trauen', wie sie selbst diesen aus ihrer Sicht anstrengenden und durchaus riskanten Weg nennt.

\title{
Studien(fach)wahl im Kontext der Herkunftsfamilie
}

Während Jennifers Weg in das Studium von ihr mit Disziplin und Zielstrebigkeit verfolgt wird, bezeichnet sie die Wahl ihrer Ausbildung nach ihrem Hauptschulabschluss als eine, ,die hab ich gar nich so wirklich selbst getroffen, die Entscheidung " und führt dazu aus:

\begin{abstract}
,[D]er Grund warum ich mich damals bei der Stadt (...) beworben hatte fürn Ausbildungsplatz war einfach der, meine Mutter arbeitet dort, meine Tante arbeitet bei der Stadt und es hieß einfach ,Da haste gute Chancen übernommen zu werden, des machste mal'. Und da ich noch nich wirklich die Ahnung hatte wo ich ich hinwill, des mir aber zu dem Zeitpunkt noch gar nich so richtig bewusst war glaub ich, da hieß es einfach nur ,Schule fertig, jetzt ne Ausbildung, des is einfach so'. Und dann hab ich mich halt da beworben."
\end{abstract}

Die Einmündung in ihren Ausbildungsberuf scheint weniger aus einem aktiven, reflektierten Entscheidungsprozess von Jennifer als vielmehr aus pragmatischen und sicherheitsorientierten Gründen und den bereits vorhandenen familiären, ,weiblichen' Berufslaufbahnen hervorgegangen zu sein, durch die der Eintritt in eine Büroausbildung nahelag. Eine Ausbildung zu beginnen, scheint nie in Frage gestanden zu haben - sicherlich auch wegen Jennifers Hauptschulabschluss, der als Grundlage für einen Studienbeginn nicht in Frage gekommen wäre. So mündet Jennifer in einen unter den Frauen ihrer Familie verbreiteten Beruf ein, der einen sicheren Arbeitsplatz verspricht. Ein Einfluss ihres Stiefvaters, der zu dieser Zeit bereits Teil der Familie war, wird hier nicht deutlich.

Ein Blick auf Jennifers vorangegangene Schullaufbahn zeichnet ein noch detaillierteres Bild von ihrem Weg hin zum Hauptschulabschluss und zu ihrer Ausbildung: Jennifer hat die Kindheit mit ihren vier Geschwistern ,laut und lebhaft" in Erinnerung und findet rückblickend: „, [N]e große Familie is schön“. Für die jüngeren Geschwister war sie häufig Babysitterin und hat dabei schon früh eine fürsorgliche, verantwortungsvolle Rolle eingenommen: „Und ich musste früh 
Verantwortung übernehmen, ich glaub da hab ich mit elfes erste Mal auf meinen kleinen Bruder aufgepasst und da war der gradn Baby. (I: Okay) Ja, und dann hat äh, war ich allein mit dem zu Hause und musste halt des volle Programm und hier ((räuspert sich)) durchmachen. “

Aus Jennifers Beschreibung geht weniger eine sporadische, lockere, unbedarfte Form des Babysittings hervor als vielmehr eine regelmäßige und tatsächliche Verantwortung für das Wohlergehen und die Pflege des kleinen Bruders, die aus einer Notwendigkeit resultierte und nicht nur Freude, sondern auch Anstrengung bedeutet hat (,musste halt des volle Programm durchmachen“). Jennifer hat früh fürsorgliche Tätigkeiten übernommen, die auch in ihrer weiteren Biografie immer wieder eine Rolle spielen und ihr Selbstbild übergegangen sind - bis hin dazu, dass sie sich in der Berufsschule rückblickend als „Klassenmutti“ bezeichnet, weil sie für die Klassenkamerad*innen eine wichtige Vertrauensperson war, bei persönlichen Problemen geholfen und bei den Hausaufgaben unterstützt hat.

Ihre Jugendphase und Schulzeit beschreibt Jennifer als teilweise schwierig und krisenhaft. Zum einen waren die häufigen Wohnortwechsel - vier Mal innerhalb von zehn Jahren ${ }^{20}$ - für Jennifer ,kompliziert“, weil sie sich regelmäßig an ein neues (soziales) Umfeld gewöhnen musste. Zum anderen waren damit auch Schulwechsel verbunden, wobei insbesondere der Wechsel auf ihre letzte Schule in die achte Klasse für Jennifer problematisch war: Sie hatte dort „Schwierigkeiten irgendwie reinzukommen äh, war dann immer der Außenseiter". Ihre Freunde waren eher aus Parallelklassen oder außerhalb der Schule, in der eigenen Klasse dagegen war es für sie ,nich so angenehm“. Deshalb ist Jennifer ,nich mehr so oft hingegangen“, sie hat also regelmäßig geschwänzt. Der Klassenlehrer habe ihr Fehlen nicht ausreichend dokumentiert und auch keine Rücksprache mit ihrer Mutter gehalten; diese wiederum hat keine Elternabende besucht und so waren Jennifers Fehlzeiten zu Hause lange nicht aufgefallen. Außerdem kontrastiert Jennifer ihre eigene Situation zu dieser Zeit zu der ihrer Mitschüler*innen und stellt eine geringe familiäre Unterstützung durch ihre Familie fest (,Mmh.. ich glaub die andern hatten alle mehr Unterstützung von zu Hause “). So kam es, dass Jennifer ihren angestrebten Realschulabschluss nicht bestanden hat, sondern mit einem Hauptschulabschluss von der Schule ging.

Allgemein beschreibt Jennifer das Verhältnis zu ihrer Mutter in Kindheit und Schulzeit in Teilen als sehr schwierig: Sie kritisiert, dass ihre Mutter in der Zeit, als der Stiefvater neu in die Familie gekommen ist, ,son bisschen auf ihn fokussiert [war] und hat die Kinder, die schon da warn, son bisschen außer Acht

${ }^{20}$ Die Gründe für diese häufigen Umzüge werden von Jennifer nicht benannt. 
gelassen“. Die relativierende Wortwahl (,,son bisschen“, „, son bisschen“) deutet darauf hin, dass Jennifer ihre Mutter hier vor Kritik zu schützen sucht. Zu ihrem Stiefvater hatte sie in dieser Zeit ebenfalls ein schwieriges Verhältnis, da er sich in die Erziehung stark einbrachte, konträre Prinzipien zu denen der Mutter an den Tag legte und es durch ihn so bspw. „mehr Konsequenzen“ wie „Hausarrest en masse" gab. Jennifer ist in dieser Zeit zwei Mal für je einen Tag von zu Hause ausgerissen, einmal in der fünften und einmal in der achten Klasse. Sie ist ungefragt mit zu Freundinnen gegangen und wollte dort bleiben, aber ihre Mutter hat sie am Ende des Tages aufgefunden.

Es zeichnet sich ab, dass Jennifers Aufwachsen von Unstetem und von Erfahrungen der Notwendigkeit geprägt war. Die häufigen Umzüge und Schulwechsel, die Integrationsprobleme in der letzten Schule, das problematische Verhältnis zu ihrem Stiefvater und die geringe Beaufsichtigung und Intervention durch ihre Mutter führten alles in allem zu einer krisenhaften Jugendphase von Jennifer und dem Abbruch des Realschulabschlusses. Vor diesem Hintergrund schärft sich auch der Blick auf Jennifers Weg in ihre Ausbildung, denn nach ihrem gescheiterten Realschulabschluss ist es ihre Mutter, die ihr die Büroausbildung nahelegt, Kontakte vermittelt und Jennifer sogar bei den Bewerbungen begleitet (,[M]eine Mutter hat (...) auch mit mir dann die Bewerbungen geschrieben ähm für den Ausbildungsplatz“"). So scheinen die aktive Unterstützung und das soziale Kapital der Mutter Jennifer zu einem nahtlosen Berufseinstieg zu verhelfen in einen qualifizierten Beruf, den sie anschließend für immerhin sechs Jahre bei verschiedenen Arbeitgebern ausübt. Während ihrer Ausbildung zieht Jennifer von zu Hause aus und zu ihrem damaligen Freund, kehrt allerdings zu ihrer Familie zurück, als die Beziehung vier Jahre später zerbricht - von ihrer Mutter wurde sie ,quasi wieder daheim aufgenommen". Ihre Herkunftsfamilie (insbesondere ihre Mutter) war für Jennifer so ein , sicherer Hafen', auf den sie sich in Zeiten des Umbruchs verlassen und in den sie zurückkommen konnte.

Was die Entscheidung für das Studium angeht, so ist Jennifers Mutter ihrer Einschätzung nach ,sehr stolz“ auf sie. Allerdings fügt sie hinzu: „[I]ch glaub sie is da son bisschen überfordertweil sie selbst gar keine Vorstellung hat von nem Studium“. Auch was konkrete Unterstützung und Tipps zu Klausuren, zum Umgang mit vorlesungsfreien Zeiten oder zum Verhalten in studentischen Gruppenarbeiten angeht, kann Jennifers Mutter wenig helfen, sondern hier ist Jennifers Partner ihr zentraler Ansprechpartner:

„Ja, so aber mein Freund war eher derjenige der da son bisschen mehr, also die Ratschläge von ihm ham mich dann deutlich weitergebracht weil von meiner Mutter 
war des eigentlich eher son.. joa.. hab ich jetzt mal so hingenommen, aufgenommen, wie auch immer, schön, mach,.. ja.“

Es liegt die Lesart nahe, dass Jennifer und ihr Freund ähnliche familiäre Bildungshintergründe haben und nun gemeinsam einen Bildungsaufstieg praktizieren, ohne dass sie auf akademische Erfahrungen aus ihren Herkunftsfamilien zurückgreifen können. Stattdessen unterstützen sie sich gegenseitig und Jennifer profitiert von den Erfahrungen ihres Freundes, der sich bereits im Master-Studium befindet.

\section{Studien(fach)wahl und antizipierte Zukunft}

Neben dem Studium arbeitet Jennifer zehn Wochenstunden im Behindertenbereich, was ihr ,richtig Spaß“ macht. Ersten Kontakt zu der Arbeit mit Beeinträchtigten hatte sie durch den Zivildienst ihres Freundes, wo ihr der Kontakt mit den Bewohner*innen einer stationären Einrichtung „Freude“ bereitet hat. Dieses Tätigkeitsfeld könnte sie sich nach wie vor gut als späteren Beruf vorstellen, ist aber auch offen dafür, andere Bereiche auszuprobieren, etwa die Wohnungslosenoder Flüchtlingshilfe. Auf die Frage hin, warum sie sich gerade für diese Bereiche interessiert und was einen Beruf für sie erfüllend macht, antwortet Jennifer:

„Gebraucht zu werden. (I: Mhmh) ... Mmh.. ich muss gerne zur Arbeit äh gehen wollen, was auch immer dazu führt, obs jetzt des Team is ähm, die Klienten selbst oder, aber auf jeden Fall Freude an der Arbeit, ich, ich persönlich mag des Gefühl, gebraucht zu werden und ich mag des Gefühl, helfen zu können. Des is auch der Grund warum ich des studier was ich studier. Des tut mir unheimlich gut."

Zum einen wird hier wieder deutlich, dass für Jennifer der Sinn und die Freude an ihrem Beruf entscheidend ist. Zum anderen spiegelt sich auch hier ihr von Fürsorge und Gemeinschaft geprägtes Selbstbild wieder, durch das dispositionell Jennifers Nähe zu einem Beruf entsteht, der ihr das „Gefühl“ gibt, ,helfen zu können“. Diese gemeinschaftliche Orientierung, die Jennifers Berufsvorstellungen prägt, zeigen deutliche Parallelen zu Dominics Fall auf (Dominic: ,[A]nderen Menschen zu helfen, des.. des gibt ja en ganz besonderes Gefühl").

Was ihre Gehaltsvorstellungen angeht, ist Jennifer dabei bescheiden und wäre mit dem Gehalt zufrieden, das sie auch in ihrem Bürojob hatte: $1600 €$ netto. Das Studium ist nach ihrer Darstellung also kein Mittel, um mehr Geld zu verdienen, sondern um inhaltlich das tun zu können, was ihr Spaß macht und ihrem Bedürfnis nach Gemeinschaft und Fürsorge entspricht. Außerdem kommt eine leitende Position für sie eher nicht in Frage, denn die Positionen als Haus- oder Teamleitung sind ihr zu ,stressig“ und insbesondere zu sehr mit ,administrativem 
Quatsch" verbunden, den sie im Rückblick auf ihre Büroausbildung gerade nicht mehr ausüben will. Daher strebt Jennifer eine Tätigkeit an, in der sie direkt mir ihrer Klientel arbeitet.

Ihr Privatleben in zehn Jahren stellt sich Jennifer folgendermaßen vor:

„Wenns richtig gut verläuft hab ich in zehn Jahren zwei Kinder, bin verheiratet,..habn Häuschen.. krass, das is echt spießig ((I lacht - Jennifer lacht)) (...). Ja vielleicht erst ein Kind, aber mit 36 wärn zwei eigentlich schon ganz schön, weil irgendwann wirds schwierig ((lacht)), ja. Also zwo Kinder vielleicht, ja. Und alles soll, und auf ja, n Job der mich zufrieden macht und nich mehr dieses ich weiß nich was ich will und wo gehör ich hin, des soll dann vorbei sein. Also ich will dann irgendwie angekommen sein. Ja, des wär schon schön.“

Jennifers Zukunftsvorstellungen sind durch ihre sicherheitsorientierten Wünsche nach Familiengründung und Zufriedenheit im Beruf geprägt, zeugen aber auch von einer gewissen Anstrengung. Es deutet sich eine habituelle (Such-) Bewegung und Anstrengung an, denkt man an Jennifers bildungsbezogenen Aufstieg (gemeinsam mit ihrem Partner) und ihren Wunsch, ,,angekommen zu sein" und zu wissen „wo gehör ich hin“.

Ihre Vorstellungen von einer eigenen Familie sind außerdem davon geprägt, dass sie selbst die Erziehung für ihre Kinder hauptverantwortlich ausübt. Dass ihr Partner in Elternzeit geht, kann sie sich nur bedingt vorstellen:

\footnotetext{
„Wär des okay für mich. Wir ham auch schonmal drüber gesprochen. Aber ähm, des is unvernünftig in dem Fall, weil ich werde definitiv weniger verdienen ((lacht)), so isses (...). Ja also ich würd zu Hause bleiben. Weil die Wahrscheinlichkeit dass er weniger verdient als ich, is so gering, ja die is echt verschwindend gering. Aber ich hätte kein Problem damit wenn er zu Hause bleiben würde.“
}

Jennifers Formulierung, dass die Kindererziehung auf männlicher Seite „okay“ und ,kein Problem“" wäre, weist zwar auf vorreflexive Zuteilung der Sorgearbeit zur weiblichen Seite hin, zeugt aber zugleich von einer grundsätzlichen Offenheit gegenüber einer anderen Aufgabenteilung. Mit Jennifers entscheidendem ,Argument" des unterschiedlichen Gehalts, durch das dieses Arrangement ohnehin „unvernünftig“" wäre, rationalisiert sie wiederum eine traditionell-geschlechtliche Arbeitsteilung und nimmt sie als selbstverständlich vorweg. Dass dieser finanzielle Sicherheitsaspekt für Jennifer so maßgeblich ist, lässt sich im Kontext ihrer Erfahrungen von Notwendigkeit nachvollziehen.

Vor dem Hintergrund der Vereinbarkeit von Familie und Beruf stellt Jennifer ihren Beruf hinter die Familie, denn „.... wenn sich des dann mit ner Schichtarbeit 
zum Beispiel nich mehr vereinbaren ließe, dann würd ich den Bereich wechseln weil die Familie geht in dem Fall vor, da kann die Arbeit Spaß machen wie se will." Wie sehr sie sich selbst in der Rolle und Zuständigkeit als erziehende, präsente, fürsorgliche Mutter sieht, wird hier klar. Das bildet einen Gegensatz etwa zu Rebecca, die ebendieses Rollenbild abwertet.

So entsteht in Bild von Jennifers Zukunftsaussichten, innerhalb derer sie die Nähe zu einem sinnstiftenden, ihr Freude bringenden und mit Fürsorge verbundenen Beruf antizipiert, der für sie zwar eine Aufstiegsbewegung bedeutet, aber auch einen - etwa im Vergleich zu ihrem Partner - bescheidenen akademischen Weg darstellt. Darüberhinausgehendes Aufstiegsstreben hin zu einer beruflichen Führungsposition oder einem höher entlohnten Berufsfeld zeigen sich bei Jennifer nicht. In Kombination mit ihrer heterosexuellen Paarkonstellation mit einem künftigen Bauingenieur ist so die Konstitution eines finanziell hierarchischen Geschlechterverhältnisses mit traditionaler Arbeitsteilung wahrscheinlich. Zugleich scheint die Arbeitsteilung nicht unreflektiert von Jennifer übernommen zu werden, sondern die Familienorganisation scheint eine Frage der gemeinsamen Aushandlung mit ihrem Partner zu sein.

Jennifers Orientierung an Gemeinschaft und Bescheidenheit drückt sich auch noch einmal aus, wenn sie erzählt, worauf es ihr im Leben ankommt:

\begin{abstract}
„Also ganz wichtig finde ich, dass man immer einen Ort hat an den man zurückgehen kann. Also ähm.. nich unbedingt es zu Hause, sondern eher bezogen auf Menschen, ja, also immer jemanden, wie son Hafen in den man einkehren kann wenn irgendwas is, man einfach immer jemanden hat zu dem man gehen kann. (..) $\mathrm{Ja}$, man sollte zufrieden sein mit sich und seinem Leben und wenn man des nich is, dann sollte man sich überlegen was man ändern muss. Des, ja, die Erfahrung hab ich gemacht.. ja.“
\end{abstract}

Und in dieser Antwort klingt ebenfalls der Weg an, den sie hinter sich hat: Die für Jennifer negative Berufserfahrung im Büro veranlasst sie zu einer Umorientierung hin zur Sozialen Arbeit. Der damit verbundene Weg ist für sie beschwerlich und sie wird dabei sowohl von ihrem Parther wie auch ihrer Mutter unterstützt. Der Wunsch, ihr Leben eigenständig zu gestalten und dabei auch Risiken einzugehen mit dem Ziel, finanzielle und soziale Sicherheit zu erreichen, prägt Jennifers Studien(fach)wahl und ihre Lebensführung allgemein und sozialen Beziehungen kommt hierbei eine große unterstützende Bedeutung zu.

Jennifers Streben nach Autonomie zeigt sich auch noch einmal beim Abschluss des Interviews, in dem sie ihre drei Wünsche äußert: 


\begin{abstract}
„Was würde ich mir wünschen... Dass meine Familie und ich aber auch selbst gesund bleiben so lange wir leben. Schon en großer Wunsch. Dass ähm... mh... Dass weiterhin alles so planmäßig verläuft wies des bis jetzt, also dass einfach alles immer so klappt wie man sich des vorstellt, des wär schon schön, dass man nich so viele Kompromisse eingehen muss. ...Ah und.. meinen Vater würde ich gern kennenlernen ((lacht)), des wärn die drei, ja des wär schon schön, ja, ja.“
\end{abstract}

Mit der Gesundheit ihrer Familie bestätigen sich hier ihre Werte von Gemeinschaft und Sicherheit. Und ihr Wunsch, nicht mehr viele Kompromisse eingehen zu müssen, verdeutlicht erneut ihr Bestreben, eigenständig und unabhängig Entscheidungen treffen zu können und sich nicht äußeren Zwängen fügen zu müssen. Auch das passt zu Jennifers Entwicklung weg von ihrer von außen bestimmten Büroausbildung hin zur mutigen und selbstgewählten Entscheidung des Studiums der Sozialen Arbeit.

\title{
Habitus, Studien(fach)wahl und Milieuspezifika
}

Jennifers Weg in das Studium ist von einer Aufwärtsbewegung geprägt, den sie diszipliniert und strategisch beschreitet. Jennifer musste ,früh Verantwortung übernehmen", ihre Kindheit und ihre Jugend sind geprägt von Erfahrungen der Unsicherheit und Krisen: Der Tod ihres Vaters, der häufige Wohnortwechsel der Familie, der neue Partner der Mutter - zu dem Jennifer ein konfliktbehaftetes Verhältnis verband -, die geringe familiäre Aufmerksamkeit für Jennifers schulische Probleme und ihr aus diesen Umständen erwachsender Schulabbruch vor dem Realschulabschluss stellen sie vor das Ende ihrer Schullaufbahn mit einem Hauptschulabschluss. An dieser Stelle sind es das Einwirken ihrer Mutter und der Nutzen deren sozialen Kapitals, wodurch Jennifer nahtlos eine Ausbildung zur Bürokauffrau absolviert und in diesem Beruf sechs Jahre tätig ist. Während dieser Zeit wächst zugleich ihre Unzufriedenheit, vor allem mit der Arbeit als Assistentin der Geschäftsführung: Unterforderung, Monotonie, aber auch fehlende Anerkennung führen dazu, dass Jennifer beginnt, sich beruflich umzuorientieren. Die Entscheidung, wie es für sie weitergehen soll, trifft sie gemeinschaftlich: Sie sucht den Austausch mit ihrem Umfeld - ihren Peers in der Heilerziehungspflege und der Sozialen Arbeit und ihrem Partner - und sie erörtern gemeinsam ihre möglichen Perspektiven, um das ,Passende` für sich zu finden. Auf dieser Grundlage wendet sie sich dem sozialen Berufsfeld und schließlich dem Studium der Sozialen Arbeit zu. Die Nähe zu einem sozialen Beruf und Jennifers Wunsch, „gebraucht“" zu werden und zu ,helfen“, lassen dabei Parallelen erkennen zu ihrer frühen Erfahrung mit fürsorglichen und verantwortungsvollen Aufgaben in der familiären Gemeinschaft. Die Tätigkeit in einem sozialen Beruf auf der Grundlage einer Ausbildung oder eines Studiums setzt sie in ihrer Anerkennung gleich - der 
Status spielt für sie hier keine dominante Rolle. Zugleich kommt eine Ausbildung für sie nicht in Frage, da sie diese selbst finanzieren müsste.

Zentraler Unterstützer der Entscheidung für das Studium ist ihr Partner, der wie Jennifer aus einer Familie ohne Hochschulerfahrung kommt und nun studiert. Das Studium stellt damit für beide eine Herausforderung und einen gemeinsamen Bildungsaufstieg dar. Jennifer geht damit den für sie ,anstrengenden“ Weg über das nachgeholte Fachabitur an die Hochschule, verlässt ihre sichere Anstellung im Büro, verzichtet für mehrere Jahre auf das gewohnte Gehalt und geht damit risikobereit und diszipliniert vor, um ihr Studium zu absolvieren. Ihr Wunsch, einen ,passenden' Beruf zu finden, der ihr Freude bereitet und sie fordert, wird besonders deutlich - ebenso ihr Streben nach Autonomie, denn Jennifer möchte in Zukunft „nich so viele Kompromisse“ eingehen. Bei ihrer Mutter deutet sich zwar eine Distanz zum Studium der Tochter an - diese Form der Ausbildung ist ihr fremd -, gleichzeitig begegnet sie diesem Weg aber mit Stolz und Unterstützung, sie scheint also der akademischen Bildung gegenüber offen und stellt deren Sinnhaftigkeit nicht in Frage.

Jennifers risikobereites Streben nach ,Mehr ${ }^{\text {- }}$ nach mehr Freude, Forderung, Sinn und Autonomie - scheint jedoch zugleich ein bescheidenes und prestigeunabhängiges zu sein: So antizipiert sie weder eine Führungsposition noch legt sie Wert auf ein hohes Gehalt. Die Frage der Arbeitsteilung scheint zumindest bis zu einem gewissen $\mathrm{Ma}$ eine Frage der Aushandlung zwischen ihr und ihrem Partner zu sein. Dass sich Jennifer schwerpunktmäßig in der erziehenden Funktion sieht, scheint dabei weniger auf einer unhinterfragten Reproduktion traditionaler Rollen zu basieren als vielmehr auf monetären Überlegungen und dem von Fürsorge geprägten Selbstbild von Jennifer. Im Kontext von Familiengründung drückt sich bei Jennifer damit weniger ein Streben nach Autonomie als vielmehr nach Absicherung aus, das durch die Strukturierung der betreffenden Arbeitsfelder (technisch und sozial) wahrscheinlich zur Reproduktion einer traditionalen Arbeitsteilung führen würde.

Was die Verortung im Milieumodell angeht, deuten Jennifers Erfahrungen der Unsicherheit, ihre Risikobereitschaft und Disziplin sowie ihre Orientierung an Autonomie und Gemeinschaft auf eine Verortung des Falls im vertikal-unteren und horizontal-mittleren Bereich des Leistungsorientierten Arbeitnehmermilieus hin mit Wurzeln im Traditionellen Arbeitermilieu (siehe auch Vester 2015: $160 \mathrm{ff}$.). 


\subsection{Fall Hanna:„Also dass ich auch einfach meine eigenen Entscheidungen treffen kann, ja.. dafür eigentlich das Studium"}

\section{Reflexion der Interviewsituation}

Die Interviewsituation mit Hanna lässt sich, gerade im Vergleich zu den anderen Interviews, als verhalten und vorsichtig beschreiben. Mit knapp 45 Minuten Länge handelt es sich zudem um das kürzeste Interview. Das Angebot, sich an Keksen und Kaffee zu bedienen, lehnt Hanna vorerst ab. Sie kommt wenig ins Erzählen, sondern beantwortet die Interviewfragen kurz und bündig auf Sachebene. Ihr Sprachstil wirkt ruhig und überlegt. Zusätzlich spiegelt ihre Körperhaltung gelegentlich eine gewisse Skepsis oder Unsicherheit wider, indem sie etwa die Arme verschränkt. Gleichzeitig deutet sich Neugierde auf Hannas Seite an, da sie am Ende des Interviews etwa fragt ob sich „viele dafür [für das Interview, LL] gemeldet" haben.

Die Interviewerin versucht, die Atmosphäre gesprächsnaher zu gestalten und aufzulockern, indem sie Hanna gegenüber häufiger ihre Zustimmung signalisiert und sich zwischendurch kurz mit ihr austauscht, z. B. über die studentischen Lokalitäten in Hierstadt, auf die Hanna zu Sprechen kommt. Nachdem sich die Interviewerin einen Keks nimmt, greift auch Hanna zu und der Gesprächsverlauf lockert sich zunehmend etwas auf. Das zurückhaltende Antwortverhalten prägt jedoch das gesamte Interview.

\section{Kurzeinführung in den Fall}

Hanna ist zum Zeitpunkt des Interviews 21 Jahre alt und ist für ihr Bauingenieurstudium vor kurzem aus Ostdeutschland in das mehrere hundert Kilometer entfernte Hierstadt gezogen. Ihr Heimatort hat 400 Einwohner*innen; sie hat dort gemeinsam in einem Haus mit ihren Großeltern, Eltern, Geschwistern und ihrer Patentante gewohnt.

Hannas Eltern haben jeweils die zehnte Klasse der polytechnischen Oberschule in der DDR absolviert. Ihr Vater ist Maurer und Bautechniker und war im Rohbau tätig, kann seinen Beruf allerdings aus gesundheitlichen Gründen nicht mehr ausüben. Ihre Mutter übt Kontrolltätigkeiten in einer Metallfirma aus. Hanna sowie ihre zwei Geschwister haben Ausbildungen absolviert: Ihr älterer Bruder hat seinen Hauptschulabschluss gemacht und ist als Maurer tätig, ihre Schwester hat die Mittlere Reife und anschließend eine Ausbildung zur Versicherungskauffrau durchlaufen. In diesem Zuge hat sie auch ihre Fachhochschulreife absolviert. In dem Beruf der Versicherungskauffrau arbeitet sie allerdings nicht mehr, sondern studiert Wirtschaftswissenschaften an einer hessischen Universität. Hanna hat 
nach Abschluss ihrer Mittleren Reife eine Ausbildung zur Bauzeichnerin abgeschlossen, damit auch das Fachabitur absolviert und sich im Anschluss für das Studium des Bauingenieurwesens entschieden.

In Hierstadt wohnt Hanna in einer Wohngemeinschaft mit fünf Berufstätigen und einem Studierenden und hält engen Kontakt mit ihrer Herkunftsfamilie, u. a. indem sie mit ihrer Zwillingsschwester an den meisten Wochenenden ihre Heimat besucht - auch, um ihr Engagement im für sie wichtigen Karnevalsverein aufrecht $\mathrm{zu}$ erhalten.

\title{
Weg hin zum Studium
}

Hanna beginnt die Erzählungen über ihre Studien(fach)wahl mit dem Bezug auf ihre Ausbildung, hält sich in ihren Ausführungen aber - und das prägt das gesamte Interview - kurz:

\begin{abstract}
„Also ich hab mich eigentlich hauptsächlich dafür entschieden, weil ich vorher ne Ausbildung als Bauzeichnerin gemacht hab.. und ich wollt auf jeden Fall in dem Bereich bleiben, weil mir das auf jeden Fall Spaß gemacht hat.. und ich hab dann eigentlich nur noch überlegt ob Architektur oder Bauingenieurwesen.., aber da ich eigentlich nich so die kreative Person bin, hab ich mich dann doch für Bauingenieurwesen entschieden... Aber ich war auch immer zu den Infotagen an den Hochschulen, is ja dann auch immer noch die Frage welche Hochschule, und dann hab ich mich dann auch nochmal informiert."
\end{abstract}

Für Hanna ist die positive Erfahrung mit der Ausbildung zur Bauzeichnerin und der damit verbundene „Spa ${ }^{“}$ “ an diesem Bereich maßgeblich für ihren Weg in das Bauingenieurstudium. Sie distanziert sich von der Architektur mit ihren ,kreativen" Inhalten und informiert sich umfassend über mögliche Standorte für das Bauingenieurstudium, um ihre Entscheidung für eine Hochschule fundiert $\mathrm{zu}$ treffen und abzusichern. Im Anschluss an diese Passage erläutert sie, dass ein Universitätsstudium zum einen aufgrund ihres Abschlusses (Fachabitur) weniger in Frage gekommen ist, aber auch weil ,man hört ja doch, dass die Uni schwer, schwerer sein soll". Ein Universitätsstudium traut sie sich offensichtlich nicht $\mathrm{zu}$ und gleichzeitig scheint ihre Einschätzung desselben auf diffusem Wissen und unklaren Quellen zu beruhen (,man hört ja doch...“). Zur Wahl zwischen der Architektur und dem Bauingenieurwesen erläutert sie auf Nachfrage, dass das Bauingenieurwesen ,viel praxisorientierter" sei und sie beide Berufe aus ihrer Ausbildung kenne - auf dieser Grundlage hält sie die Arbeit in der Architektur für eine eher ,kreative“ Arbeit (,„[W]eil der Architekt is ja doch eher kreativ, der macht viel Entwürfe und.. das ist ja eigentlich doch der Hauptjob“), wovon sie das Bauingenieurwesen abgrenzt. Die Eingebundenheit auf der Baustelle 
scheint Hanna zu liegen: „En Bauingenieur, der is auch auf Baustelle, kontrolliert und des fand ich doch intressanter, nich so langweilig."

Dass und aus welchen Gründen Hanna das Fachhochschulstudium ,eher liegt", zeigt sich auch bei einer ihrer späteren Ausführungen über die Atmosphäre im Hörsaal:

I: „Und wie findest du so die Atmosphäre, wenn du im Hörsaal sitzt, ist des so des was du vorher erwartest hast vom Studium?“

Hanna: „Ja doch, also das is auch noch son Grund warum ich mich für die FH entschieden hab und nich für die Uni weil an Unis sind ja wirklich zweihundert Leute in einem Hörsaal, und hier sinds angenehme fünfzig Leute, also. Des is auch richtig schön, da kennt auch jeder jeden eigentlich s"on bisschen."

Mit der Formulierung ,jeder kennt jeden" verdichtet sich die Lesart, dass Hanna überschaubare Strukturen positiv bewertet und sie zudem die Gemeinschaft mit anderen schätzt, das ist ,richtig schön“ für sie. Die Anonymität an der Universität dagegen schreckt sie ab. Zugleich geht Hanna mit ihrem Weg in das Studium durchaus einen neuen, unbekannten Weg und wagt diesen offenbar im Rahmen der für sie überschaubaren Hochschule für Angewandte Wissenschaften.

Ähnliche Bewertungsmuster kommen auch zum Tragen, wenn Hanna von ihrem Heimatort und ihrem Aufwachsen dort spricht: Der Kontakt dorthin ist ihr auch heute noch sehr wichtig, ,weil wir [ihre Schwester und sie, L.L.] sind noch im Karnevalsverein und Kirmes und alles so. Des wollten wir eigentlich auchn bisschen beibehalten. "Über ihr „Dorf“, wie sie es nennt, sagt sie, dort „kennt jeder jeden“ und betont: „Ach, ich mag das Dorf." Sie scheint sich in ihrer bekannten, dörflichen Heimat wohlzufühlen und verwendet hier bezeichnenderweise den gleichen Ausdruck, mit dem sie auch die Vorlesungen in der Fachhochschule charakterisiert hat (,Da kennt jeder jeden“) - diese überschaubaren Strukturen und die familiäre Atmosphäre scheinen Hanna zu liegen.

Wie bereits erwähnt, schlug Hanna die Richtung Technik bereits durch ihre Entscheidung für die Ausbildung zur Bauzeichnerin ein. Die Wahl der Ausbildung wiederum kam dadurch zustande, dass Hanna bereits noch früher Kontakt zu diesem Tätigkeitsfeld hatte, nämlich bei ihrem schulischen Pflichtpraktikum in der siebten Klasse. Sie beschreibt diese Entwicklung als eher ,zufällig“:

\footnotetext{
„Also ich hab ja Realschule gemacht, da war ich praktisch sechzehn als ich fertig war... Ja wie bin ich dazu gekommen, es war eigentlich eher zufällig, unsere Schule war ziemlich darauf spezialisiert, die Schüler früh ins Berufsleben zu orientieren,
} 
wir hatten schon ab der siebten Klasse Praktikum, erst nur in so Leerbauhallen und dann ab der achten Klasse so richtig Praktikum und da hab ich auch Praktikum als Bauzeichnerin gemacht und.. das hat mir gefallen und dann hab ich das auch gemacht."

Den fachlichen Weg hin zum Bauingenieurwesen ist Hanna Schritt für Schritt gegangen, vom Schulpraktikum über die Ausbildung bis hin zum Studium. Beeinflusst hat diesen Weg offensichtlich auch ihre besuchte Schulart, durch die sie ein Praktikum in einem Ausbildungsberuf machen musste ${ }^{21}$.

Ihre Überlegung, nach der Ausbildung noch ein fachlich anschließendes Studium zu absolvieren, ist wiederum von Hannas Wunsch nach mehr Autonomie geprägt:

I: „Mhmh. Das heißt, du wusstest nach der Ausbildung die Richtung ist die richtige?

(I: Genau) Und warum dann doch noch es Studium?“

Hanna: „Ja weil als Bauzeichnerin ist man ziemlich abhängig von den Architekten und Bauingenieuren, weil du kannst ja keine Entscheidung selber treffen, musst die immer fragen und.. die sind ja.. vielbeschäftigte Menschen, die sind nur am Telefonieren oder irgendwas, das ging mir schon en bisschen auf die Nerven. Also dass ich auch einfach meine eigenen Entscheidungen treffen kann, ja,.. dafür eigentlich das Studium."

Hannas Perspektive zeugt von einer gewissen Distanz gegenüber den beruflichen Positionen der Architekt*innen und Bauingenieur*innen, die sie in einem Verständnis als „vielbeschäftigte Menschen“ bezeichnet, die ,nur am Telefonieren oder irgendwas" seien. Zugleich sind ebendiese Positionen für sie erstrebenswert - schließlich möchte sie durch das Studium selbst Bauingenieurin werden und dann beruflich ihre ,eigenen Entscheidungen treffen“ können. Für Hanna ist das Studium also verbunden mit dem Streben nach mehr Autonomie.

\section{Studien(fach)wahl im Kontext der Herkunftsfamilie}

Gehen wir in der Entwicklung von Hannas Fachinteresse nun noch weiter zurück zu der Frage, wie sie sich für das Praktikum als Bauzeichnerin entschieden hat, wird der Blick auf den Einfluss ihres Vaters gelenkt:

I: „Mhmh. Und wie kams zu der Entscheidung für des Praktikum? Hattest du da vorher schon drüber nachgedacht, dass du, keine Ahnung, die Gebäude spannend findest oder?“

${ }^{21}$ Etwa im Gegensatz zu Sonja, die ein Gymnasium besucht und in der siebten Klasse ein Praktikum bei einem Architekten absolviert hat. 
Hanna: „Ne, des weiß ich gar nich wie ich dazu gekommen bin. Also wahrscheinlich doch auch eher durch meinen Vater, der hat äh, ähm, der hat Maurer gemacht und dann hat er noch staatlich geprüfter Bautechniker gemacht (...). [A]lso er hat mir mal zum Beispiel die Zeichnungsprogra-, Programme an den Computern gezeigt und so, des fand ich ganz spannend und.. deswegen hab ich da eigentlich auch en Praktikum drin gemacht.“

Hannas anfängliche Einschätzung, ihr Weg in das zur Ausbildung als Bauzeichnerin sei eher ,zufällig“ gewesen, entpuppt sich so eher als Weg, der durch die familiäre - genauer gesagt väterliche - Nähe zu Berufen in der Baubranche entstanden und durch ihre eigenen Erfahrungen im entsprechenden Praktikum verstärkt worden ist. Ihre Mutter erwähnt sie in diesem Kontext nicht.

Hannas Weg in eine akademische Ausbildung ist wiederum geprägt von der engen Beziehung zu ihrer Zwillingsschwester: Mit ihr ist sie aus ihrem Elternhaus ausgezogen, als die beiden ihre Ausbildungen begonnen haben. Sie haben außerdem zum gleichen Zeitpunkt ihr Studium begonnen - jeweils in dem fachlichen Bereich, der Schnittstellen mit der vorigen Ausbildung hat. Bei Hanna sind dies die Ausbildung zur Bauzeichnerin und das Studium im Bauingenieurwesen, bei ihrer Schwester folgt das Studium der Wirtschaftswissenschaften auf die Ausbildung zur Versicherungskauffrau.

Auf die Frage der Interviewerin hin, wie Hannas Eltern die Entscheidung ihrer Töchter fanden, ein Studium zu beginnen, zeigt sich deren Skepsis der akademischen Ausbildung gegenüber:

„Ja meine Eltern sind da nicht so begeistert von gewesen eigentlich. Weil die sind ja doch immer so.. ja lieber Geld verdienen sag ich mal, als dann so.. noch was studieren. Also die sind damit halt auch nich groß geworden, die kennen das ja eigentlich auch gar nich so richtig. Aber die unterstützen da uns auch, die sagen dann immer, Wenn ihrs nich schafft, dann lassts sein“ ((lacht)). Ja und dadurch dass wir schon ne Ausbildung ham, beide, isses ja auch nich so tragisch wenn wirs nich schaffen würden, dann können wir einfach in dem Job weiterarbeiten."

Grundsätzlich hätten die Eltern den direkten Berufseinstieg ihrer Töchter gegenüber einem Studium bevorzugt, möglicherweise, weil sie eine akademische Ausbildung nicht einschätzen können. Die Skepsis gegenüber dem Studium, die Antizipation eines möglichen Scheiterns der Tochter und die Akzeptanz desselben kann wiederum als latente elterliche Abgrenzung von Aufstiegs- und Statusstreben gedeutet werden. In jedem Fall bewegen sich Hanna und ihre Schwester mit ihren Wegen an die Fachhochschule und die Universität ein Stück weg den elterlichen Vorstellungen für deren Bildungs- und Berufswege, die stärker auf Sicherheit und Berufserfahrung setzen. Hanna und ihre Schwester beginnen den 
Bildungsaufstieg indes gemeinsamen, was in Hannas Fall von Autonomiestreben geprägt ist.

\section{Studien(fach)wahl und antizipierte Zukunft}

Für ihre Zukunft in der Hochschule ist Hanna wichtig, dass sie ihr Studium in der Regelstudienzeit abschließt, denn „(...) es is ja auch immer so ne Geldfrage, ich möchte eigentlich, BaföG kriegt man ja nur fünf Jahre und dann.. möchte ich eigentlich am liebsten auch fertig sein ((lacht))... Ich möcht da nicht unbedingt.. trödeln. “ Das Studium ist für Hanna also mit der „Geldfrage“ verbunden, nämlich mit der Angewiesenheit auf ihre BAföG-Finanzierung, durch den sie einen konkreten Zeithorizont für ihre Studiendauer hat. Hinzu kommt, dass sie an der Aufnahme eines anschließenden Masterstudiums zweifelt:

„Mh, also eigentlich wollt ichs nicht machen, aber.. viele Profs sagen doch, dass Master eigentlich notwendig ist, um.. ich weiß nich, Anerkennung zu bekommen und deswegen überleg ichs mir jetzt schon, aber ich find fünf Jahre, is schon viel Zeit also die dann nochmal draufgeht bis man mitm Studium fertig ist, is schon viel Zeit.“

Den Wert der akademischen Ausbildung macht Hanna in erster Linie von deren Verwertbarkeit auf dem Arbeitsmarkt ab. Eine eine klar begrenzte Ausbildungsdauer in der Regelstudienzeit ist ihr wichtig. Hannas Disposition zu praktischen, greifbaren Tätigkeiten wird noch einmal in ihrer Beschreibung unterstrichen, wie sie sich ihren Traumjob in zehn Jahren vorstellt:

„Mmh, also ich hätt auch cool gefunden, also son Projekt einfach zu haben, was du dann organisierst. Nich unbedingt nur Bauleitung, wo du die ganze Zeit auf Baustelle fährst und dann nach dem Rechten schaust sozusagen, sondern auch halt planst und Statik vielleicht auch, Statik macht mir eigentlich auch viel Spaß, dass ich das dann auch noch, genau. Eigentlich so en Projektleiter praktisch.“"

Ausschließlich Bauleitung $\mathrm{zu}$ sein, ist nicht ihre Idealvorstellung. Stattdessen will Hanna ein „Projekt“ haben, das ,organisieren“ und „planen“, inklusive der Beschäftigung mit ihrem Lieblingsbereich Statik. Hanna fasst diese Tätigkeitsbeschreibung unter der Berufsbezeichnung des „Projektleiters“ zusammen. Damit antizipiert Hanna durchaus eine leitende Position, bei der die ,Fäden zusammenlaufen " und die für übergeordnete, vielfältige Aspekte der Baustellenorganisation und -koordination zuständig ist. Gleichzeitig möchte sie in dieser Position auch ihre fachliche Leidenschaft erfüllen, nämlich ihren „,Spa ${ }^{“}$ a an Statik. Es wird deutlich, dass Hanna durch ihre Ausbildung bereits grobe Vorstellungen von der 
Arbeit auf der Baustelle hat und zugleich möchte sie sich nicht auf einen ganz konkreten Berufswunsch festlegen, sondern schwächt dies in ihren Formulierungen ab (,,...ich hätt auch cool gefunden “). Möglicherweise ist sie nicht sicher, ob diese Position des Projektleiters für sie erreichbar ist.

Eine Führungsposition, die über die der Projektleitung hinausgeht, strebt Hanna jedoch nicht an. Das macht ihre Sicht auf den Stellenwert von Aufstiegsmöglichkeiten und Gehalt deutlich:

„Sowas war mir eigentlich gar nicht wichtig, weil ich möchte eigentlich nie so die Chef-, die Chefposition haben. Des is so viel Verantwortung und.. eigentlich möcht ich dann auch nich so viel arbeiten, also.. manche arbeiten halt tagelang und.. dass man ne geregelte Zeit hat einfach, vierzig oder einundvierzig Stunden die Woche,.. dann is man dann auch zu Hause."

Während sich Hanna in der vorhergehenden Passage positiv an der Tätigkeit des Projektleiters orientiert und dabei insbesondere auf deren inhaltliche Ausrichtung eingeht, grenzt sie sich von einer möglichen „Chefposition“ wiederum ab. Diese Abgrenzung wird wahrscheinlich auch durch die Stichworte „Aufstiegsmöglichkeiten oder Karriere und Gehalt“ befördert, die die Interviewerin in ihrer Frage genannt hat. Die von ihr mit einer Chefposition verbundene „Verantwortung“ und die dafür notwendige ausufernde Arbeitszeit schrecken Hanna eher ab. Eine Abgrenzung gegenüber ausgeprägtem Karrierestreben wird somit deutlich. Gleichzeitig schwingt in ihren Ausführungen der Wunsch nach einer gewissen ,Balance“ mit: „Geregelte“ Arbeitszeiten mit einer klaren Trennung zwischen beruflicher Zuständigkeit und privatem Bereich $(, \ldots$ dann is man dann auch zu Hause") sind ihr wichtig. Zusammengenommen sind Hannas berufliche Zukunftsvorstellungen zwar als Aufstiegs- und Autonomiestreben zu deuten, diesen beruflichen Aufstieg will sie allerdings nicht um jeden Preis der Beruf geht Hanna nicht ,über alles'. Es handelt sich daher eher um einen (begrenzten) Aufstiegswunsch nach ihren Vorstellungen eines ausbalancierten Lebens. Eine alternative Lesart wäre, dass Hanna sich die von ihr antizipierte hohe „Verantwortung“ einer Chefposition nicht zutraut und sie dieses fehlende Zutrauen als eigene Entscheidung umdeutet. Diese Interpretation soll an dieser Stelle nicht ausgeschlossen werden.

Was wiederum ihre Vorstellungen von Familiengründung angeht, erläutert Hanna auf Nachfrage:

„[A]lso auf jeden Fall Familie, ich würd mir schon gern auch noch en Haus bauen, muss ich sagen (...). Äh, ja dann halt auch einfach Zeit für die Familie auf jeden Fall haben, dass man da nich heimkommt und die Kinder gehen schon ins Bett und 
du kommst da grad heim oder so, ne. Deswegen wollt ich auch nie so in die Chef-, Chefposition, weil die ja doch länger am Tag arbeiten.“

Hannas Wunsch nach Familiengründung und -leben scheint ihre Abgrenzung von einer besonders zeitintensiven Führungsposition noch zu verstärken. Dass sie sich „en Haus bauen“ will, verweist zudem auf die Antizipation einer aktiven Rolle auch in den materiellen Aspekten ihrer (familiären) Zukunftsgestaltung. Einen Partner erwähnt sie an dieser Stelle nicht. Auf die Nachfrage der Interviewerin, wie Hanna es fände, wenn ihr Partner einen Teil der Erziehungsarbeit ausführen würde, antwortet sie: „Fänd ich auch okay, aber ich würds mir teilen, also ich würd auch schon ein Jahr mich um mein Kind kümmern wollen." Ob diese Formulierung (,Fänd ich auch okay") auf eine latente Ablehnung der Erziehungsarbeit auf Seiten des Partners verweist, kann aufgrund der Kürze von Hannas Antwort nicht näher eruiert werden. Ihre Ausführungen lassen lediglich den Schluss zu, dass die Übernahme eines Teils der Erziehungsarbeit für sie wichtig ist und sie sich einer geteilten Erziehungszeit gegenüber nicht verschließt.

Auf die Abschlussfragen des Interviews antwortet Hanna gewohnt kurz angebunden: Das, worauf es ihr im Leben ankomme, sei ,...Ich glaub einfach die Balance zwischen Arbeiten und ähm Privatleben zu finden. Ich glaub, das is mir am Wichtigsten. " Zu ihren drei Wünschen wiederum äußert sie sich wie folgt:

„...̈hm, nen guten Job zu finden, am liebsten auch in meiner Gegend. Und das so, mit der Familie zusammen zu bleiben, also ich könnt mir glaub ich nicht vorstellen noch dann am Ende meines Lebens so weit weg von meiner Schwester zum Beispiel zu wohnen, also das wär noch son Wunsch, dass man da son bisschen zusammenbleibt... Ja, ich weiß nich ((lacht)). .... Mh, ne mir fällt sonst nichts ein.“

Der Wunsch, später wieder einmal in ihre Heimat zurückzukehren, scheint für Hanna besonders wichtig und eng verbunden mit dem familiären Zusammenhalt vor allem mit ihrer Schwester. Hannas Heimatverbundenheit und der Stellenwert ihrer familiären Beziehungen werden an dieser Stelle noch einmal deutlich.

\section{Habitus, Studien(fach)wahl und Milieuspezifika}

Hanna geht ihren Weg hin zum Studium Schritt für Schritt: Die beruflichen Einblicke durch ihren Vater wecken ihr Interesse an der Baubranche und seitdem durchzieht ihre berufliche Entwicklung diese fachliche Ausrichtung - von ihrem Schulpraktikum über die Ausbildung zur Bauzeichnerin bis hin zum Studium des Bauingenieurwesens. Bei der Wahl von Hochschule und Hochschulstandort geht sie sowohl methodisch-planend vor, um ihre Wahl abzusichern, zieht aber ebenso eine für sie realistische Grenze hin zu einem Universitätsstudium, 
das sie sich nicht zutraut. Flankiert wird ihre Studien(fach)wahl von der Risikobereitschaft, sich auf den für sie unbekannten Weg in eine akademische Ausbildung einzulassen - ein Weg, den sie über die für sie überschaubare Hochschule für Angewandte Wissenschaften einschlägt. Kritisch gesehen, aber trotzdem unterstützt, wird diese Entscheidung von den Eltern, bei denen eine stärkere Sicherheitsorientierung und Abgrenzung von Aufstiegs- und Statusstreben zu vermuten ist.

In Hannas Studien(fach)wahl zeichnet sich wiederum ein gewisses Autonomie- und Aufstiegsstreben ab. Sie arbeitet sie sich mit ihrem Blick hin zu ,Architekten“, „Bauingenieuren“ und „Chefs" an sozialen Hierarchien ab und möchte in diesen Hierarchien aufsteigen und mehr Handlungsspielräume durch einen Studienabschluss erreichen. Den Weg in die Hochschule geht Hanna gemeinsam mit ihrer Schwester, die ebenfalls ein Studium beginnt, das an die fachliche Ausrichtung ihrer Ausbildung anschließt. Beide haben schon während ihren Ausbildungen ihren Heimatort verlassen, zusammengewohnt und beginnen nun zeitgleich und im selben Bundesland ein Studium. Sie vollziehen so einen gemeinsamen Bildungsaufstieg. So zeigt sich in der Familie eine bildungs- und berufsbezogene Bewegung hin zu einem Aufstiegsprozess, der ausschließlich die beiden Töchter umfasst ${ }^{22}$.

Dass Hanna ihre beruflichen Autonomieansprüche nicht ,um jeden Preis“ erfüllen will, zeigt sich in ihren Zukunftsvorstellungen: In Antizipation einer Position als Projektleitung möchte sie eigene Entscheidungsräume, aber auch eine „Balance“ zwischen Erwerbsarbeit und Privatleben. Ihre Vorstellungen von Familiengründung sind davon geprägt, dass sie Erziehungsarbeit selbst ausüben und diese grundsätzlich mit einem Partner teilen würde. Wie Hannas habitusspezifische Vorstellungen von Familienorganisation in der Praxis umgesetzt und welche lenkenden Einflüsse - etwa vor dem Hintergrund des Gehalts - hier noch wirken werden, muss an dieser Stelle allerdings offengelassen werden.

Zusammengefasst hat Hannas Fall einiges gemeinsam mit dem Jennifers: Beide sind Bildungsaufsteigerinnen der ersten Generation und vollziehen diesen Aufstieg gemeinsam mit einer nahestehenden Person, die selbst aus einem nicht-akademischen Elternhaus kommt. Für Hanna wie Jennifer spielt dabei der Wunsch nach mehr Autonomie eine entscheidende Rolle. Als Milieuhypothese kann für Hannas Fall daher ebenfalls das Leistungsorientierte Arbeitnehmermilieu mit Wurzeln im Traditionellen Arbeitnehmermilieu aufgestellt

\footnotetext{
${ }^{22}$ Der Bildungsverlauf des Bruders kann auf der Grundlage des vorliegenden Interviews mit Hanna nicht näher rekonstruiert werden.
} 


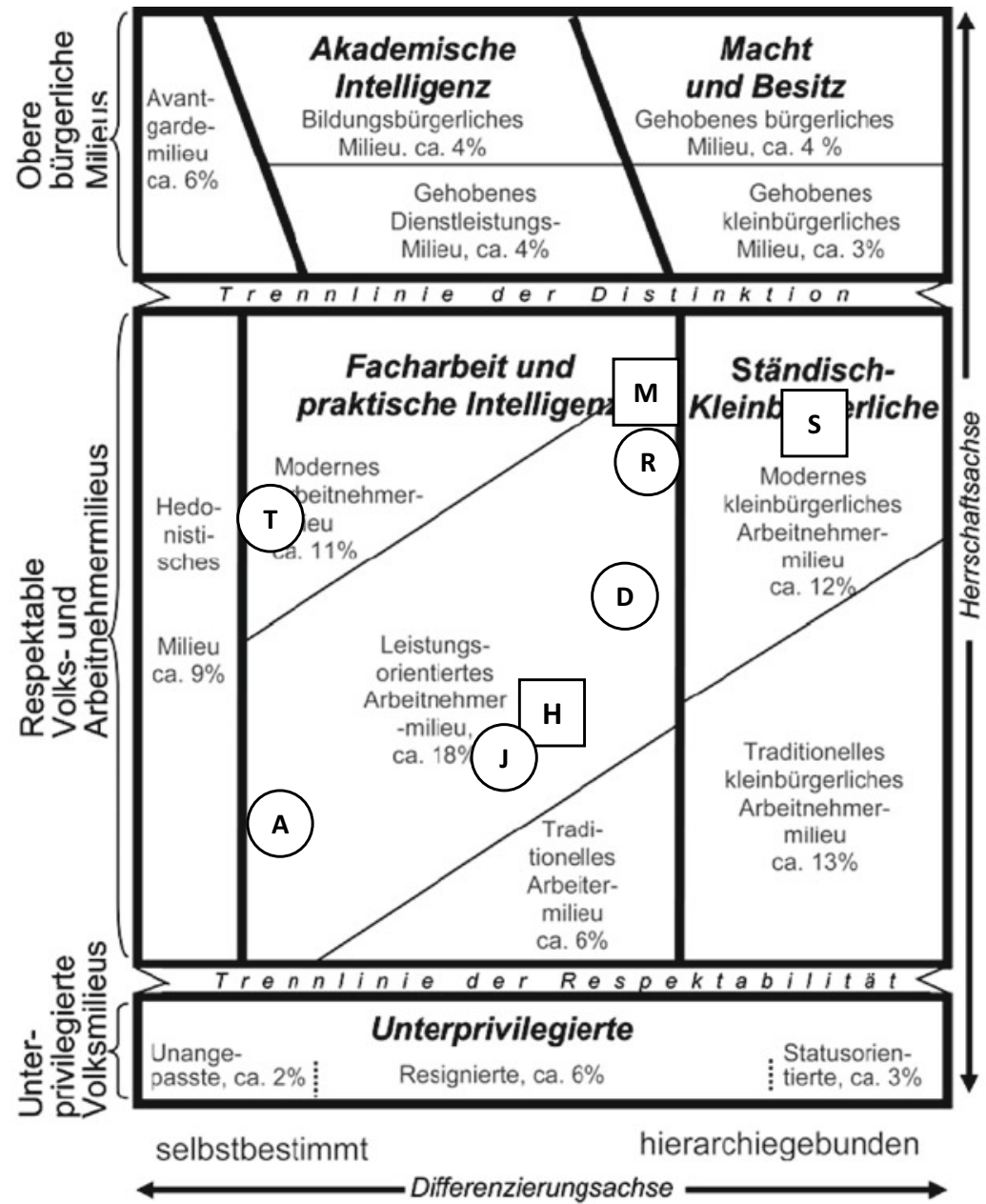

Abbildung 6.1 Landkarte sozialer Milieus nach Vester und anderen mit Verortung der Vergleichsfälle. Kreisförmig: Fälle der Sozialen Arbeit; quadratisch: Fälle des Bauingenieurwesens. (Quelle: eigene Darstellung) 
werden (siehe auch ebd.). Gleichzeitig deutet sich bei Jennifers Herkunftsfamilie eine grundsätzliche Offenheit und Unterstützung ihres akademischen Weges an, während Hannas Familie dem skeptisch gegenübersteht. Die Notwendigkeitserfahrungen, die Jennifer gemacht hat, zeichnen sich bei Hanna nicht ab. Auch ist die Gemeinschaftsorientierung von Hanna weniger ausgeprägt. Zusammengenommen sind Hanna und Jennifer daher in ähnlicher horizontaler Lage zu verorten, wobei Hanna wahrscheinlich vertikal eine etwas höhere Position einnimmt (Abbildung 6.1).

Open Access Dieses Kapitel wird unter der Creative Commons Namensnennung 4.0 International Lizenz (http://creativecommons.org/licenses/by/4.0/deed.de) veröffentlicht, welche die Nutzung, Vervielfältigung, Bearbeitung, Verbreitung und Wiedergabe in jeglichem Medium und Format erlaubt, sofern Sie den/die ursprünglichen Autor(en) und die Quelle ordnungsgemäß nennen, einen Link zur Creative Commons Lizenz beifügen und angeben, ob Änderungen vorgenommen wurden.

Die in diesem Kapitel enthaltenen Bilder und sonstiges Drittmaterial unterliegen ebenfalls der genannten Creative Commons Lizenz, sofern sich aus der Abbildungslegende nichts anderes ergibt. Sofern das betreffende Material nicht unter der genannten Creative Commons Lizenz steht und die betreffende Handlung nicht nach gesetzlichen Vorschriften erlaubt ist, ist für die oben aufgeführten Weiterverwendungen des Materials die Einwilligung des jeweiligen Rechteinhabers einzuholen.

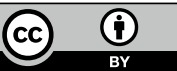

